\title{
Novel Mechanisms Controlling the Expression of the Antidiabetic Hepatokine Fibroblast Growth Factor 21
}

\author{
Kimberly M. Alonge
}

Follow this and additional works at: https://researchrepository.wvu.edu/etd

\section{Recommended Citation}

Alonge, Kimberly M., "Novel Mechanisms Controlling the Expression of the Antidiabetic Hepatokine Fibroblast Growth Factor 21" (2017). Graduate Theses, Dissertations, and Problem Reports. 5083. https://researchrepository.wvu.edu/etd/5083

This Dissertation is protected by copyright and/or related rights. It has been brought to you by the The Research Repository @ WVU with permission from the rights-holder(s). You are free to use this Dissertation in any way that is permitted by the copyright and related rights legislation that applies to your use. For other uses you must obtain permission from the rights-holder(s) directly, unless additional rights are indicated by a Creative Commons license in the record and/ or on the work itself. This Dissertation has been accepted for inclusion in WVU Graduate Theses, Dissertations, and Problem Reports collection by an authorized administrator of The Research Repository @ WVU. For more information, please contact researchrepository@mail.wvu.edu. 


\title{
Novel Mechanisms Controlling the Expression of the Antidiabetic Hepatokine Fibroblast Growth Factor 21
}

\author{
Kimberly M. Alonge \\ Dissertation submitted \\ to the School of Medicine \\ at West Virginia University \\ in partial fulfillment of the requirements for the degree of \\ Doctor of Philosophy in \\ Biochemistry and Molecular Biology \\ Frank B. Hillgartner, Ph.D., Chair \\ Peter Stoilov, Ph.D. \\ Roberta Leonardi, Ph.D. \\ Peter Mathers, Ph.D. \\ Joseph McFadden, Ph.D. \\ Department of Biochemistry and Molecular Biology
}

Morgantown, West Virginia

2017

Keywords: Activating Transcription Factor 4, Bile Acid, Eukaryotic Initiation Factor 2, Fibroblast Growth Factor, Glucagon, Insulin, Liver Metabolism, Mammalian Target of Rapamycin Complex 1, Metabolic Syndrome, Protein Kinase A, Transcription Regulation Copyright 2017 Kimberly M. Alonge 


\section{ABSTRACT \\ Novel Mechanisms Controlling the Expression of the
Antidiabetic Hepatokine Fibroblast Growth Factor 21}

Kimberly M. Alonge

The incidence of obesity has increased at an alarming rate during the past thirty years. Current therapies for the treatment and prevention of obesity and metabolic syndrome are ineffective and/or produce undesirable side effects. Fibroblast growth factor 21 (FGF21) is a liver derived hormone that mediates adaptive changes in hepatic glucose and lipid metabolism by elevating energy expenditure and reducing lipid storage. Pharmacological administration of FGF21 analogs in both animal and human models induces striking reversals of obesity and type 2 diabetes. However, the activity of FGF21 analogs exhibit short half-lives in blood circulation and are unsuitable for current treatment. Therefore it is imperative that mechanisms mediating the activity of endogenous FGF21 be understood.

FGF21 expression is enhanced during starvation, high-fat low-carbohydrate (HF-LC) ketogenic diet, type 2 diabetes, and obesity. Starvation induces a high glucagon to insulin metabolic hormone ratio in the portal vein. Type 2 diabetics also exhibit chronically high glucagon to insulin ratios in blood circulation. Furthermore, infusions with high glucagon, low insulin hormone concentrations increase the production and secretion of splanchnic FGF21 in man. The mechanisms by which glucagon and insulin work cooperatively to selectively increase hepatic FGF21 expression and secretion is currently unknown.

To understand the molecular mechanisms mediating the induction of FGF21 expression in the liver, we recapitulated the conditions of starvation in primary rat hepatocytes by treating cultures with glucagon and insulin using concentrations similar to that observed in the portal vein during starvation. We then utilized a reverse genetics approach to identify two conserved amino acid response elements (AAREs) on the FGF21 promoter that were critical in mediating the effects of starvation on FGF21 gene expression. We further defined the transcription factor, activating transcription factor 4 (ATF4), as the primary transcription fact responsible in stimulating FGF21 gene transcription during glucagon plus insulin treatment. We then characterized the glucagon and insulin signaling pathways mediating the cooperative actions of glucagon plus insulin on FGF21 gene expression using loss-of-function and gain-of-function techniques, and determined that both the PI3K/Akt/mTORC1 and cAMP/PKA signaling pathways were responsible for inducing FGF21 expression. Lastly, we applied these novel findings to further define the mechanisms other stimuli, such as chenodeoxycholic acid (CDCA), employ to induce FGF21 expression. Understanding the fundamental mechanisms by which these two hormones work together provided the scientific community with in-depth knowledge on pathways mediating the endogenous expression of hepatic FGF21 and also identified additional targets for drug development for the treat of metabolic syndrome. 


\section{Acknowledgements}

The work presented in this dissertation could not have been possible without the support and guidance of many individuals including my mentors, colleagues and friends.

First and foremost, I must thank my loving husband, Dr. Aric F. Logsdon. You were always available to lend an ear when I troubleshot results, lend a pair of hands during sample collections, and my absolute savior when I was in a pinch with reagents. You still push me intellectually and you have always believed in my capabilities as a scientist. Aric, you provide me with the confidence to complete my degree and encourage me to set aggressive goals for my further career choices.

I would next like to thank my mentor, Dr. F.B. Hillgartner, for the many years of mentorship in his laboratory. Working in Brad's lab I was provided opportunities to learn a wide range of classical biochemistry techniques that has since allowed me to move forward in my scientific career. Brad has always approached my apprenticeship as a time of independent learning and I credit my ability to focus my intellectual curiosity to his continuous blunt realism.

I would next like to thank all the current and previous members of the biochemistry weekly lab meetings and forums for their advice and encouragement throughout the years. It is only in hindsight that I can truly appreciate the aggressive curiosity from those who attended. Their tough questions have shaped me into the professional, composed, and analytical thinking scientist that I am today.

I want to thank Dr. Mike Schaller and the Biochemistry Department for their overwhelming generosity and support throughout the years. Also, special thanks to Dr. Gordon Meares for his selfless dedication to the advancement of knowledge and technical skills to the graduate students in the biomedical program here at WVU, despite their department label.

Lastly, I would like to thank my friends who have emotionally supported me throughout this journey. Marty you are the best, just the best, and rest assure our "-ism" talks don't stop here; Abi-mo you are literally my twin and I'm going to be quite lost when I move to Seattle; and Steve, Matt, Robin, and Dakota you guys saved me in the end and I don't know if I would have finished without you.

If anyone was left out of these acknowledgements, please know that I am grateful for your help! 


\section{Table of Contents}

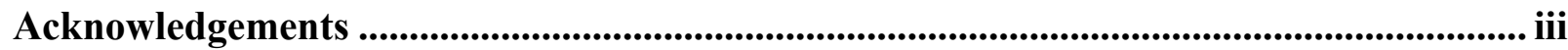

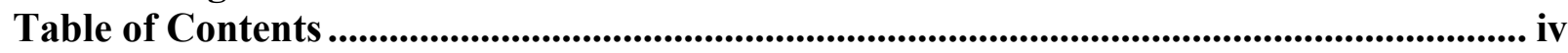

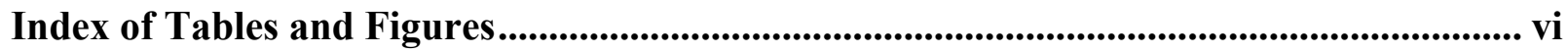

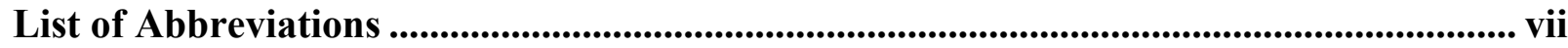

\section{Chapter 1: Literature Review}

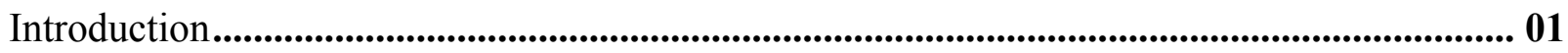

Pharmacological Modulation of FGF21 Signaling .......................................................... 04

Recombinant FGF21 Protein and FGF21 Analog Therapy .......................................... 04

Targeting and Activating the FGF-Receptor .............................................................. 05

Tissue-Specific FGF21 Signaling ....................................................................................................07

Tissue Expression of $\beta$-Klotho ................................................................................................... 07

FGF21 Signaling in Adipose Tissue ................................................................................. 08

FGF21 Signaling in Central Metabolism ................................................................. 09

FGF21 Resistance .............................................................................................. 10

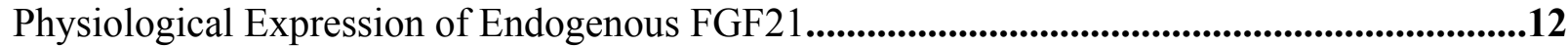

Starvation and PPAR $\alpha$..................................................................................... 12

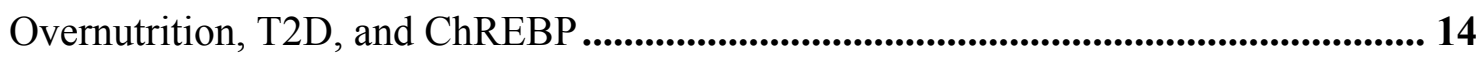

Bile Acids and FXR ....................................................................................................... 17

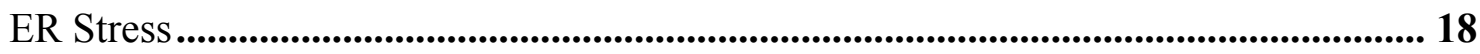

Glucagon and Insulin ............................................................................................................. 24

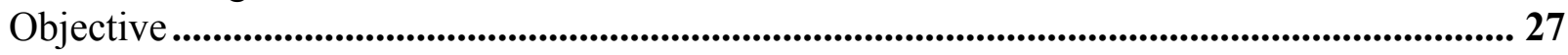

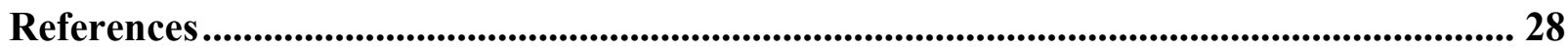




\section{Chapter 2: Mechanisms Mediating Glucagon Plus Insulin and Chenodeoxycholic Acid Stimulation of FGF21 Gene Transcription in Primary Hepatocytes}

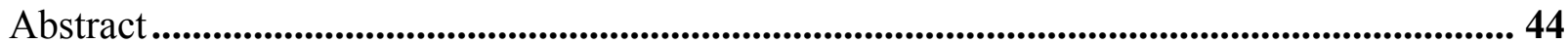

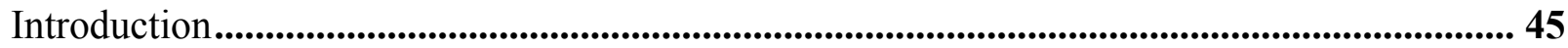

Experimental Procedures ............................................................................................................ 48

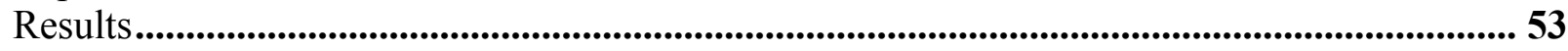

Identification of Glucagon Plus Insulin Responsive Promoter Sequences...................... 53

Role of ATF4 in Mediating Glucagon Plus Insulin Stimulation of FGF21..................... 55

Role of ChREBP in Mediating Glucagon Plus Insulin Stimulation of FGF21 ............. 57

PI3K, Akt, \& mTORC1 Cooperatively Interact with Glucagon on FGF21 Expression $\mathbf{5 8}$

PKA, not EPAC, Cooperatively Interacts with Insulin on FGF21 Expression ............... 59

Role of ATF4 in Mediating CDCA Stimulation of FGF21 ................................................. 61

Role of Akt and eIF2 $\alpha$ in Mediating CDCA Stimulation of FGF21 ............................... 62

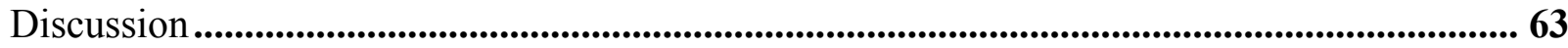

Figure Legends........................................................................................................................................ 71

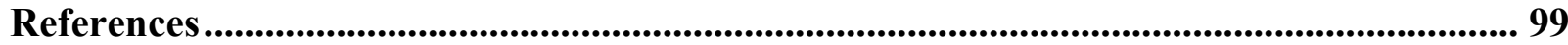

\section{Chapter 3: General Discussion}

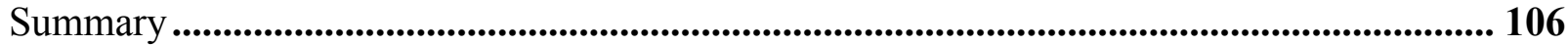

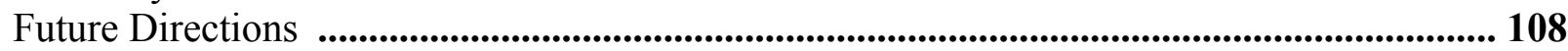

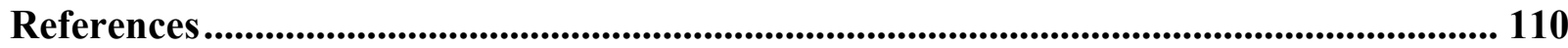




\section{Chapter 1}

1.1 Current Therapy Treatments for Obesity...................................................................................... 3

1.2 Current Therapy Treatments for Type 2 Diabetes ............................................................... 3

\section{Index of Figures}

\section{Chapter 1}

1.1 FGF21 Signals Through FGFR1c 05

1.2 Fates of Lipid Intermediates During Starvation............................................................. 13

1.3 Physiological Modulation of Endogenous FGF21 Expression in the Liver ....................... 15

1.4 The Three Arms of the Unfolded Protein Response.

\section{Chapter 2}

2.1 Effects of 5'-Deletions of the FGF21 Promoter after Glucagon Plus Insulin Treatment. 85

2.2 Effects of 5'-Deletions of the FGF21 Promoter after Insulin Treatment............................ 86

2.3 Effects of Site Specific Mutations of the FGF21 Promoter after Gln/Ins Treatment .........87

2.4 Glucagon Plus Insulin Increases ATF4 Expression and Transactivation .............................88

2.5 Knockdown of ATF4 Protein Expression Decreases FGF21 mRNA Abundance ..............89

2.6 Knockdown of ChREBP Protein Expression does not Decrease FGF21 mRNA...............90

2.7 Effects of Inhibiting PI3K, Akt, and mTORC1 on ATF4 and FGF21 Expression.............91

2.8 Effects of Inhibiting PI3K, Akt, and mTORC1 on ATF4 mRNA abundance......................92

2.9 Effects of Activating PKA and EPAC on ATF4 and FGF21 Expression.......................... 93

2.10 Effects of Inhibiting PKA on ATF4 and FGF21 Expression...............................................94

2.11 CDCA Increases ATF4 Expression and Transactivation....................................................95

2.12 Effects of Inhibiting Akt and eIF2 $\alpha$ Signaling on ATF4 and FGF21 Expression ............96

2.13 Proposed Model for Glucagon Plus Insulin and CDCA Increase in FGF21 Expression.97

2.14 Proposed Model for Glucagon Plus Insulin Increase in ATF4 Expression .......................98 


\section{List of Abbreviations}

6-Bnz-cAMP: $\mathrm{N}^{6}$ - Benzoyladenosine- 3', 5'- cyclic monophosphate

AARE: $\quad$ Amino Acid Response Element

Akt: $\quad$ Protein Kinase B

ASK1: $\quad$ Apoptotic-signaling Kinase-1

ATF4: $\quad$ Activating Transcription Factor 4

ATF6: $\quad$ Activating Transcription Factor 6

BiP: $\quad$ Binding Immunoglobulin Protein

bZIP: $\quad$ Basic Leucine Zipper

cAMP: $\quad$ Cyclic Adenosine Monophosphate

CCK: Cholecystokinin

CDCA: $\quad$ Chenodeoxycholic Acid

C/EBP: $\quad$ CCAAT/Enhancer-binding Protein

CHOP: $\quad$ C/EBP Homology Protein

ChoRE: Carbohydrate Response Element

ChREBP: Carbohydrate Response Element Binding Protein

CNS: $\quad$ Central Nervous System

cpTOME: 8-(4-chlorophenylthio)-2'-O-methyladenosine- 3', 5'-cyclic monophosphate

Db cAMP: Dibutyryl cAMP

DIO: $\quad$ Diet Induced Obesity

DVC: $\quad$ Dorsal Vagal Complex

DPP-IV: Dipeptidyl Deptidase-IV

eIF2 $\alpha$ : $\quad$ Eukaryotic Initiation Factor 2 alpha

EPAC: $\quad$ Exchange Protein Directly Activated by cAMP

ER: $\quad$ Endoplasmic Reticulum

ERAD: $\quad$ ER-associated Degradation

ERK: $\quad$ Extracellular Signal-regulated Kinase

ERSE: $\quad$ ER-stress Response Element

FAP: $\quad$ Fibroblast Activating Protein

FFA: $\quad$ Free Fatty Acids

FGF21: $\quad$ Fibroblast Growth Factor 21

FGFR: $\quad$ Fibroblast Growth Factor Receptor

FOX01: $\quad$ Forkhead Box O1

FRS2: $\quad$ Fibroblast Growth Factor Receptor Substrate 2

FXR: $\quad$ Farnesoid X Receptor

FXRE: $\quad$ FXR-response Element

GCN2: General Control Nonderepressible 2

GI: Gastrointestinal

Gln: Glucagon

GnRH: Gonadotropin-releasing Hormone

HF-LC: $\quad$ High-fat, Low-Carbohydrate

HRI: Heme-regulated Inhibitory Kinase

Ins: Insulin

IRE1a: $\quad$ Inositol Requiring Enzyme 1 alpha

IRS: Insulin Receptor Substrate 


\begin{tabular}{|c|c|}
\hline & Internal Stress Response Inhibitor B \\
\hline JNK: & c-Jun N-terminal Kinase \\
\hline LPK: & Liver Pyruvate Kinase \\
\hline mTORC1: & Mammalian Target of Rapamycin Complex 1 \\
\hline MEF: & Mouse Embryonic Fibroblasts \\
\hline NAFLD: & Non-alcoholic Fatty Liver Disease \\
\hline NE: & Nuclear Extracts \\
\hline NEFA: & Non-esterified Fatty Acids \\
\hline Nrf2: & Nuclear Factor E2-related Factor 2 \\
\hline p38 МАРК: & p38 Mitogen-activated Protein Kinase \\
\hline PCR: & Polymerase Chain Reaction \\
\hline PEPCK: & Phosphoenolpyruvate Carboxykinase \\
\hline PERK: & Protein Kinase RNA-like Endoplasmic Reticulum Kinase \\
\hline PI3K: & Phosphoinositide 3-kinase \\
\hline $\mathbf{P I P}_{2}$ : & Phosphatidylinositol 4,5-bisphosphate \\
\hline $\mathbf{P I P}_{3}$ : & Phosphatidylinositol 3,4,5-triphosphate \\
\hline PKA: & Protein Kinase A \\
\hline PKR: & Protein Kinase RNA-activated \\
\hline PPAR $\alpha:$ & Proliferator-activated Receptor alpha \\
\hline PPRE: & PPAR-response Element \\
\hline PVN: & Paraventricular Nucleus \\
\hline RIDD: & Regulated IRE1-dependent Decay \\
\hline RNA: & Ribonucleic Acid \\
\hline RPS6: & Ribosomal Protein S6 \\
\hline RXR: & Retinoid X Receptor \\
\hline SCN: & Suprachiasmatic Nucleus \\
\hline SE: & Standard Error of the Mean \\
\hline siRNA: & Small Interfering RNA \\
\hline SIRS: & Systematic Inflammatory Response Syndrome \\
\hline SREBP1c: & Sterol Regulatory Element-binding Protein 1c \\
\hline Stat3: & Signaling Transducer and Activator of Transcription 3 \\
\hline T2D: & Type 2 Diabetes \\
\hline TCA: & Tricarboxylic Acid Cycle \\
\hline TG: & Triglycerides \\
\hline TSC2: & Tuberous Sclerosis Complex 2 \\
\hline UCP1: & Uncoupling Protein 1 \\
\hline UPR: & Unfolded Protein Response \\
\hline UPRE: & UPR-response Elements \\
\hline UTI: & Urinary Tract Infection \\
\hline XBP1: & X-box Binding Protein 1 \\
\hline XBP1(s): & X-box Binding Protein 1 Spliced \\
\hline WM: & Waymouth’s Media \\
\hline
\end{tabular}




\section{Chapter One}

\section{LITERATURE REVIEW}

\section{INTRODUCTION}

Obesity is a state of metabolic dysregulation that targets both children and adults alike and is the gateway illness to a lifetime of medical and financial burden. Alarmingly, the prevalence for type 2 diabetes (T2D) in children and adolescents have dramatically increased by 30.5\% from 2001-2009 (1). The increase in obesity and T2D diagnoses in children suggest future generations of Americans will continue to be burdened with weight-related medical complications for much of their lives. Currently, over $30 \%$ of adults in the US are classified obese and this percentage is expected to soar to $42 \%$ by 2030 (2).

The high-fat, high protein, and high-carbohydrate "Western diet" of today is affordable, conveniently obtained, and encourages nutrient consumption in dietary excess (3). The consumption of daily nutrient surpluses combined with an ever-increasing sedentary behavior and poor education contributes to the increasing rates of obesity throughout the nation. Obesity contributes to the development of metabolic syndrome and secondary diseases states such (e.g. cardiovascular disease and T2D) (4). T2D is a metabolic disease that results from lifestyle choices, as well as an individual's genetics, and is associated with obesity, insulin deficiency, and selective insulin resistance in peripheral metabolic tissues (5). Obesity directly contributes to the development of over half of T2D cases, therefore the majority of individuals diagnosed with T2D have been found to be either obese or overweight (6). Although T2D is most often associated with obesity and insulin resistance, it can also further develop into additional medical 
complications such as limb neuropathy, kidney disease, stroke, and depression (4). The effects of obesity, and secondary diseases resulting from obesity, is predicted to coast Americans $\$ 147$ billion dollars annually in medical expenses (7).

One way to reverse the effects of obesity and T2D is to first target patient weight-loss through diet and exercise programs. Unfortunately, up to $98 \%$ of individuals who initially lose weight through these traditional methods gain the weight back within 2 years (8). The lack of success in traditional weight loss strategies has produced a much-anticipated market for alternative weight loss therapies. Throughout the years a slew of over-the-counter and prescription drugs, which falsely claim to increase weight-loss of the consumer without changes in diet and exercise, have been introduced into the public market $(9,10)$. Meanwhile, current drug therapies that have been shown to successful treat and prevent obesity and T2D become ineffective overtime and/or produce undesirable side effects (Tables 1.1 and 1.2). The lack of safe and reliable weight-loss treatments to counteract today's obesity epidemic has pressured the medical field to identify novel targets for the development of anti-obesogenic and anti-diabetic therapies.

Fibroblast growth factor 21 (FGF21) is an atypical member of the fibroblast growth factor family that lacks the ability to bind to heparin sulfate proteoglycans, allowing it to escape the extracellular matrix and function in an endocrine-like manner $(11,12)$. FGF21 acts on peripheral and central metabolic tissues to mediate adaptive glucose and lipid metabolism by inducing fatty acid oxidation while decreasing fatty acid synthesis and triglyceride storage (1217). Most importantly, administration of FGF21 analogs dramatically increases weight loss and decreases characteristics of T2D in rodent and human models $(18,19)$. Currently, little is known about the endogenous regulation of FGF21 expression. Understanding the mechanisms 
mediating the endogenous production of FGF21 will help identify novel pharmacological targets for the production of successful weight-loss therapies in the future.

\title{
Table 1.1. Current Therapy Treatments for Obesity
}

\begin{tabular}{ll}
\hline Treatment & Side Effects \\
\hline $\begin{array}{l}\text { Sibutramine } \\
\text { (Serotonin/Norepinephrine Re-uptake Inhibitor) }\end{array}$ & Heart attack, stroke (20) \\
\hline Orlistat & GI side effects, liver disease (21) \\
\hline $\begin{array}{l}\text { Lorcaserin Hydrochloride } \\
\text { (Serotonin 2C Receptor Agonist) }\end{array}$ & Headache, cancer, GI side effects (22) \\
\hline Weight Loss Surgery & $\begin{array}{l}\text { Infection, bowel tearing, vitamin/mineral deficiency, stenosis, } \\
\text { vomiting, ulceration, bleeding, splenic injury, death (23) }\end{array}$ \\
\hline http://www mayoclinic.org/diseases-conditions/type-2-diabetes/diagnosis- treatment/ treatment/t xc-20169988
\end{tabular}

http://www.mayoclinic.org/diseases-conditions/type-2-diabetes/diagnosis- treatment/ treatment/t xc-20169988

\section{Table 1.2. Current Therapy Treatments for Type 2 Diabetes}

\author{
Treatment \\ $\underline{\text { Side Effects }}$ \\ Metformin \\ Resistance, nausea, GI side effects (24) \\ (Glucophage, Glumetza) \\ Hypoglycemia, weight gain (25) \\ Insulin Therapy \\ Hypoglycemia, weight gain, heart failure (26) \\ Insulin Sensitizing Agents (Sulfonylureas, Meglitinides, \\ Thiazolidinediones) \\ Glucagon-like Peptide 1 Receptor Agonists \\ Nausea, pancreatitis, GI issues (27) \\ Dipeptidyl Peptidase 4 Inhibitors \\ GI side effects, flu-like symptoms, \\ skin reactions, heart failure (28) \\ Sodium/Glucose Transporter 2 Inhibitors \\ Yeast infections, UTI, hypotension (29) \\ https://www.nhlbi.nih.gov/health/health-topics/topics/obe/treatment
}




\section{PHARMACOLOGICAL MODULATION OF FGF21 SIGNLAING}

\section{Recombinant FGF21 Protein and FGF21 Analog Therapy}

Administration of recombinant FGF21 protein in obese and T2D animal models increases energy expenditure and decreases adiposity, weight, and blood TG (30,31). FGF21 recombinant protein administration also decreases blood glucose, increases insulin sensitivity, and diminishes arterial plaque formation (31-36). Interestingly, some studies show recombinant FGF21 protein and FGF21 analog administration in mice causes a marked decrease in food intake and increased weight loss $(19,37)$, while in other studies employing FGF21 treatment increased weight loss but did not decrease food intake (38-40). These results suggest FGF21 functions by increasing fatty acid $\beta$-oxidation and energy expenditure, but are inconclusive as to whether FGF21 mediates overall energy intake.

Recently, interest in FGF21 as a weight-loss target has intensified with reports of successful phase 1 clinical trials in obese and T2D human subjects $(18,19)$. In these trials FGF21 exhibited a strong anti-obesogenic, anti-diabetic effects after being injected into human subjects. For example, treatment using the FGF21 analog PF-05231023 improved the circulating lipid profile and decreased body weight in humans (19). Disadvantages to using a recombinant FGF21 protein stem from its short half-life in blood circulation in addition to the tendency for the recombinant protein to aggregate during synthesis (41-44). 


\section{Targeting and Activating the FGF-Receptor}

FGF21 signals through the fibroblast growth factor receptor isoform 1c (FGFR1c) $(45,46)$. Binding of FGF21 to FGFR1c requires the presence of the co-activator $\beta$-Klotho, a type I transmembrane protein (47). Prior to ligand binding, $\beta$-Klotho must first bind to FGFR and form a FGFR/Klotho heterodimer (Fig. 1.1A) (48). After heterodimerization, two FGFR/Klotho heterodimers homodimerize to form an inactive tetramer (Fig 1.1B). FGF21 activates the FGFR/Klotho tetramer by interacting its $\mathrm{C}$-terminus with $\beta$-Klotho and its $\mathrm{N}$ terminus with the FGFR, thus forming a fully active FGF receptor complex (Fig. 1.1C) (47).

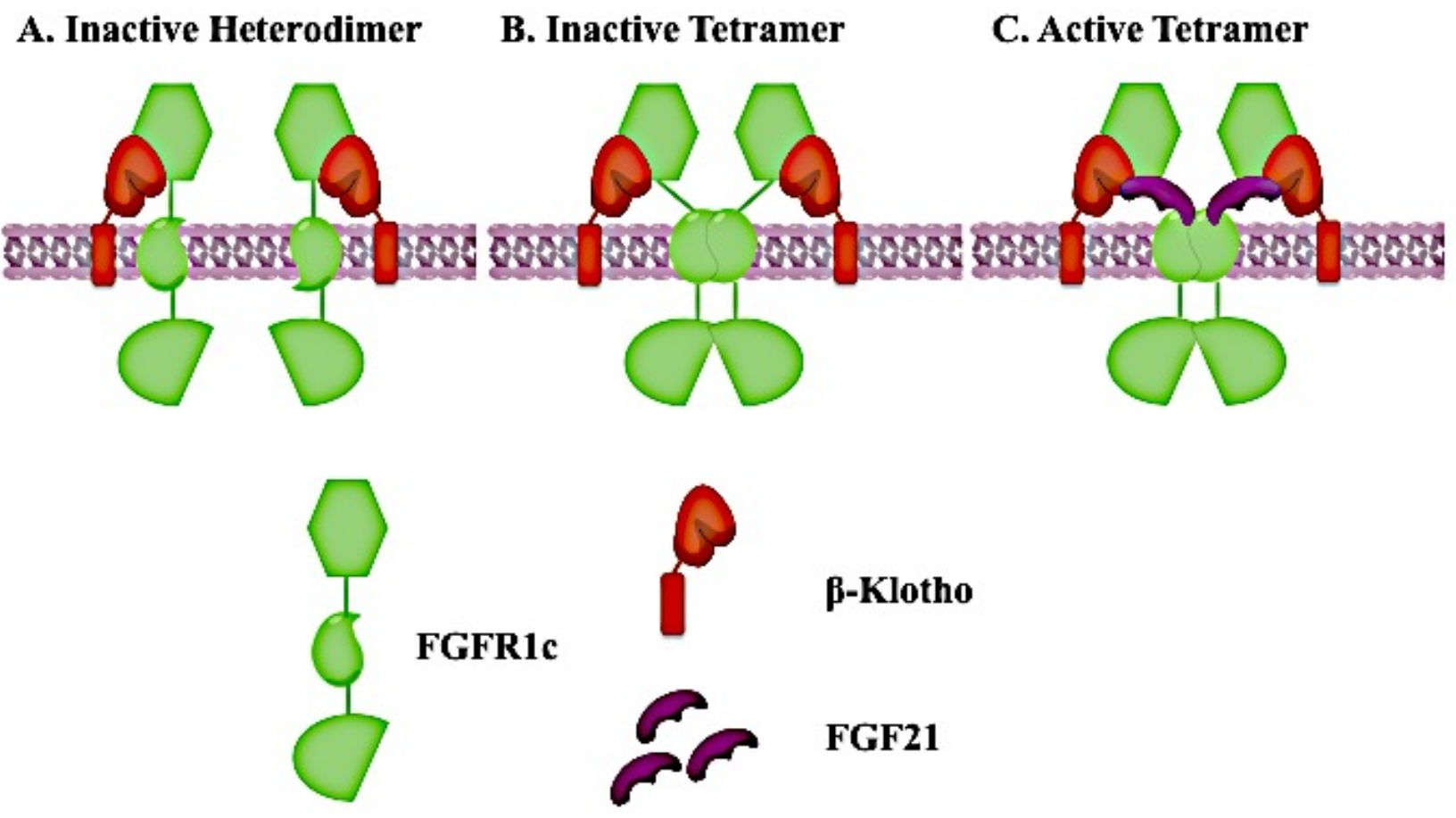

Figure 1.1. FGF21 signals through FGFR1c. (A) Co-activator $\beta$-Klotho first binds to the FGFR and forms a FGFR/Klotho heterodimer. (B) Two FGFR/Klotho heterodimers homodimerize to form an inactive tetramer. (C) FGF21 activates the FGFR/Klotho tetramer by interacting its $\mathrm{C}$-terminus with $\beta$-Klotho and its N-terminus with the FGFR. 
Another approach to increase FGF21 signaling without administering a recombinant FGF21 protein or FGF21 analog is to target and activate the FGFR1c complex independently of FGF21 ligand binding (49). A single dose injection of RM1Ab, an antibody designed to target and activate the FGFR1, reduces hyperglycemia and hepatosteatosis and improves hyperinsulemia and hyperlipidemia in obese diabetic mice (50). Unexpectedly, RM1Ab targets and activates FGFR1 in the absence of $\beta$-Klotho, which leads to an inappropriate activation of the receptor across all tissues types expressing FGFR1. To overcome this promiscuity, avimers were designed to recognize and bind to the FGFR1/ $\beta$-Klotho tetramer distinct from the unbound FGFR1. Although these artificial proteins display similar activities to that of endogenous FGF21 ligand (51), they too exhibit high immunogenicity and quickly lose activity in blood circulation.

One alternative to increasing FGF21 signaling independently of recombinant FGF21 protein injections or molecular activation of receptor complexes, is to target and increase the endogenous production of FGF21 within the body. Markan et al. (2014) proved the liver is the main source of circulating FGF21 protein (52). Tailoring to the discovery that circulating FGF21 is liver derived, the remainder of this review aims to provide insights into the physiological conditions and metabolic pathways mediating the endogenous expression of FGF21 in the liver. 


\section{TISSUE-SPECIFIC FGF21 SIGNALING}

\section{Tissue Expression of $\beta$-Klotho}

As previously mentioned, the prerequisite for $\beta$-Klotho to induce higher order ligandindependent receptor complex formation prior to the binding of the FGF21 ligand is crucial (Fig.

1.1). Due to the strict requirement of $\beta$-Klotho in FGFR1c/FGF21 signaling, it is widely believed the actions of FGF21 are restrained to the selective metabolic tissues that simultaneously express both the FGFR1c receptor isoform and the $\beta$-Klotho co-activator $(45,46,48)$. Surprisingly, although circulating FGF21 protein expression is liver derived, the liver does not express the FGFR1c isoform at physiologically relevant levels $(52,53)$. It can be concluded that, since the liver does not express FGFR1c, FGF21 does not directly signal back upon its tissue of origin. Samms et al. (2016) showed that mice overexpressing adipocyte $\beta$ Klotho leads to enhanced FGF21 signaling, energy expenditure, thermogenesis, and weight loss under high fat dietary conditions (54). In contrast, mice overexpressing hepatocyte $\beta$-Klotho were unable to counteract the negative effects of high fat dietary conditions. These results support the theory that FGF21 protein expression is liver derived but signals distinct from the liver at FGFR1c/ $\beta$-Klotho expressing tissues to mediate the anti-diabetic, anti-obesogenic effects of FGF21 in the body. 


\section{FGF21 Signaling in Adipose Tissue}

White adipose tissue is highly enriched for the FGFR1c isoform $(46,55)$. In adipocytes, activation of the FGFR1 increases downstream phosphorylation of extracellular signal-regulated kinase (ERK), fibroblast growth factor receptor substrate 2 (FRS2), protein kinase B (Akt), and signaling transducer and activator of transcription 3 (Stat3) (49,56). FGF21 decreases circulating non-esterified fatty acids (NEFAs) by increasing uptake in white adipose tissue and decreases circulating glucose levels by increasing disposal into brown adipose tissues $(52,57)$. Knockout of FGFR1 signaling in adipocytes increases adipose lipolysis that results in elevated circulating serum NEFAs, TG, and increasing hepatic steatosis (58). Interestingly, adipose specific FGFR1null mice also correlate to enhanced FGF21 expression in the liver, presumably to compensate for the repressed FGFR signaling in the adipose tissue. Together these results suggest that circulating intermediate metabolites, such as NEFAs, produced from adipocyte lipolysis act upon the liver to elevate expression of hepatic FGF21 and that the increase in FGF21 protein expression acts as a compensatory mechanism to halt adipose lipolysis and reverse hepatic steatosis.

Adiponectin, an anti-inflammatory, lipid-lowering adipokine, mediates the physiological effects of FGF21 in the body. Adiponectin acts upon blood vessels to decrease low density lipoproteins (LDL), cholesterol, and triglycerides while simultaneously increasing the production of very low density lipoprotein (VLDL) catabolism (59). Mice fed a high fat diet increase circulating FGF21 expression, stimulate adiponectin secretion from adipocytes, lowers circulating lipids levels, and increases whole body insulin sensitivity $(49,60)$. Meanwhile, adiponectin-null mice are resistant to the lipid lowing effects produced by FGF21 pharmacological administration, suggesting the majority of FGF21's actions are governed 
through downstream adiponectin secretion $(61,62)$. In humans, atherosclerosis increases both circulating FGF21 and adiponectin protein concentrations (34). Adiponectin protects against atherosclerosis by reducing oxidative stress, lesion formation, and circulating triglycerides (63). Overall, FGF21 lowers circulating lipids and protects against heart disease and obesity through the actions of adiponectin.

\section{FGF21 Signaling in Central Metabolism}

Another tissue highly enriched for both the FGFR1c isoform and co-activator $\beta$-Klotho is the brain. In situ hybridization studies show $\beta$-Klotho is selectively enriched in the hypothalamic suprachiasmatic nucleus ( $\mathrm{SCN})$ as well as the hindbrain dorsal vagal complex (DVC), while FGFR1c is broadly expressed throughout the central nervous system (17). Selective brain specific knockout of $\beta$-Klotho in the SCN/DVC impairs the ability of transgenic FGF21 mice

overexpressing hepatic FGF21 to resist weight gain, induce thermogenesis, and increase energy expenditure when placed on a high fat diet (64). Interestingly, patients with hypothyroidism show decreased FGF21 expression in serum (65). These results suggest the central nervous system not only plays a crucial role in mediating the metabolic actions of FGF21 in the body, but also may mediate FGF21 expression in general.

In addition to FGF21's lipid lowering actions, FGF21 also plays an important role in feeding behaviors. Overexpression of endogenous hepatic FGF21 protein expression, as well as exogenous administration of recombinant FGF21 protein, decreases sugar preference and meal size in mice $(37,66)$. In contrast, knockout of FGF21 protein expression increases sugar choice and food intake. Furthermore, knockout of $\beta$-Klotho expression in the paraventricular nucleus (PVN) decreases FGF21 signaling and abolishes the ability of FGF21 to decrease sweet 
preference in mice. Overall, these finding suggest FGF21 signals in the central nervous system to mediate feeding behaviors.

FGF21 also acts upon the central nervous system to regulate bodily functions not directly related to metabolism. For example, FGF21 decreases kisspeptin hormone expression in the hypothalamus, which decreases gonadotropin-releasing hormone $(\mathrm{GnRH})$ secretion and increases female infertility in mice $(67,68)$. FGF21 also increases glucocorticoid levels, decreases physical activity, and alters circadian behavior $(17,69,70)$. Of particular interest, overexpression of FGF21 markedly increases lifespan in rodent models $(39,71)$. Taken together, FGF21 plays a critical role in mediating a variety of nutritional and physiological adaptive responses by signaling through the central nervous system.

\section{FGF21 Resistance}

Obese mice and humans exhibit chronic elevated levels FGF21 protein expression in blood circulation and mRNA abundance in the liver $(16,56,72)$. This observation directly contradicts the predicted anti-diabetic, anti-obesogenic actions of FGF21 within the body. The paradoxical increase in FGF21 protein expression in blood circulation in obese and T2D individuals may be related to the development of FGF21 "resistance" within the body. This resistance may originate at the FGF21-FGFR1c signaling interface, or it may occur further downstream of FGF21 receptor signaling. In support FGF21 resistance, obese patients show increased circulating FGF21 protein expression in serum but decreased adiponectin expression (61). Since adiponectin mediates the specific actions of FGF21 within the body, the resistance in obese individuals may be due to the inability of FGF21-FGFR1c signaling pathway to stimulate adiponectin secretion in adipocytes. Alternatively, FGF21 may still be able to successfully 
signal through FGFR1c in adipose tissue, but adiponectin synthesis or secretion is repressed by additional unknown mechanisms.

Additional evidence supporting the idea that FGF21-FGFR1c receptor signaling is impaired in metabolic disease conditions originate from studies examining $\beta$-Klotho protein expression in response to obesity. Obese mice exhibit increased c-Jun N-terminal kinase (JNK) activity in adipocytes, which decreases $\beta$-Klotho protein expression, FGFR/Klotho heterodimer formation, and corresponding downstream FGF21 signaling (56). Db/db mice also exhibit repressed $\beta$-Klotho protein expression and FGF21 signaling, but also show increased hepatic FGF21 mRNA abundance and circulating FGF21 protein expression presumably due to an overcompensation effect (73). Taken together, these results suggest FGF21 resistance originates from repressed $\beta$-Klotho protein expression and impaired FGFR1c receptor signaling.

Most recently, another novel theory exploring an alternative mechanism for FGF21 resistance by protein cleavage has emerged. Both human and murine FGF21 proteins are cleaved by dipeptidyl peptidase-IV (DPP-IV) at 2 specific proline locations (Pro2 and Pro4) at the N-terminus of the FGF21 peptide (44). Cleavage at these two proline residues does not affect the activity of circulating FGF21 protein. Unexpectedly, the cleavage of a third proline residue at the C-terminus (Pro171), found exclusively in the human FGF21 peptide, has been identified. Pro171 is cleaved by a newly discovered serine proteinase, fibroblast activating protein (FAP), which cleaves and inactivates the FGF21 protein (43). Interestingly, inhibiting FAP activity increases circulating FGF21 protein expression in non-human primates (43). Further investigation is needed to further identify whether dietary conditions affect the activity, or abundance, of circulating FAP and sequential inactivation of FGF21 protein. 


\section{PHYSIOLOGICAL EXPRESSION OF ENDOGENOUS FGF21}

\section{Starvation and PPARa}

FGF21 acts as a nutritional adapter during times of extreme nutritional stress. For example, the nutritional stress induced by long-term fasting and starvation robustly stimulates FGF21 gene transcription in the liver and FGF21 protein secretion into the blood circulation (7476). During starvation, FGF21 functions to increase factors involved in gluconeogenesis, fatty acid oxidation, ketogenesis, and gluconeogenesis while simultaneously repressing those involved in lipogenesis $(13,16,53,56)$. Interestingly, overexpression of FGF21 in mice does not increase glycogenolysis, suggesting FGF21 plays a role in mediating late fasting responses after glycogen storages have already been depleted (77). In agreement with this argument, circulating FGF21 protein expression in humans is decreased during the early fasting period but robustly increased after long-term (10 day) fasting conditions (78).

Starvation also enhances lipolysis in adipocytes to breakdown lipids for energy (79). Lipids, stored as TG in adipose tissue, are broken down into NEFA and glycerol (Fig. 1.2) (79). NEFAs travel from the adipose tissue to peripheral metabolic tissues where they are utilized as cellular energy sources when blood glucose concentrations are low (80). In the liver, NEFAs undergo mitochondrial oxidation and form acetyl-CoA, a substrate utilized in ketone body production (ketogenesis), or further oxidized in the tricarboxylic acid cycle (TCA) to form ATP for glucose production (gluconeogenesis) (Fig. 1.2) (81,82). Meanwhile, the free glycerol released by TG lipolysis can also be used as a substrate in gluconeogenesis to promote glucose production. Both ketone bodies and glucose are used as energy sources in peripheral tissues during starvation (83). Infusion of NEFAs increases circulating FGF21 protein concentration in 


\section{Starvation}

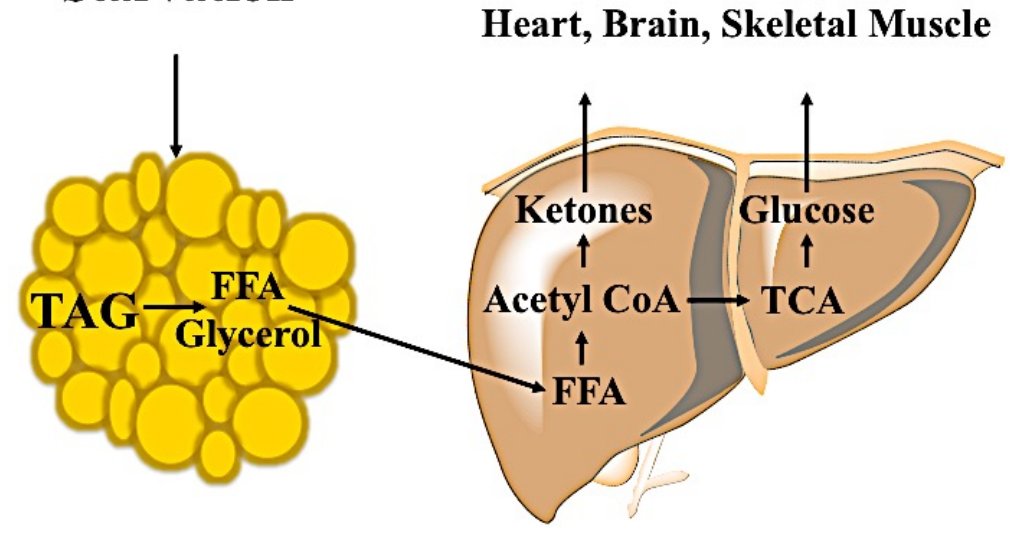

Figure 1.2. Fates of lipid intermediates during starvation. Breakdown of TAGs in adipocytes releases free fatty acids (FFA) and glycerol which are transported to peripheral tissues for energy sources. In the liver, FFAs are oxidized in the mitochondria to produce acetyl-CoA, a substrate for ketogenesis, tricarboxylic citric acid cycle (TCA), and gluconeogenesis. Glycerol is also a substrate for gluconeogenesis. Both ketone bodies and glucose are used as energy sources in peripheral tissues during starvation.

human and animal models (Fig. 1.3) $(78,84,85)$. These results suggest hepatic FGF21 expression is stimulated during conditions of starvation where adipocytes lipolysis increases circulating NEFA concentrations. Interestingly, anorexic individuals are unable to induce FGF21 expression during starvation, presumably due to their low body fat concentrations (56).

In addition to being substrates for ketogenesis and gluconeogenesis, long-chain fatty acids are also endogenous ligands for the transcription factor peroxisome proliferator-activated receptor alpha (PPAR $\alpha)(86)$. Ligand activated PPAR $\alpha$ heterodimerizes with the retinoid X receptor (RXR) and binds to PPAR-response elements (PPREs) on target gene promoters and increases transcription of genes involved in fatty acid metabolism and lipoprotein formation $(87,88)$. Notably, PPAR $\alpha$ enhances hepatic FGF21 gene transcription by heterodimerizing with RXR and localizing to an upstream PPRE located on the FGF21 promoter (Fig. 1.3) (88-90). Chemical activators of PPAR $\alpha$, such as fenofibrate and GW7647, also increase FGF21 
expression in both rodents and human models $(69,89,91-94)$. Benzafibrate, a lipid lowering drug, increases PPAR $\alpha$ activity and stimulates FGF21 expression (69). Interestingly, the stimulatory effect of starvation on FGF21 gene expression is greatly reduced, but not completely abolished, in PPARa knockout mice $(89,91,94)$. Since PPAR $\alpha$-null mice are unable to completely suppress the effects of starvation on FGF21 gene expression, additional signaling pathways may play a role in mediating the nutritional regulation of FGF21 during fasting conditions.

\section{Overnutrition, T2D, and ChREBP}

As previously stated, FGF21 acts as a metabolic adapter during conditions of extreme nutritional stress. In contrast to starvation, a second type of extreme nutritional stress in the liver occurs during overnutrition. Circulating FGF21 protein levels are elevated in obese and T2D animal and human models suggesting that overnutrition and obesity related diseases also enhance FGF21 gene activity (Fig 1.3) $(95,96)$. For example, overexpression or administration of FGF21 decreases NEFAs, triglycerides, and serum glucose in mice fed a high fat, obesogenic diet $(57,97,98)$. FGF21 also signals in the CNS to increase sympathetic nerve activity, peripheral thermogenesis, and browning of adipose tissue through the actions of uncoupling protein-1 (UCP-1) in obese animals $(64,74)$.

Obesogenic diets increase glucose availability to peripheral metabolic tissues (99). Glucose increases the activity of glucokinase and protein phosphatase 2a which results in the dephosphorylation, nuclear translocation, and increased transcriptional activation of the carbohydrate response element binding protein (ChREBP). ChREBP is a transcription factor 
that binds to carbohydrate response elements (ChoREs) on target metabolic promoters and controls $50 \%$ of lipogenesis by regulating glycolytic and lipogenic genes (100-104).

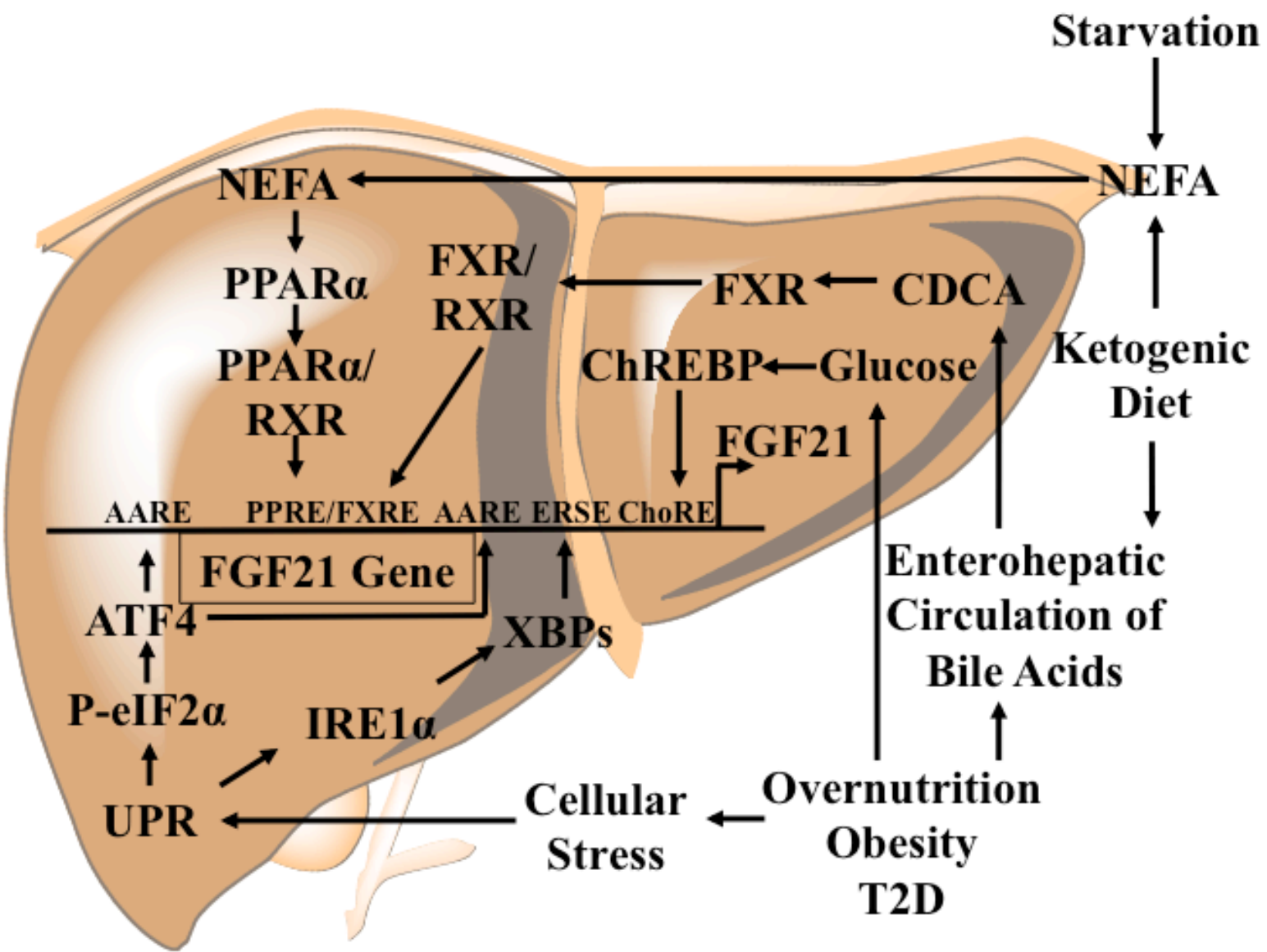

Figure 1.3. Physiological Modulation of Endogenous FGF21 Expression in the Liver. Starvation increases the circulation of FFA. Long-chain FFAs are endogenous ligands for PPAR $\alpha$. Ligand activated PPAR $\alpha$ dimerizes with the RXR and binds to the upstream PPRE site on the FGF21 promoter to enhance gene transcription. Overnutrition increases circulating glucose levels. Glucose increases the transactivation of ChREBP, a transcription factor that binds to a downstream ChoRE sites on the FGF21 promoter to stimulate FGF21 gene transcription. High-fat, low-carbohydrate keotgenic diets increase the hepatic circulation of bile acids. Chenodeoxycholic acid activates FXR. Ligand activated FXR heterodimerizes with RXR and binds to an upstream FXRE on the FGF21 promoter to stimulate gene transcription. Unfolded proteins in the lumen of the ER induce the UPR. Activation of the downstream IRE1 $\alpha$ arm of the UPR induces splicing of XBP1. Spliced and activated XBP1s binds to the downstream ERSE on the FGF21 promoter to stimulate gene transcription. Activation of the downstream PERK arm of the UPR leads to the phosphorylation of eIF2 $\alpha$ and induced translation of ATF4. ATF4 is a transcription factor that binds to both upstream and downstream AAREs on the FGF21 promoter to stimulate gene transcription. 
ChREBP activity is stimulated by glucose independently of insulin and functions to convert excess circulating glucose into triglycerides in the liver and adipose for storage $(105,106)$. In primary hepatocytes, glucose induces transactivation of ChREBP to a downstream ChoRE site located on the FGF21 promoter and stimulates FGF21 gene transcription (Fig. 1.3) (37,107). It is speculated that enhanced glucose availability during overnutrition, obesity, and T2D increases ChREBP activity and FGF21 gene transcription. Although in vitro data suggests ChREBP is a mediator of FGF21 promoter activity, in vivo studies examining carbohydrate re-feeding and resulting FGF21 expression are conflicting. Palou et al. (2008) showed a marked decrease in hepatic FGF21 mRNA abundance after carbohydrate re-feeding in mice (76), while other studies showed an increase in hepatic FGF21 mRNA after carbohydrate re-feeding $(37,108)$. The mechanisms regulating FGF21 expression during carbohydrate re-feeding are not yet clear and likely involve multiple pathways distinct from ChREBP. For example, carbohydrate re-feeding decreases PPAR $\alpha$ signaling in the liver and may account for the decrease in FGF21 expression observed in some studies (109). On the contrary, a high fat diet containing carbohydrates increases circulating dietary fatty acids, hepatic PPAR $\alpha$ activity, and FGF21 gene expression which may account for the increase in FGF21 expression in those studies (110). It is no surprise that differing dietary compositions between studies play a crucial role in regulating FGF21 expression. These results suggest additional signaling pathways independent of PPAR $\alpha$ may mediate overnutrition, obesity, and T2D induction of hepatic FGF21 expression. 


\section{Bile Acids and FXR}

Bile acids are amphipathic, detergent-like molecules stored in the gallbladder that function to solubilize cholesterol and lipids in the intestines (111). Chenodeoxycholic acid (CDCA) and cholic acid make up $80 \%$ of the bile acid composition in humans (112). During feeding, the duodenum secretes cholecystokinin (CCK) which signals to the gallbladder, the primary storage location for bile acids (113). In response to CCK, the gallbladder contracts and secretes bile acids into the large intestines where they form mixed micelles with cholesterol and phospholipids to solubilize dietary nutrients $(111,114)$. After feeding, $\sim 95 \%$ of bile acids are reabsorbed at the distal ileum and enter the enterohepatic circulation where they pass through the liver before being recycled back into the gallbladder $(114,115)$. Dietary fats increase the production of CCK and consecutive secretion of bile acids (116,117). Obese and T2D humans and mice exhibit a correlation between increased CDCA synthesis and bile acid pool size with circulating FGF21 protein expression (Fig. 1.3) (112,118-120). In addition, humans with biliary atresia also exhibit increased serum and hepatic FGF21 expression (121).

In particular, CDCA is a potent activator of FGF21 mRNA gene transcription in primary rat hepatocytes (Fig. 1.3) (122). CDCA activates the bile acid nuclear receptor, farnesoid X receptor (FXR), which dimerizes with RXR and binds to a upstream farnesoid X receptor response element (FXRE) on the FGF21 promoter (Fig. 1.3) (122). Ablation of FXR gene partially represses the ability of a ketogenic diet to induce hepatic FGF21 mRNA abundance and serum FGF21 protein concentrations (122). These results suggest that a high-fat, lowcarbohydrate ketogenic diet induces the production of CCK, secretion of bile acids, and enterohepatic circulation of bile acids through the liver where they stimulate FXR/RXR heterodimerization and induce hepatic FGF21 gene transcription. Since FXR-null mice do not 
completely repress the ability of ketogenic diet to increase FGF21 expression in the liver, other mechanisms independent of FXR activation are required to induce FGF21 gene expression during a high-fat, low-carbohydrate ketogenic diet.

\section{ER Stress}

Circulating FGF21 protein expression is increased in additional, non-dietary mediated states of cellular stress including patients with chronic kidney disease, viral infection, and systematic inflammatory response syndrome (SIRS) (123-125). Even mechanical stress, such as ischemic reperfusion injuries in liver transplants, endurance exercise, and wound healing, is correlates with an increase in FGF21 expression (126-128). Due to the wide range stress stimuli, nutritional and cellular, that induce expression and circulation of FGF21, FGF21 is now widely accepted as a general stress induced factor $(49,129)$.

The endoplasmic reticulum (ER) is a versatile organelle that plays a critical role in transmembrane lipid and protein biosynthesis (130). Secretory and transmembrane proteins are translated by ribosomes on the cystolic surface of the ER but translocate into the lumen of the ER for proper folding, stabilization, and modification. In addition to protein biosynthesis, the ER also contains a calcium reservoir used for both storage and signaling. The calcium pool within the ER lumen is 3-4 fold higher compared to that of the cytosol, and the ER is highly sensitive to lumen calcium perturbations. For example, calcium dysregulation and/or protein misfolding within the ER lumen can activate the unfolded protein response (UPR) if equilibrium is breached (131). Overnutrition produces an excess in glucose, insulin, NEFA, and cytokines that have been shown to increase protein misfolding/aggregation and induce ER stress and activate the UPR (132). The three branches of the UPR consists of inositol requiring enzyme 1 
alpha (IRE1 $\alpha$ ), activating transcription factor 6 (ATF6), and protein kinase RNA-like endoplasmic reticulum kinase (PERK) (Fig. 1.4) (133).

During basal conditions, when ER stress is low, the molecular chaperone binding immunoglobin protein (BiP/GRP78) binds to and inactivates the three arms of the UPR (Fig. 1.4) $(130,134)$. When ER stress is induced, either through chemical or endogenous manipulations, unfolded proteins accumulate within the lumen of the ER and bind BiP. The binding of unfolded proteins to BiP sequesters the protein away from IRE1 $\alpha$, ATF6, and PERK. Once unbound from $\mathrm{BiP}$, the three arms of the UPR become active and are able to signal to downstream pathways. Unbinding of BiP from IRE1 $\alpha$ causes IRE1 $\alpha$ to oligomerize, autophosphorylate, and activate downstream signaling pathways (135). Oligomerization and autophosphorylation of IRE1 $\alpha$ conformationally changes the protein's structure, resulting in increased RNase activity of the protein oligomer. IRE1 $\alpha$ splices the UPR transcription factor, $\mathrm{x}$-box binding protein 1 (XBP1), at two separate sites resulting in the excision of a small intron and yielding a functional, activated transcriptional factor (XBP1s) (136).

Splicing of XBP1 leads to enhanced binding of XBP1s at UPR elements (UPRE) or ERstress response elements (ERSE) located on target promoters of cytoprotective genes involved in the UPR and ER-assisted degradation (ERAD) pathways $(137,138)$. For example, tunicamycin treatment in hepatocytes induces IRE1 $\alpha$ activation, XBP1 splicing, and transactivation of XBP1s to a downstream ERSE located on the FGF21 promoter, leading to stimulated FGF21 gene transcription during ER stress (Fig. 1.3) (139). Activation of IRE1 $\alpha$ can also induce apoptosis by activating additional downstream signaling pathways including apoptotic-signaling kinase 1 (ASK1), JNK, and p38 mitogen-activated protein kinase (p38 MAPK) (Fig. 1.4) (140). A third 
pathway IRE1 $\alpha$ mediates is the regulated IRE1-dependent decay (RIDD) pathway. RIDD is a specialized pathway used to target and degrade selective UPR mRNAs (Fig. 1.4) $(141,142)$.

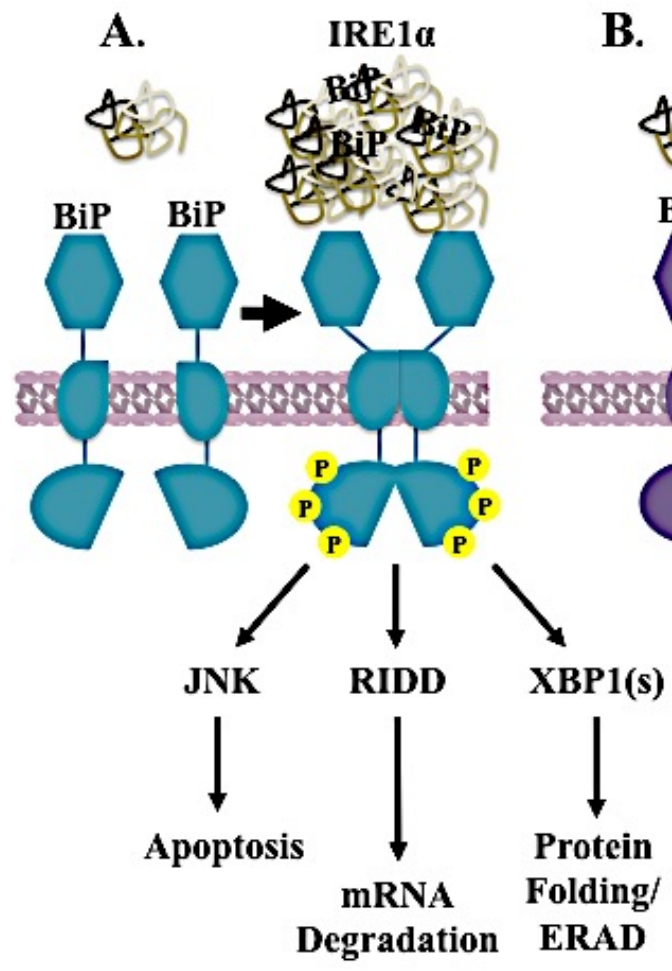

B.

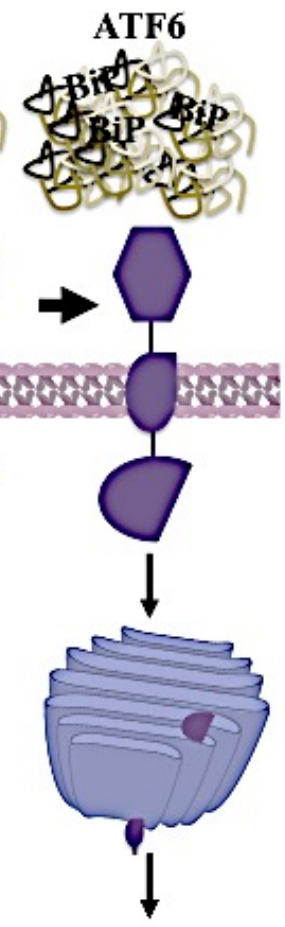

BiP/GRP78

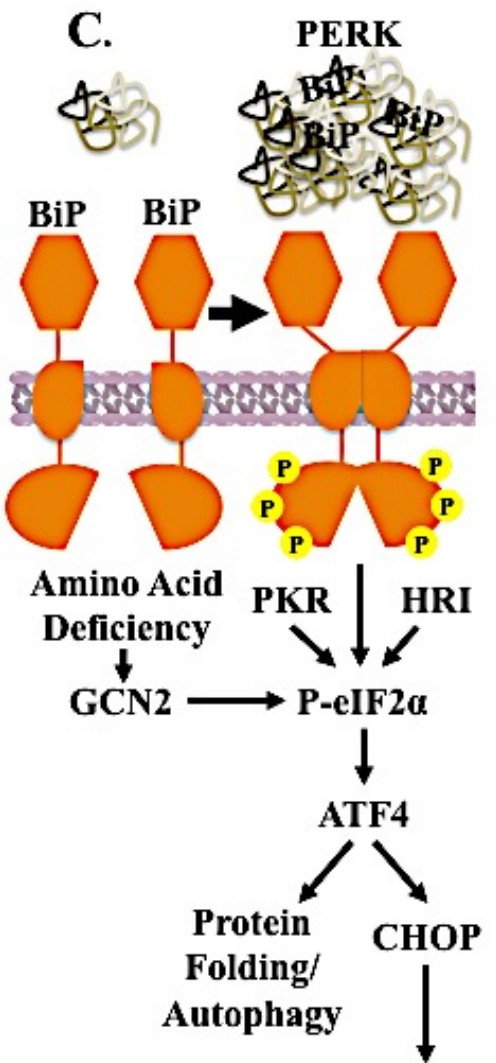

Apoptosis

Figure 1.4. The three arms of the unfolded protein response. During conditions of low cellular stress, BiP binds to and inactivates IRE1a, ATF6, and PERK. During conditions of high ER stress, unfolded proteins accumulated within the lumen of the ER and sequester BiP from the three arms, thus leading to the activation of the UPR. (A) IRE1a oligomerizes, autophosphorylates, and activates its RNase domain. IRE1 $\alpha$ splices XBP1, a transcription factor that, once spliced, binds to ERSE and URSE elements on target promoters to induce gene transcription for UPR genes. IRE1 $\alpha$ can also activate RIDD mediated mRNA degradation and JNK mediated apoptosis. (B) ATF6 is cleaved from the ER membrane and further processed in the Golgi. After cleavage in the Golgi, ATF6 travels to the nucleus and stimulates gene transcription for UPR chaperones. (C) PERK oligomerizes, autophosphorylates, and phosphorylates the downstream target eIF2 $\alpha$. eIF $2 \alpha$ decreases global translation while increasing translation of selective UPR chaperones and transcription factors such as ATF4. ATF4 is a transcription factor that binds to target genes and induces gene transcription for UPR chaperones. ATF4 also induces the gene transcription of C/EBP-homology protein (CHOP). CHOP is a transcription factor that induces promoter activation of apoptotic genes. GCN2, PKR, and HRI are additional kinases shown to phosphorylate eIF2 $\alpha$ under different stress conditions. 
ATF6 makes up the second arm of the UPR. ATF6 is a transcription factor that is originally synthesized as an ER-transmembrane protein. The accumulation of unfolded proteins relieves BiP repression of ATF6 and triggers the cleavage of ATF6 from the ER luminal domain where it then migrates to the Golgi for further cleavage by additional proteases (Fig. 1.4) (143145). After cleavage by proteases in the Golgi, the N-terminus of ATF6 travels to the nucleus and activates gene transcription of target UPR genes. Interestingly, gene expression analysis of ATF6 knockout in mouse embryonic fibroblasts (MEFs) shows loss of ATF6 does not inhibit the induction of downstream UPR genes in response to tunicamycin treatment, suggesting a redundancy in the UPR pathways (138). In addition, overexpression of ATF6 in hepatocytes does not stimulate hepatic FGF21 gene transcription, concluding that ATF6 does not play a role in stress induced FGF21 expression in the liver (131).

Finally PERK, an ER-resident transmemebrane kinase and the final arm of the UPR, also becomes active when ER stress is induced. Like the previous mechanisms for IRE1 $\alpha$ activation, BiP de-repression of PERK allows for PERK's N-terminal ER luminal domain to oligomerize (146). Oligomerization results in the trans-autophosphorylation of PERK's C-terminal cytoplasmic kinase domain and sequential activation of downstream UPR signaling pathways. For example, PERK phosphorylates eukaryotic initiation factor 2 alpha (eIF2 $\alpha$ ) (Fig. 1.4) (147). Phosphorylation of eIF2a represses general cap-dependent protein translation while simultaneously increasing the translation of specific ER stress chaperones through mRNA capindependent mechanisms (148). In general, unfolded proteins increase the activity of the PERK/eIF2 $\alpha$ axis such that phosphorylation of eIF $2 \alpha$ alleviates ER stress by repressing global protein translation, decreasing the flux of newly synthesized proteins into the ER lumen, and 
increasing the expression of select molecular ER chaperones for the removal and degradation of unfolded proteins by ER-associated degradation (ERAD).

Activating transcription factor 4 (ATF4) is a transcription factor whose protein translation is increased after phosphorylation of eIF2 $\alpha$ (Fig. 1.4) (148-151). ATF4 is a basic leucine zipper (bZIP) transcription factor that binds, either a homodimer with itself or a heterodimer with other bZIP transcription factors, to amino acid response elements (AARE) on target gene promoters to induce gene transcription (152-155). In the liver, ATF4 binds to two conserved AAREs located on the FGF21 promoter to stimulate FGF21 gene transcription during both nutritional stress (e.g. amino acid deprivation, obesogenic diet) and chemically induced stress (e.g. thapsigargin, tunicamycin) (Fig. 1.3) (131,156-162).

FGF21 expression is induced by multiple arms of the UPR pathway suggesting FGF21 plays a protective role during a variety of ER stress conditions (139,162-164). For example, selective amino acid deprivation and protein deficient diets increase hepatic FGF21 mRNA abundance and circulating FGF21 protein expression (164-167). The induction of FGF21 during methionine, choline, and histidine amino acid deprivation results in weight loss and resistance to hepatic steatosis $(165,167)$. The mechanisms by which amino acid deprivation increases FGF21 expression is dependent on uncharged tRNA activation of general control nonderepressible 2 (GCN2), a kinase that phosphorylates eIF2 $\alpha$ in response to ER stress (Fig. 1.4) (168). Phosphorylation of eIF2 $\alpha$ by GCN2 results in increased ATF4 protein translation, enhanced binding of ATF4 to AAREs on the FGF21 promoter, and increased FGF21 gene transcription $(166,167,169)$. Notably, the stimulation of hepatic FGF21 gene expression by amino acid deficient diets is PPAR $\alpha$ - and FXR-independent (165). Meanwhile metformin, an oral diabetic medication used to control blood sugar, induces PERK activity to phosphorylate eIF2 $\alpha$, increase 
ATF4 protein expression, and stimulate FGF21 gene transcription in primary hepatocytes (160). A recent study by Phillipson-Weiner, et al. (2016) showed that loss of GCN2 resulted in amino acid deprivation reassigning PERK as the primary kinase for eIF2 $\alpha$ when GCN2 was unavailable (170). Like the redundancy previously mentioned for ATF6, these results suggest the UPR may mediate eIF2 $\alpha$ phosphorylation through either GCN2 or PERK under the same stimulatory conditions.

Phosphorylation of eIF2 $\alpha$ is not limited to PERK or GCN2 kinase phosphorylation. Two additional kinases, protein kinase RNA-activated (PKR) and heme-regulated inhibitory kinase (HRI), also phosphorylate eIF2 $\alpha$ (Fig. 1.4) (171). PKR activity is induced when double stranded RNAs, with a minimum of $33 \mathrm{bp}$, bind to its dsRNA-binding domain $(172,173)$. Due to the strict requirement of dsRNA activation, PKR activity in the liver is often correlated with viral infections such as hepatitis $\mathrm{C}$ (174-177). It is no surprise then that hepatitis C infection increases FGF21 mRNA abundance in the liver, presumably through PKR-mediated phosphorylation of eIF2 $\alpha$ and enhanced transactivation of ATF4 to the FGF21 promoter (178). Meanwhile, kinase activity of HRI is increased during times of acute heme-deficient states, leading to the phosphorylation of eIF2 $\alpha$ and downstream stimulation of ATF4 protein translation (Fig. 1.4) (179). Interestingly, HRI activation is enhanced during high-fat feeding in mice and stimulates the eIF2 $\alpha /$ ATF4/FGF21 axis in the liver (180). Together, the above findings present eIF2 $\alpha$ as a global mediator of hepatic stress pathways (viral (PKR), amino acid deficiency (GCN2), heme deficiency (HRI), and unfolded proteins (PERK)) for the translation and transactivation of the common transcription factor, ATF4, to induce FGF21 gene transcription in the liver. 


\section{Glucagon and Insulin}

PPAR $\alpha$ only partially mediates the stimulatory effect of starvation and a ketogenic diet on FGF21 gene expression, suggesting that additional PPAR $\alpha$-independent mechanisms regulate FGF21 gene transcription during these dietary conditions. One such factor that is increased during both starvation and HF-LC diets is the pancreatic hormone, glucagon (181-183). Hyperglycemia induces the release of glucagon from pancreatic $\alpha$-cells into blood circulation (184-187). Glucagon signals in the liver to increase factors (e.g. PPAR $\alpha$ ) involved in gluconeogenesis, (e.g. PEPCK) to suppress TG synthesis $(182,188,189)$.

Glucagon receptor knockout mice are unable to induce FGF21 mRNA abundance in the liver during starvation (190). Additionally, chronic activation of the glucagon receptor increases hepatic FGF21 mRNA abundance, circulating FGF21 protein concentration, and weight loss (193). In agreement to these findings, subcutaneous administration of glucagon increases hepatic FGF21 mRNA abundance and plasma FGF21 concentrations in mice and humans (190-192) and in vitro experiments show glucagon treatment in primary hepatocytes increases FGF21 protein secretion (194). Interestingly, the increase in glucagon stimulated FGF21 protein secretion in primary hepatocytes is associated with a transient decrease in FGF21 mRNA abundance. This results suggests that glucagon acts at a translational/posttranslational step to increase hepatic FGF21 secretion but does not signal transcriptionally to mediate FGF21 mRNA abundance. The inability of glucagon to induce FGF21 mRNA abundance in hepatocyte cultures (194) contrasts with the results of glucagon receptor ablation studies $(190,193)$ demonstrating that the starvation-induced increase in FGF21 mRNA abundance is mediated, at least in part, by glucagon receptor activation. One possible explanation for the discrepancy between these findings is that glucagon stimulation of FGF21 mRNA abundance requires the presence of 
another hormone or signaling factor to enhance its transcriptional regulation on FGF21 gene transcription.

Insulin is a hormone secreted from pancreatic $\beta$-cells during the fed state and acts upon the liver to induce pathways involved in lipogenesis, glycogen synthesis, and energy storage (195-198). Results of studies with mice containing defects in the insulin-signaling pathway indicate that insulin is one such factor that potentiates the ability of glucagon to increase FGF21 mRNA abundance. Dong et al. (2008) showed that liver-specific ablation of insulin receptor substrate 1 and insulin receptor substrate 2 decreased hepatic FGF21 mRNA abundance during both the fed and starved state (199). In addition, Haeusler et al. (2010) have reported that streptozotocin-induced diabetes suppressed the stimulatory effect of starvation on hepatic FGF21 mRNA abundance (200). In agreement with these loss-of-function studies, insulin infusion increases serum FGF21 concentrations in humans (201) and insulin treatment increases both FGF21 mRNA abundance and FGF21 protein secretion in primary hepatocytes (194). Although insulin is generally regarded as a hormone signaling the fed state, these observations suggest that basal insulin levels play a role in mediating the increase in FGF21 mRNA abundance during the starved state as well.

Most strikingly, glucagon and insulin act cooperatively to increase FGF21 mRNA abundance and secretion both in vitro and in vivo $(194,202)$. Although glucagon opposes insulin regulation of a wide variety of metabolic processes, there are multiple scenarios in which glucagon enhances insulin actions (203-207). For example, infusion of glucagon and insulin into partially hepatoectomized eviscerated rats synergistically stimulates hepatic DNA synthesis (203). In addition to DNA synthesis, treatment of cultured primary hepatocytes with glucagon or glucagon analogs in the presence of insulin robustly induces nuclei proliferation when compared 
hormone treatment alone (206). This increase in nuclei proliferation is blocked with the addition of H89, suggesting glucagon requires downstream signaling kinase, protein kinase A (PKA), to potentiate insulin signaling. Glucagon also enhances insulin signaling by increasing the activity of the insulin tyrosine receptor kinase $(205,208)$. Glucagon and insulin cooperatively increase the insulin tyrosine receptor kinase activity, which leads to the phosphorylation of select downstream targets. This selectivity suggests glucagon may potentiate the ability of insulin to active unique, downstream pathways while simultaneously repressing others. At the present time, the mechanisms mediating the synergistic interaction between insulin and glucagon are not known. 


\section{OBJECTIVE}

Characterize the molecular pathways mediating the ability of starvation and a HF-LC, ketogenic diet to stimulate FGF21 mRNA abundance in primary hepatocytes.

PPAR $\alpha$ and FXR only partially mediate the stimulatory effect of starvation and ketogenic diet on hepatic FGF21 gene expression, suggesting additional PPAR $\alpha$ - and FXR-independent mechanisms stimulate FGF21 gene transcription during these dietary conditions. During starvation and HF-LC, ketogenic diets, the portal vein exhibits a high glucagon to insulin ratio. Treatment with glucagon and insulin concentrations, similar to that observed during starvation, induces FGF21 mRNA abundance in primary hepatocytes. Additionally, infusion of a high glucagon to insulin hormone concentration increases the production and secretion of splanchnic FGF21 in humans. The mechanisms by which glucagon and insulin work cooperatively to selectively increase hepatic FGF21 expression and secretion is currently unknown. Obese and T2D humans and mice also exhibit increased bile acid (e.g. CDCA) synthesis and circulating FGF21 protein expression. The objective of this study is to determine the molecular pathways mediating the ability of glucagon plus insulin and CDCA to stimulate FGF21 gene transcription in primary hepatocytes. Understanding the fundamental mechanisms by which glucagon plus insulin and CDCA signal to induce FGF21 gene transcription will provided in depth knowledge on the endogenous regulation of FGF21 expression and also identify additional targets for drug development to treat metabolic syndrome. 


\section{REFERENCES}

1. Ogden, C. L., Carroll, M. D., Kit, B. K., and Flegal, K. M. (2014) PRevalence of childhood and adult obesity in the united states, 2011-2012. JAMA 311, 806-814

2. Finkelstein, E. A., Khavjou, O. A., Thompson, H., Trogdon, J. G., Pan, L., Sherry, B., and Dietz, W. (2012) Obesity and severe obesity forecasts through 2030. Am J Prev Med 42, 563-570

3. Manzel, A., Muller, D. N., Hafler, D. A., Erdman, S. E., Linker, R. A., and Kleinewietfeld, M. (2014) Role of "Western Diet" in Inflammatory Autoimmune Diseases. Current allergy and asthma reports 14, 404-404

4. Kaur, J. (2014) A Comprehensive Review on Metabolic Syndrome. Cardiology Research and Practice 2014

5. Olokoba, A. B., Obateru, O. A., and Olokoba, L. B. (2012) Type 2 Diabetes Mellitus: A Review of Current Trends. Oman Medical Journal 27, 269-273

6. (2004) Prevalence of overweight and obesity among adults with diagnosed diabetes-United States, 1988-1994 and 1999-2002. MMWR. Morbidity and mortality weekly report 53, 1066-1068

7. Hammond, R. A., and Levine, R. (2010) The economic impact of obesity in the United States. Diabetes Metab Syndr Obes 3, 285-295

8. Stunkard, A., and Mc, L.-H. M. (1959) The results of treatment for obesity: A review of the literature and report of a series. A.M.A. Archives of Internal Medicine 103, 79-85

9. Lellis, J. C. (2016) Waving the Red Flag: FTC Regulation of Deceptive Weight-Loss Advertising 1951-2009. Health communication 31, 47-59

10. (2004) FTC warns against weight-loss scams. Health news (Waltham, Mass.) 10, 3

11. Itoh, N. (2010) Hormone-like (endocrine) Fgfs: their evolutionary history and roles in development, metabolism, and disease. Cell Tissue Res 342, 1-11

12. Long, Y. C., and Kharitonenkov, A. (2011) Hormone-like fibroblast growth factors and metabolic regulation. Biochimica et Biophysica Acta (BBA) - Molecular Basis of Disease 1812, 791-795

13. Owen, B. M., Mangelsdorf, D. J., and Kliewer, S. A. (2015) Tissue-specific actions of the metabolic hormones FGF15/19 and FGF21. Trends in Endocrinology \& Metabolism 26, 22-29

14. Markan, K. R., and Potthoff, M. J. (2016) Metabolic fibroblast growth factors (FGFs): Mediators of energy homeostasis. Seminars in Cell \& Developmental Biology 53, 85-93

15. Cuevas-Ramos, D., Aguilar-Salinas, C. A., and Gómez-Pérez, F. J. (2012) Metabolic actions of fibroblast growth factor 21. Curr. Opin. Pediatr. 24, 523-529

16. Kliewer, S. A., and Mangelsdorf, D. J. (2010) Fibroblast growth factor 21: from pharmacology to physiology. Am J Clin Nutr 91, 254S-257S

17. Bookout, A. L., de Groot, M. H. M., Owen, B. M., Lee, S., Gautron, L., Lawrence, H. L., Ding, X., Elmquist, J. K., Takahashi, J. S., Mangelsdorf, D. J., and Kliewer, S. A. (2013) FGF21 regulates metabolism and circadian behavior by acting on the nervous system. Nat Med advance online publication

18. Gaich, G., Chien, Jenny Y., Fu, H., Glass, Leonard C., Deeg, Mark A., Holland, William L., Kharitonenkov, A., Bumol, T., Schilske, Holger K., and Moller, David E. 
(2013) The Effects of LY2405319, an FGF21 Analog, in Obese Human Subjects with Type 2 Diabetes. Cell Metabolism 18, 333-340

19. Talukdar, S., Zhou, Y., Li, D., Rossulek, M., Dong, J., Somayaji, V., Weng, Y., Clark, R., Lanba, A., Owen, Bryn M., Brenner, Martin B., Trimmer, Jeffrey K., Gropp, Kathryn E., Chabot, Jeffrey R., Erion, Derek M., Rolph, Timothy P., Goodwin, B., and Calle, Roberto A. (2016) A Long-Acting FGF21 Molecule, PF-05231023, Decreases Body Weight and Improves Lipid Profile in Non-human Primates and Type 2 Diabetic Subjects. Cell Metabolism 23, 427-440

20. Florentin, M., Liberopoulos, E. N., and Elisaf, M. S. (2008) Sibutramine-associated adverse effects: a practical guide for its safe use. Obesity reviews : an official journal of the International Association for the Study of Obesity 9, 378-387

21. Garcia Diaz, E., and Martin Folgueras, T. (2011) Systematic review of the clinical efficacy of sibutramine and orlistat in weigth loss, quality of life and its adverse effects in obese adolescents. Nutricion hospitalaria 26, 451-457

22. (2014) Lorcaserin. In obesity: unacceptable risks. Prescrire international 23, 117-120

23. Gebhart, M. (2015) [Clinical Practice after Bariatric Surgery: Problems and Complications]. Praxis 104, 1379-1385

24. Dujic, T., Causevic, A., Bego, T., Malenica, M., Velija-Asimi, Z., Pearson, E. R., and Semiz, S. (2016) Organic cation transporter 1 variants and gastrointestinal side effects of metformin in patients with Type 2 diabetes. Diabetic medicine : a journal of the British Diabetic Association 33, 511-514

25. Cariou, B., Fontaine, P., Eschwege, E., Lievre, M., Gouet, D., Huet, D., Madani, S., Lavigne, S., and Charbonnel, B. (2015) Frequency and predictors of confirmed hypoglycaemia in type 1 and insulin-treated type 2 diabetes mellitus patients in a real-life setting: results from the DIALOG study. Diabetes \& metabolism 41, 116-125

26. Zhang, F., Xiang, H., Fan, Y., Ganchuluun, T. A., Kong, W., Ouyang, Q., Sun, J., Cao, B., Jiang, H., and Nie, S. (2013) The effects of sulfonylureas plus metformin on lipids, blood pressure, and adverse events in type 2 diabetes: a meta-analysis of randomized controlled trials. Endocrine 44, 648-658

27. Madsbad, S. (2016) Review of head-to-head comparisons of glucagon-like peptide-1 receptor agonists. Diabetes Obes Metab 18, 317-332

28. Gilbert, R. E., and Krum, H. (2015) Heart failure in diabetes: effects of antihyperglycaemic drug therapy. Lancet (London, England) 385, 2107-2117

29. Taylor, S. I., Blau, J. E., and Rother, K. I. (2015) SGLT2 Inhibitors May Predispose to Ketoacidosis. J Clin Endocrinol Metab 100, 2849-2852

30. Véniant, M. M., Komorowski, R., Chen, P., Stanislaus, S., Winters, K., Hager, T., Zhou, L., Wada, R., Hecht, R., and Xu, J. (2012) Long-acting FGF21 has enhanced efficacy in diet-induced obese mice and in obese rhesus monkeys. Endocrinology 153, 4192-4203

31. Xu, J., Lloyd, D. J., Hale, C., Stanislaus, S., Chen, M., Sivits, G., Vonderfecht, S., Hecht, R., Li, Y.-S., Lindberg, R. A., Chen, J.-L., Jung, D. Y., Zhang, Z., Ko, H.-J., Kim, J. K., and Véniant, M. M. (2009) Fibroblast growth factor 21 reverses hepatic steatosis, increases energy expenditure, and improves insulin sensitivity in diet-induced obese mice. Diabetes 58, 250-259

32. Andersen, B., Omar, B. A., Rakipovski, G., Raun, K., and Ahrén, B. (2015) Fibroblast growth factor 21 prevents glycemic deterioration in insulin deficient mouse models of diabetes. European Journal of Pharmacology 764, 189-194 
33. Camporez, J. P. G., Jornayvaz, F. R., Petersen, M. C., Pesta, D., Guigni, B. A., Serr, J., Zhang, D., Kahn, M., Samuel, V. T., Jurczak, M. J., and Shulman, G. I. (2013) Cellular mechanisms by which FGF21 improves insulin sensitivity in male mice. Endocrinology 154, 3099-3109

34. Jin, L., Lin, Z., and Xu, A. (2016) Fibroblast Growth Factor 21 Protects against Atherosclerosis via Fine-Tuning the Multiorgan Crosstalk. Diabetes Metab J 40, 22-31

35. Tanajak, P., Sa-nguanmoo, P., Wang, X., Liang, G., Li, X., Jiang, C., Chattipakorn, S. C., and Chattipakorn, N. (2016) Fibroblast growth factor 21 (FGF21) therapy attenuates left ventricular dysfunction and metabolic disturbance by improving FGF21 sensitivity, cardiac mitochondrial redox homoeostasis and structural changes in pre-diabetic rats. Acta Physiol, n/a-n/a

36. Xu, J., Stanislaus, S., Chinookoswong, N., Lau, Y. Y., Hager, T., Patel, J., Ge, H., Weiszmann, J., Lu, S.-C., Graham, M., Busby, J., Hecht, R., Li, Y.-S., Li, Y., Lindberg, R., and Véniant, M. M. (2009) Acute glucose-lowering and insulin-sensitizing action of FGF21 in insulin-resistant mouse models--association with liver and adipose tissue effects. Am. J. Physiol. Endocrinol. Metab. 297, E1105-1114

37. von Holstein-Rathlou, S., BonDurant, Lucas D., Peltekian, L., Naber, Meghan C., Yin, Terry C., Claflin, Kristin E., Urizar, Adriana I., Madsen, Andreas N., Ratner, C., Holst, B., Karstoft, K., Vandenbeuch, A., Anderson, Catherine B., Cassell, Martin D., Thompson, Anthony P., Solomon, Thomas P., Rahmouni, K., Kinnamon, Sue C., Pieper, Andrew A., Gillum, Matthew P., and Potthoff, Matthew J. (2016) FGF21 Mediates Endocrine Control of Simple Sugar Intake and Sweet Taste Preference by the Liver. Cell Metabolism 23, 335-343

38. Samms, R. J., Murphy, M., Fowler, M. J., Cooper, S., Emmerson, P., Coskun, T., Adams, A. C., Kharitonenkov, A., Ebling, F. J. P., and Tsintzas, K. (2015) Dual effects of fibroblast growth factor 21 on hepatic energy metabolism. J Endocrinol 227, 37-47

39. Zhang, Y., Xie, Y., Berglund, E. D., Coate, K. C., He, T. T., Katafuchi, T., Xiao, G., Potthoff, M. J., Wei, W., Wan, Y., Yu, R. T., Evans, R. M., Kliewer, S. A., and Mangelsdorf, D. J. (2012) The starvation hormone, fibroblast growth factor-21, extends lifespan in mice. Elife 1, e00065

40. Camacho, R. C., Zafian, P. T., Achanfuo-Yeboah, J., Manibusan, A., and Berger, J. P. (2013) Pegylated Fgf21 rapidly normalizes insulin-stimulated glucose utilization in dietinduced insulin resistant mice. European Journal of Pharmacology

41. Hecht, R., Li, Y.-S., Sun, J., Belouski, E., Hall, M., Hager, T., Yie, J., Wang, W., Winters, D., Smith, S., Spahr, C., Tam, L.-T., Shen, Z., Stanislaus, S., Chinookoswong, N., Lau, Y., Sickmier, A., Michaels, M. L., Boone, T., Véniant, M. M., and Xu, J. (2012) Rationale-Based Engineering of a Potent Long-Acting FGF21 Analog for the Treatment of Type 2 Diabetes. PLOS ONE 7, e49345

42. Dunshee, D. R., Bainbridge, T. W., Kljavin, N. M., Zavala-Solorio, J., Schroeder, A. C., Chan, R., Corpuz, R., Wong, M., Zhou, W., Deshmukh, G., Ly, J., Sutherlin, D. P., Ernst, J. A., and Sonoda, J. (2016) Fibroblast Activation Protein Cleaves and Inactivates Fibroblast Growth Factor 21. J. Biol. Chem. 291, 5986-5996

43. Gillum, M. P., and Potthoff, M. J. (2016) FAP finds FGF21 easy to digest. Biochem. J. 473, $1125-1127$ 
44. Zhen, E. Y., Jin, Z., Ackermann, B. L., Thomas, M. K., and Gutierrez, J. A. (2016) Circulating FGF21 proteolytic processing mediated by fibroblast activation protein. Biochemical Journal 473, 605-614

45. Kurosu, H., Choi, M., Ogawa, Y., Dickson, A. S., Goetz, R., Eliseenkova, A. V., Mohammadi, M., Rosenblatt, K. P., Kliewer, S. A., and Kuro-o, M. (2007) Tissuespecific Expression of $\beta$ Klotho and Fibroblast Growth Factor (FGF) Receptor Isoforms Determines Metabolic Activity of FGF19 and FGF21. J. Biol. Chem. 282, 26687-26695

46. Yang, C., Jin, C., Li, X., Wang, F., McKeehan, W. L., and Luo, Y. (2012) Differential specificity of endocrine FGF19 and FGF21 to FGFR1 and FGFR4 in complex with KLB. PLOS ONE 7, e33870

47. Kharitonenkov, A. (2009) FGFs and metabolism. Current Opinion in Pharmacology 9, 805-810

48. Comps-Agrar, L., Dunshee, D. R., Eaton, D. L., and Sonoda, J. (2015) Unliganded Fibroblast Growth Factor Receptor 1 Forms Density-independent Dimers. J. Biol. Chem. 290, 24166-24177

49. Gimeno, R. E., and Moller, D. E. (2014) FGF21-based pharmacotherapy - potential utility for metabolic disorders. Trends in Endocrinology \& Metabolism 25, 303-311

50. Wu, A.-L., Kolumam, G., Stawicki, S., Chen, Y., Li, J., Zavala-Solorio, J., Phamluong, K., Feng, B., Li, L., Marsters, S., Kates, L., van Bruggen, N., Leabman, M., Wong, A., West, D., Stern, H., Luis, E., Kim, H. S., Yansura, D., Peterson, A. S., Filvaroff, E., Wu, Y., and Sonoda, J. (2011) Amelioration of Type 2 Diabetes by Antibody-Mediated Activation of Fibroblast Growth Factor Receptor 1. Science Translational Medicine 3, 113ra126-113ra126

51. Smith, R., Duguay, A., Bakker, A., Li, P., Weiszmann, J., Thomas, M. R., Alba, B. M., Wu, X., Gupte, J., Yang, L., Stevens, J., Hamburger, A., Smith, S., Chen, J., Komorowski, R., Moore, K. W., Véniant, M. M., and Li, Y. (2013) FGF21 Can Be Mimicked In Vitro and In Vivo by a Novel Anti-FGFR1c/ $\beta$-Klotho Bispecific Protein. PLOS ONE 8, e61432

52. Markan, K. R., Naber, M. C., Ameka, M. K., Anderegg, M. D., Mangelsdorf, D. J., Kliewer, S. A., Mohammadi, M., and Potthoff, M. J. (2014) Circulating FGF21 Is Liver Derived and Enhances Glucose Uptake During Refeeding and Overfeeding. Diabetes 63, 4057-4063

53. Cicione, C., Degirolamo, C., and Moschetta, A. (2012) Emerging role of fibroblast growth factors 15/19 and 21 as metabolic integrators in the liver. Hepatology 56, 24042411

54. Samms, R. J., Cheng, C. C., Kharitonenkov, A., Gimeno, R. E., and Adams, A. C. (2016) Overexpression of $\beta$-Klotho in Adipose Tissue Sensitizes Male Mice to Endogenous FGF21 and Provides Protection From Diet-Induced Obesity. Endocrinology 157, 14671480

55. Adams, A. C., Yang, C., Coskun, T., Cheng, C. C., Gimeno, R. E., Luo, Y., and Kharitonenkov, A. (2012) The breadth of FGF21's metabolic actions are governed by FGFR1 in adipose tissue. Mol Metab 2, 31-37

56. Woo, Y. C., Xu, A., Wang, Y., and Lam, K. S. L. (2013) Fibroblast Growth Factor 21 as an emerging metabolic regulator: clinical perspectives. Clin Endocrinol 78, 489-496

57. Schlein, C., Talukdar, S., Heine, M., Fischer, Alexander W., Krott, Lucia M., Nilsson, Stefan K., Brenner, Martin B., Heeren, J., and Scheja, L. (2016) FGF21 Lowers Plasma 
Triglycerides by Accelerating Lipoprotein Catabolism in White and Brown Adipose Tissues. Cell Metabolism 23, 441-453

58. Yang, C., Wang, C., Ye, M., Jin, C., He, W., Wang, F., McKeehan, W. L., and Luo, Y. (2012) Control of lipid metabolism by adipocyte FGFR1-mediated adipohepatic communication during hepatic stress. Nutr Metab (Lond) 9, 94

59. Qiao, L., Zou, C., van der Westhuyzen, D. R., and Shao, J. (2008) Adiponectin Reduces Plasma Triglyceride by Increasing VLDL Triglyceride Catabolism. Diabetes 57, 18241833

60. Goetz, R. (2013) Metabolism: Adiponectin - a mediator of specific metabolic actions of FGF21. Nat Rev Endocrinol 9, 506-508

61. Hui, X., Feng, T., Liu, Q., Gao, Y., and Xu, A. (2016) The FGF21-adiponectin axis in controlling energy and vascular homeostasis. J Mol Cell Biol 8, 110-119

62. Holland, W. L., Adams, A. C., Brozinick, J. T., Bui, H. H., Miyauchi, Y., Kusminski, C. M., Bauer, S. M., Wade, M., Singhal, E., Cheng, C. C., Volk, K., Kuo, M. S., Gordillo, R., Kharitonenkov, A., and Scherer, P. E. (2013) An FGF21-adiponectin-ceramide axis controls energy expenditure and insulin action in mice. Cell Metab 17, 790-797

63. Wang, X., Pu, H., Ma, C., Jiang, T., Wei, Q., Duan, M., Zhang, C., Shou, X., Su, L., Zhang, J., and Yang, Y. (2014) Adiponectin Abates Atherosclerosis by Reducing Oxidative Stress. Medical Science Monitor : International Medical Journal of Experimental and Clinical Research 20, 1792-1800

64. Owen, Bryn M., Ding, X., Morgan, Donald A., Coate, Katie C., Bookout, Angie L., Rahmouni, K., Kliewer, Steven A., and Mangelsdorf, David J. (2014) FGF21 Acts Centrally to Induce Sympathetic Nerve Activity, Energy Expenditure, and Weight Loss. Cell Metabolism 20, 670-677

65. Wang, G., Liu, J., Yang, N., Hu, Y., Zhang, H., Miao, L., Yao, Z., and Xu, Y. (2016) Levothyroxine treatment restored the decreased circulating fibroblast growth factor 21 levels in patients with hypothyroidism. European Journal of Internal Medicine 31, 94-98

66. Talukdar, S., Owen, B. M., Song, P., Hernandez, G., Zhang, Y., Zhou, Y., Scott, W. T., Paratala, B., Turner, T., Smith, A., Bernardo, B., Müller, C. P., Tang, H., Mangelsdorf, D. J., Goodwin, B., and Kliewer, S. A. (2016) FGF21 Regulates Sweet and Alcohol Preference. Cell Metabolism 23, 344-349

67. Owen, B. M., Bookout, A. L., Ding, X., Lin, V. Y., Atkin, S. D., Gautron, L., Kliewer, S. A., and Mangelsdorf, D. J. (2013) FGF21 contributes to neuroendocrine control of female reproduction. Nat Med 19, 1153-1156

68. Bass, J. (2013) Forever (FGF) 21. Nat Med 19, 1090-1092

69. Oishi, K., Uchida, D., and Ishida, N. (2008) Circadian expression of FGF21 is induced by PPARalpha activation in the mouse liver. FEBS letters 582, 3639-3642

70. Montagner, A., Korecka, A., Polizzi, A., Lippi, Y., Blum, Y., Canlet, C., TremblayFranco, M., Gautier-Stein, A., Burcelin, R., Yen, Y.-C., Je, H. S., Maha, A.-A., Mithieux, G., Arulampalam, V., Lagarrigue, S., Guillou, H., Pettersson, S., and Wahli, W. (2016) Hepatic circadian clock oscillators and nuclear receptors integrate microbiome-derived signals. Sci Rep 6

71. McCarty, M. F. (2015) Practical prospects for boosting hepatic production of the "prolongevity" hormone FGF21. Horm Mol Biol Clin Investig

72. Giralt, M., Gavalda-Navarro, A., and Villarroya, F. (2015) Fibroblast growth factor-21, energy balance and obesity. Mol Cell Endocrinol 418 Pt 1, 66-73 
73. So, W. Y., Cheng, Q., Chen, L., Evans-Molina, C., Xu, A., Lam, K. S. L., and Leung, P. S. (2013) High Glucose Represses $\beta$-Klotho Expression and Impairs Fibroblast Growth Factor 21 Action in Mouse Pancreatic Islets. Diabetes 62, 3751-3759

74. C. Adams, A., and Kharitonenkov, A. (2012) FGF21: The Center of a Transcriptional Nexus in Metabolic Regulation. Current Diabetes Reviews 8, 285-293

75. Kharitonenkov, A., Shiyanova, T. L., Koester, A., Ford, A. M., Micanovic, R., Galbreath, E. J., Sandusky, G. E., Hammond, L. J., Moyers, J. S., Owens, R. A., Gromada, J., Brozinick, J. T., Hawkins, E. D., Wroblewski, V. J., Li, D.-S., Mehrbod, F., Jaskunas, S. R., and Shanafelt, A. B. (2005) FGF-21 as a novel metabolic regulator. Journal of Clinical Investigation 115, 1627-1635

76. Palou, M., Priego, T., Sánchez, J., Villegas, E., Rodríguez, A. M., Palou, A., and Picó, C. (2008) Sequential changes in the expression of genes involved in lipid metabolism in adipose tissue and liver in response to fasting. Pflugers Arch - Eur J Physiol 456, 825836

77. Potthoff, M. J., Inagaki, T., Satapati, S., Ding, X., He, T., Goetz, R., Mohammadi, M., Finck, B. N., Mangelsdorf, D. J., Kliewer, S. A., and Burgess, S. C. (2009) FGF21 induces PGC-1 $\alpha$ and regulates carbohydrate and fatty acid metabolism during the adaptive starvation response. PNAS 106, 10853-10858

78. Fazeli, P. K., Lun, M., Kim, S. M., Bredella, M. A., Wright, S., Zhang, Y., Lee, H., Catana, C., Klibanski, A., Patwari, P., and Steinhauser, M. L. FGF21 and the late adaptive response to starvation in humans. J Clin Invest 125, 4601-4611

79. Finn, P. F., and Dice, J. F. (2006) Proteolytic and lipolytic responses to starvation. Nutrition 22, 830-844

80. Zechner, R., Strauss, J. G., Haemmerle, G., Lass, A., and Zimmermann, R. (2005) Lipolysis: pathway under construction. Curr Opin Lipidol 16, 333-340

81. Lopes-Cardozo, M., Mulder, I., van Vugt, F., Hermans, P. G., van den Bergh, S. G., Klazinga, W., and de Vries-Akkerman, E. (1975) Aspects of ketogenesis: control and mechanism of ketone-body formation in isolated rat-liver mitochondria. Mol Cell Biochem 9, 155-173

82. Eaton, S. (2002) Control of mitochondrial beta-oxidation flux. Prog Lipid Res 41, $197-$ 239

83. Krebs, H. A., and Hems, R. (1970) Fatty acid metabolism in the perfused rat liver. Biochem J 119, 525-533

84. Domouzoglou, E. M., and Maratos-Flier, E. (2011) Fibroblast growth factor 21 is a metabolic regulator that plays a role in the adaptation to ketosis. Am J Clin Nutr 93, 901S-905S

85. Mai, K., Andres, J., Biedasek, K., Weicht, J., Bobbert, T., Sabath, M., Meinus, S., Reinecke, F., Möhlig, M., Weickert, M. O., Clemenz, M., Pfeiffer, A. F. H., Kintscher, U., Spuler, S., and Spranger, J. (2009) Free Fatty Acids Link Metabolism and Regulation of the Insulin-Sensitizing Fibroblast Growth Factor-21. Diabetes 58, 1532-1538

86. Kersten, S., Seydoux, J., Peters, J. M., Gonzalez, F. J., Desvergne, B., and Wahli, W. (1999) Peroxisome proliferator-activated receptor alpha mediates the adaptive response to fasting. J Clin Invest 103, 1489-1498

87. Kersten, S., Desvergne, B., and Wahli, W. (2000) Roles of PPARs in health and disease. Nature 405, 421-424 
88. Lundåsen, T., Hunt, M. C., Nilsson, L.-M., Sanyal, S., Angelin, B., Alexson, S. E. H., and Rudling, M. (2007) PPAR $\alpha$ is a key regulator of hepatic FGF21. Biochemical and Biophysical Research Communications 360, 437-440

89. Inagaki, T., Dutchak, P., Zhao, G., Ding, X., Gautron, L., Parameswara, V., Li, Y., Goetz, R., Mohammadi, M., Esser, V., Elmquist, J. K., Gerard, R. D., Burgess, S. C., Hammer, R. E., Mangelsdorf, D. J., and Kliewer, S. A. (2007) Endocrine regulation of the fasting response by PPARalpha-mediated induction of fibroblast growth factor 21. Cell metabolism 5, 415-425

90. Kim, H., Mendez, R., Zheng, Z., Chang, L., Cai, J., Zhang, R., and Zhang, K. (2014) Liver-Enriched Transcription Factor CREBH Interacts With Peroxisome ProliferatorActivated Receptor $\alpha$ to Regulate Metabolic Hormone FGF21. Endocrinology 155, 769782

91. Oishi, K., Uchida, D., Ohkura, N., and Horie, S. (2010) PPAR $\alpha$ deficiency augments a ketogenic diet-induced circadian PAI-1 expression possibly through PPAR $\gamma$ activation in the liver. Biochemical and Biophysical Research Communications 401, 313-318

92. Gao, M., Bu, L., Ma, Y., and Liu, D. (2013) Concurrent Activation of Liver X Receptor and Peroxisome Proliferator-Activated Receptor Alpha Exacerbates Hepatic Steatosis in High Fat Diet-Induced Obese Mice. PLOS ONE 8, e65641

93. Gälman, C., Lundåsen, T., Kharitonenkov, A., Bina, H. A., Eriksson, M., Hafström, I., Dahlin, M., Åmark, P., Angelin, B., and Rudling, M. (2008) The Circulating Metabolic Regulator FGF21 Is Induced by Prolonged Fasting and PPAR $\alpha$ Activation in Man. Cell Metabolism 8, 169-174

94. Badman, M. K., Pissios, P., Kennedy, A. R., Koukos, G., Flier, J. S., and Maratos-Flier, E. (2007) Hepatic fibroblast growth factor 21 is regulated by PPARalpha and is a key mediator of hepatic lipid metabolism in ketotic states. Cell metabolism 5, 426-437

95. Uebanso, T., Taketani, Y., Yamamoto, H., Amo, K., Ominami, H., Arai, H., Takei, Y., Masuda, M., Tanimura, A., Harada, N., Yamanaka-Okumura, H., and Takeda, E. (2011) Paradoxical regulation of human FGF21 by both fasting and feeding signals: is FGF21 a nutritional adaptation factor? PLOS ONE 6, e22976

96. Korwutthikulrangsri, M., Mahachoklertwattana, P., Chanprasertyothin, S., Pongratanakul, S., and Poomthavorn, P. (2015) Serum fibroblast growth factor 21 in overweight and obese Thai children and adolescents: its relation to glucose metabolism and its change after glucose loading. Clin Endocrinol 83, 820-827

97. Singhal, G., Fisher, f. M., Chee, M. J., Tan, T. G., Ouaamari, A. E., Adams, A. C., Najarian, R., Kulkarni, R. N., Benoist, C., Flier, J. S., and Maratos-Flier, E. (2016) Fibroblast Growth Factor 21 (FGF21) Protects against High Fat Diet Induced Inflammation and Islet Hyperplasia in Pancreas. PLOS ONE 11, e0148252

98. Kwon, M. M., O’Dwyer, S. M., Baker, R. K., Covey, S. D., and Kieffer, T. J. (2015) FGF21-Mediated Improvements in Glucose Clearance Require Uncoupling Protein 1. Cell Reports 13, 1521-1527

99. Teodoro, J. S., Varela, A. T., Rolo, A. P., and Palmeira, C. M. (2014) High-fat and obesogenic diets: current and future strategies to fight obesity and diabetes. Genes \& Nutrition 9, 406

100. Yamashita, H., Takenoshita, M., Sakurai, M., Bruick, R. K., Henzel, W. J., Shillinglaw, W., Arnot, D., and Uyeda, K. (2001) A glucose-responsive transcription factor that regulates carbohydrate metabolism in the liver. PNAS 98, 9116-9121 
101. Kawaguchi, T., Takenoshita, M., Kabashima, T., and Uyeda, K. (2001) Glucose and cAMP regulate the L-type pyruvate kinase gene by phosphorylation/dephosphorylation of the carbohydrate response element binding protein. PNAS 98, 13710-13715

102. Davies, M. N., O'Callaghan, B. L., and Towle, H. C. (2008) Glucose Activates ChREBP by Increasing Its Rate of Nuclear Entry and Relieving Repression of Its Transcriptional Activity. J. Biol. Chem. 283, 24029-24038

103. Tsatsos, Nikolas G., Davies, Michael N., O'callaghan, Brennon L., and Towle, Howard C. (2008) Identification and function of phosphorylation in the glucose-regulated transcription factor ChREBP. Biochemical Journal 411, 261-270

104. Iizuka, K., and Horikawa, Y. (2008) ChREBP: a glucose-activated transcription factor involved in the development of metabolic syndrome. Endocr J 55, 617-624

105. Iizuka, K., Bruick, R. K., Liang, G., Horton, J. D., and Uyeda, K. (2004) Deficiency of carbohydrate response element-binding protein (ChREBP) reduces lipogenesis as well as glycolysis. Proc Natl Acad Sci U S A 101, 7281-7286

106. Herman, M. A., Peroni, O. D., Villoria, J., Schon, M. R., Abumrad, N. A., Bluher, M., Klein, S., and Kahn, B. B. (2012) A novel ChREBP isoform in adipose tissue regulates systemic glucose metabolism. Nature 484, 333-338

107. Iizuka, K., Takeda, J., and Horikawa, Y. (2009) Glucose induces FGF21 mRNA expression through ChREBP activation in rat hepatocytes. FEBS Letters 583, 2882-2886

108. Sánchez, J., Palou, A., and Picó, C. (2009) Response to Carbohydrate and Fat Refeeding in the Expression of Genes Involved in Nutrient Partitioning and Metabolism: Striking Effects on Fibroblast Growth Factor-21 Induction. Endocrinology 150, 5341-5350

109. Montagner, A., Polizzi, A., Fouché, E., Ducheix, S., Lippi, Y., Lasserre, F., Barquissau, V., Régnier, M., Lukowicz, C., Benhamed, F., Iroz, A., Bertrand-Michel, J., Al Saati, T., Cano, P., Mselli-Lakhal, L., Mithieux, G., Rajas, F., Lagarrigue, S., Pineau, T., Loiseau, N., Postic, C., Langin, D., Wahli, W., and Guillou, H. (2016) Liver PPAR $\alpha$ is crucial for whole-body fatty acid homeostasis and is protective against NAFLD. Gut 65, 1202-1214

110. Patsouris, D., Reddy, J. K., Muller, M., and Kersten, S. (2006) Peroxisome proliferatoractivated receptor alpha mediates the effects of high-fat diet on hepatic gene expression. Endocrinology 147, 1508-1516

111. Hylemon, P. B., Zhou, H., Pandak, W. M., Ren, S., Gil, G., and Dent, P. (2009) Bile acids as regulatory molecules. J Lipid Res 50, 1509-1520

112. Bennion, L. J., and Grundy, S. M. (1977) Effects of Diabetes Mellitus on Cholesterol Metabolism in Man. New England Journal of Medicine 296, 1365-1371

113. Li, T., and Chiang, J. Y. (2014) Bile acid signaling in metabolic disease and drug therapy. Pharmacol Rev 66, 948-983

114. Chiang, J. Y. (2013) Bile acid metabolism and signaling. Compr Physiol 3, 1191-1212

115. de Aguiar Vallim, T. Q., Tarling, E. J., and Edwards, P. A. (2013) Pleiotropic roles of bile acids in metabolism. Cell metabolism 17, 657-669

116. McLaughlin, J. T., Lomax, R. B., Hall, L., Dockray, G. J., Thompson, D. G., and Warhurst, G. (1998) Fatty acids stimulate cholecystokinin secretion via an acyl chain length-specific, Ca2+-dependent mechanism in the enteroendocrine cell line STC-1. $J$ Physiol 513 ( Pt 1), 11-18

117. Green, G. M., Taguchi, S., Friestman, J., Chey, W. Y., and Liddle, R. A. (1989) Plasma secretin, CCK, and pancreatic secretion in response to dietary fat in the rat. Am J Physiol 256, G1016-1021 
118. Bennion, L. J., and Grundy, S. M. (1977) Effects of Diabetes Mellitus on Cholesterol Metabolism in Man. New England Journal of Medicine 296, 1365-1371

119. Subbiah, M. T., and Yunker, R. L. (1984) Cholesterol 7 alpha-hydroxylase of rat liver: an insulin sensitive enzyme. Biochemical and Biophysical Research Communications 124, 896-902

120. Chiang, J. Y. L. (2013) Bile acid metabolism and signaling. Compr Physiol 3, 1191-1212

121. Li, D., Lu, T., Shen, C., Liu, Y., Zhang, J., Shan, Y., Luo, Y., Xi, Z., Qiu, B., Chen, Q., Zhang, J., and Xia, Q. (2016) Expression of fibroblast growth factor 21 in patients with biliary atresia. Cytokine 83, 13-18

122. Cyphert, H. A., Ge, X., Kohan, A. B., Salati, L. M., Zhang, Y., and Hillgartner, F. B. (2012) Activation of the Farnesoid X Receptor Induces Hepatic Expression and Secretion of Fibroblast Growth Factor 21. J Biol Chem 287, 25123-25138

123. Lin, Z., Zhou, Z., Liu, Y., Gong, Q., Yan, X., Xiao, J., Wang, X., Lin, S., Feng, W., and $\mathrm{Li}, \mathrm{X}$. (2011) Circulating FGF21 levels are progressively increased from the early to end stages of chronic kidney diseases and are associated with renal function in Chinese. PLOS ONE 6, e18398

124. Gariani, K., Drifte, G., Dunn-Siegrist, I., Pugin, J., and Jornayvaz, F. R. (2013) Increased FGF21 plasma levels in humans with sepsis and SIRS. Endocr Connect 2, 146-153

125. Domingo, P., Gallego-Escuredo, J. M., Domingo, J. C., Gutiérrez, M. d. M., Mateo, M. G., Fernández, I., Vidal, F., Giralt, M., and Villarroya, F. (2010) Serum FGF21 levels are elevated in association with lipodystrophy, insulin resistance and biomarkers of liver injury in HIV-1-infected patients. AIDS 24, 2629-2637

126. Ye, D., Li, H., Wang, Y., Jia, W., Zhou, J., Fan, J., Man, K., Lo, C., Wong, C., Wang, Y., Lam, K. S. L., and Xu, A. (2016) Circulating Fibroblast Growth Factor 21 Is A Sensitive Biomarker for Severe Ischemia/reperfusion Injury in Patients with Liver Transplantation. Sci Rep 6

127. Kim, K. H., Kim, S. H., Min, Y.-K., Yang, H.-M., Lee, J.-B., and Lee, M.-S. (2013) Acute Exercise Induces FGF21 Expression in Mice and in Healthy Humans. PLOS ONE 8, e63517

128. Song, Y., Ding, J., Jin, R., Jung, J., Li, S., Yang, J., Wang, A., and Li, Z. (2016) Expression and purification of FGF21 in Pichiaï $i^{1 / 2}$ pastoris and its effect on fibroblastcell migration. Molecular Medicine Reports

129. Fernandes-Freitas, I., and Owen, B. M. (2015) Metabolic roles of endocrine fibroblast growth factors. Current Opinion in Pharmacology 25, 30-35

130. Eizirik, D. L., Cardozo, A. K., and Cnop, M. (2008) The role for endoplasmic reticulum stress in diabetes mellitus. Endocr Rev 29, 42-61

131. Schaap, F. G., Kremer, A. E., Lamers, W. H., Jansen, P. L. M., and Gaemers, I. C. (2013) Fibroblast growth factor 21 is induced by endoplasmic reticulum stress. Biochimie $\mathbf{9 5}$, 692-699

132. Kim, O. K., Jun, W., and Lee, J. (2015) Mechanism of ER Stress and Inflammation for Hepatic Insulin Resistance in Obesity. Annals of Nutrition and Metabolism 67, 218-227

133. Walter, P., and Ron, D. (2011) The Unfolded Protein Response: From Stress Pathway to Homeostatic Regulation. Science 334, 1081-1086

134. Hetz, C. (2012) The unfolded protein response: controlling cell fate decisions under ER stress and beyond. Nat Rev Mol Cell Biol 13, 89-102 
135. Joshi, A., Newbatt, Y., McAndrew, P. C., Stubbs, M., Burke, R., Richards, M. W., Bhatia, C., Caldwell, J. J., McHardy, T., Collins, I., and Bayliss, R. (2015) Molecular mechanisms of human IRE1 activation through dimerization and ligand binding. Oncotarget 6, 13019-13035

136. Calfon, M., Zeng, H., Urano, F., Till, J. H., Hubbard, S. R., Harding, H. P., Clark, S. G., and Ron, D. (2002) IRE1 couples endoplasmic reticulum load to secretory capacity by processing the XBP-1 mRNA. Nature 415, 92-96

137. Sano, R., and Reed, J. C. (2013) ER stress-induced cell death mechanisms. Biochimica et Biophysica Acta (BBA) - Molecular Cell Research 1833, 3460-3470

138. Lee, A. H., Iwakoshi, N. N., and Glimcher, L. H. (2003) XBP-1 regulates a subset of endoplasmic reticulum resident chaperone genes in the unfolded protein response. $\mathrm{Mol}$ Cell Biol 23, 7448-7459

139. Jiang, S., Yan, C., Fang, Q.-c., Shao, M.-1., Zhang, Y.-1., Liu, Y., Deng, Y.-p., Shan, B., Liu, J.-q., Li, H.-t., Yang, L., Zhou, J., Dai, Z., Liu, Y., and Jia, W.-p. (2014) Fibroblast Growth Factor 21 Is Regulated by the IRE1 $\alpha$-XBP1 Branch of the Unfolded Protein Response and Counteracts Endoplasmic Reticulum Stress-induced Hepatic Steatosis. $J$. Biol. Chem. 289, 29751-29765

140. Ron, D., and Hubbard, S. R. (2008) How IRE1 Reacts to ER Stress. Cell 132, 24-26

141. Hollien, J., Lin, J. H., Li, H., Stevens, N., Walter, P., and Weissman, J. S. (2009) Regulated Ire1-dependent decay of messenger RNAs in mammalian cells. The Journal of Cell Biology 186, 323-331

142. Han, D., Lerner, A. G., Vande Walle, L., Upton, J. P., Xu, W., Hagen, A., Backes, B. J., Oakes, S. A., and Papa, F. R. (2009) IRE1 alpha kinase activation modes control alternate endoribonuclease outputs to determine divergent cell fates. Cell 138, 562-575

143. Schindler, A. J., and Schekman, R. (2009) In vitro reconstitution of ER-stress induced ATF6 transport in COPII vesicles. Proc Natl Acad Sci US A 106, 17775-17780

144. Haze, K., Yoshida, H., Yanagi, H., Yura, T., and Mori, K. (1999) Mammalian transcription factor ATF6 is synthesized as a transmembrane protein and activated by proteolysis in response to endoplasmic reticulum stress. Molecular biology of the cell 10, 3787-3799

145. Okada, T., Haze, K., Nadanaka, S., Yoshida, H., Seidah, N. G., Hirano, Y., Sato, R., Negishi, M., and Mori, K. (2003) A serine protease inhibitor prevents endoplasmic reticulum stress-induced cleavage but not transport of the membrane-bound transcription factor ATF6. J Biol Chem 278, 31024-31032

146. Cui, W., Li, J., Ron, D., and Sha, B. (2011) The structure of the PERK kinase domain suggests the mechanism for its activation. Acta crystallographica. Section D, Biological crystallography $\mathbf{6 7}, 423-428$

147. Su, Q., Wang, S., Gao, H. Q., Kazemi, S., Harding, H. P., Ron, D., and Koromilas, A. E. (2008) Modulation of the eukaryotic initiation factor 2 alpha-subunit kinase PERK by tyrosine phosphorylation. $J$ Biol Chem 283, 469-475

148. Wek, R. C., Jiang, H. Y., and Anthony, T. G. (2006) Coping with stress: eIF2 kinases and translational control. Biochem. Soc. Trans. 34, 7-11

149. Ait Ghezala, H., Jolles, B., Salhi, S., Castrillo, K., Carpentier, W., Cagnard, N., Bruhat, A., Fafournoux, P., and Jean-Jean, O. (2012) Translation termination efficiency modulates ATF4 response by regulating ATF4 mRNA translation at 5 ' short ORFs. Nucleic Acids Res 40, 9557-9570 
150. Ameri, K., and Harris, A. L. (2008) Activating transcription factor 4. Int. J. Biochem. Cell Biol. 40, 14-21

151. B'Chir, W., Maurin, A. C., Carraro, V., Averous, J., Jousse, C., Muranishi, Y., Parry, L., Stepien, G., Fafournoux, P., and Bruhat, A. (2013) The eIF2alpha/ATF4 pathway is essential for stress-induced autophagy gene expression. Nucleic Acids Res 41, 7683-7699

152. Hai, T., and Curran, T. (1991) Cross-family dimerization of transcription factors Fos/Jun and ATF/CREB alters DNA binding specificity. Proc Natl Acad Sci U S A 88, 3720-3724

153. Podust, L. M., Krezel, A. M., and Kim, Y. (2001) Crystal structure of the CCAAT box/enhancer-binding protein beta activating transcription factor-4 basic leucine zipper heterodimer in the absence of DNA. J Biol Chem 276, 505-513

154. Vallejo, M., Ron, D., Miller, C. P., and Habener, J. F. (1993) C/ATF, a member of the activating transcription factor family of DNA-binding proteins, dimerizes with CAAT/enhancer-binding proteins and directs their binding to cAMP response elements. Proc Natl Acad Sci U S A 90, 4679-4683

155. Vinson, C. R., Hai, T., and Boyd, S. M. (1993) Dimerization specificity of the leucine zipper-containing bZIP motif on DNA binding: prediction and rational design. Genes Dev 7, 1047-1058

156. Ebert, S. M., Monteys, A. M., Fox, D. K., Bongers, K. S., Shields, B. E., Malmberg, S. E., Davidson, B. L., Suneja, M., and Adams, C. M. (2010) The Transcription Factor ATF4 Promotes Skeletal Myofiber Atrophy during Fasting. Molecular Endocrinology 24, 790-799

157. Ables, G. P., Perrone, C. E., Orentreich, D., and Orentreich, N. (2012) Methioninerestricted $\mathrm{C} 57 \mathrm{BL} / 6 \mathrm{~J}$ mice are resistant to diet-induced obesity and insulin resistance but have low bone density. PLOS ONE 7, e51357

158. Sousa-Coelho, A. L. D., Relat, J., Hondares, E., Pérez-Martí, A., Ribas, F., Villarroya, F., Marrero, P. F., and Haro, D. (2013) FGF21 mediates the lipid metabolism response to amino acid starvation. J Lipid Res 54, 1786-1797

159. Perrone, C. E., Mattocks, D. A. L., Plummer, J. D., Chittur, S. V., Mohney, R., Vignola, K., Orentreich, D. S., and Orentreich, N. (2012) Genomic and metabolic responses to methionine-restricted and methionine-restricted, cysteine-supplemented diets in Fischer 344 rat inguinal adipose tissue, liver and quadriceps muscle. J Nutrigenet Nutrigenomics 5, 132-157

160. Kim, K. H., Jeong, Y. T., Kim, S. H., Jung, H. S., Park, K. S., Lee, H.-Y., and Lee, M.-S. (2013) Metformin-induced inhibition of the mitochondrial respiratory chain increases FGF21 expression via ATF4 activation. Biochemical and Biophysical Research Communications 440, 76-81

161. Yuzefovych, L. V., Musiyenko, S. I., Wilson, G. L., and Rachek, L. I. (2013) Mitochondrial DNA Damage and Dysfunction, and Oxidative Stress Are Associated with Endoplasmic Reticulum Stress, Protein Degradation and Apoptosis in High Fat DietInduced Insulin Resistance Mice. PLOS ONE 8, e54059

162. Kim, S. H., Kim, K. H., Kim, H.-K., Kim, M.-J., Back, S. H., Konishi, M., Itoh, N., and Lee, M.-S. (2014) Fibroblast growth factor 21 participates in adaptation to endoplasmic reticulum stress and attenuates obesity-induced hepatic metabolic stress. Diabetologia 58, 809-818

163. Li, S.-m., Yu, Y.-h., Li, L., Wang, W.-f., and Li, D.-s. (2015) Treatment of CIA Mice with FGF21 Down-regulates TH17-IL-17 Axis. Inflammation 39, 309-319 
164. Ozaki, Y., Saito, K., Nakazawa, K., Konishi, M., Itoh, N., Hakuno, F., Takahashi, S.-I., Kato, H., and Takenaka, A. (2015) Rapid increase in fibroblast growth factor 21 in protein malnutrition and its impact on growth and lipid metabolism. British Journal of Nutrition 114, 1410-1418

165. Tanaka, N., Takahashi, S., Zhang, Y., Krausz, K. W., Smith, P. B., Patterson, A. D., and Gonzalez, F. J. (2015) Role of fibroblast growth factor 21 in the early stage of NASH induced by methionine- and choline-deficient diet. Biochimica et Biophysica Acta (BBA) - Molecular Basis of Disease 1852, 1242-1252

166. Wilson, G. J., Lennox, B. A., She, P., Mirek, E. T., Baghdadi, R. J. T. A., Fusakio, M. E., Dixon, J. L., Henderson, G. C., Wek, R. C., and Anthony, T. G. (2015) GCN2 is required to increase fibroblast growth factor 21 and maintain hepatic triglyceride homeostasis during asparaginase treatment. American Journal of Physiology - Endocrinology and Metabolism 308, E283-E293

167. De Sousa-Coelho, Ana L., Marrero, Pedro F., and Haro, D. (2012) Activating transcription factor 4-dependent induction of FGF21 during amino acid deprivation. Biochemical Journal 443, 165-171

168. Bunpo, P., Dudley, A., Cundiff, J. K., Cavener, D. R., Wek, R. C., and Anthony, T. G. (2009) GCN2 protein kinase is required to activate amino acid deprivation responses in mice treated with the anti-cancer agent L-asparaginase. J Biol Chem 284, 32742-32749

169. Malmberg, S. E., and Adams, C. M. (2008) Insulin signaling and the general amino acid control response. Two distinct pathways to amino acid synthesis and uptake. J Biol Chem 283, 19229-19234

170. Phillipson-Weiner, L., Mirek, E. T., Wang, Y., McAuliffe, W. G., Wek, R. C., and Anthony, T. G. (2016) General control nonderepressible kinase 2 (GCN2) deletion predisposes to asparaginase-associated pancreatitis in mice. Am. J. Physiol. Gastrointest. Liver Physiol., ajpgi.00052.02016

171. Harding, H. P., Zhang, Y., and Ron, D. (1999) Protein translation and folding are coupled by an endoplasmic-reticulum-resident kinase. Nature 397, 271-274

172. Vattem, K. M., Staschke, K. A., and Wek, R. C. (2001) Mechanism of activation of the double-stranded-RNA-dependent protein kinase, PKR: role of dimerization and cellular localization in the stimulation of PKR phosphorylation of eukaryotic initiation factor-2 (eIF2). Eur J Biochem 268, 3674-3684

173. Manche, L., Green, S. R., Schmedt, C., and Mathews, M. B. (1992) Interactions between double-stranded RNA regulators and the protein kinase DAI. Mol Cell Biol 12, 52385248

174. Hiasa, Y., Kamegaya, Y., Nuriya, H., Onji, M., Kohara, M., Schmidt, E. V., and Chung, R. T. (2003) Protein kinase $R$ is increased and is functional in hepatitis $C$ virus-related hepatocellular carcinoma. The American journal of gastroenterology 98, 2528-2534

175. Mohamed, A. A., Amin, M. A., Ragab, M. M., Ismail, S. A., and Baki, A. A. M. (2014) Protein kinase expression as a predictive factor for interferon response in chronic hepatitis C patients. Journal of Advanced Research 5, 117-123

176. Castet, V., Fournier, C., Soulier, A., Brillet, R., Coste, J., Larrey, D., Dhumeaux, D., Maurel, P., and Pawlotsky, J. M. (2002) Alpha interferon inhibits hepatitis C virus replication in primary human hepatocytes infected in vitro. Journal of virology 76, 81898199 
177. Dauber, B., and Wolff, T. (2009) Activation of the Antiviral Kinase PKR and Viral Countermeasures. Viruses 1, 523-544

178. Kukla, M., Berdowska, A., Stygar, D., Gabriel, A., Mazur, W., Łogiewa-Bazger, B., Sobala-Szczygieł, B., Bułdak, R. J., Rokitka, M., Zajęcki, W., Kępa, L., Sawczyn, T., and Zwirska-Korczala, K. (2012) Serum FGF21 and RBP4 levels in patients with chronic hepatitis C. Scand. J. Gastroenterol. 47, 1037-1047

179. Acharya, P., Chen, J.-J., and Correia, M. A. (2010) Hepatic Heme-Regulated Inhibitor (HRI) Eukaryotic Initiation Factor $2 \alpha$ Kinase: A Protagonist of Heme-Mediated Translational Control of CYP2B Enzymes and a Modulator of Basal Endoplasmic Reticulum Stress Tone. Mol. Pharmacol. 77, 575-592

180. Zarei, M., Barroso, E., Leiva, R., Barniol-Xicota, M., Pujol, E., Escolano, C., Vazquez, S., Palomer, X., Pardo, V., Gonzalez-Rodriguez, A., Valverde, A. M., Quesada-Lopez, T., Villarroya, F., Wahli, W., and Vazquez-Carrera, M. (2016) Heme-Regulated eIF2alpha Kinase Modulates Hepatic FGF21 and Is Activated by PPARbeta/delta Deficiency. Diabetes 65, 3185-3199

181. Sankar, R., and Sotero de Menezes, M. (1999) Metabolic and endocrine aspects of the ketogenic diet. Epilepsy Research 37, 191-201

182. Jones, B. J., Tan, T., and Bloom, S. R. (2012) Minireview: Glucagon in Stress and Energy Homeostasis. Endocrinology 153, 1049-1054

183. Manninen, A. H. (2004) Metabolic Effects of the Very-Low-Carbohydrate Diets: Misunderstood "Villains" of Human Metabolism. Journal of the International Society of Sports Nutrition 1, 7-11

184. Quesada, I., Tudurí, E., Ripoll, C., and Nadal, Á. (2008) Physiology of the pancreatic $\alpha$ cell and glucagon secretion: role in glucose homeostasis and diabetes. J Endocrinol 199, 5-19

185. Gromada, J., Bokvist, K., Ding, W.-G., Barg, S., Buschard, K., Renström, E., and Rorsman, P. (1997) Adrenaline Stimulates Glucagon Secretion in Pancreatic A-Cells by Increasing the $\mathrm{Ca}<\sup >2+</$ sup $>$ Current and the Number of Granules Close to the LType $\mathrm{Ca}<\sup >2+</$ sup $>$ Channels. The Journal of General Physiology 110, 217-228

186. Gylfe, E., and Gilon, P. (2014) Glucose regulation of glucagon secretion. Diabetes Research and Clinical Practice 103, 1-10

187. Quoix, N., Cheng-Xue, R., Mattart, L., Zeinoun, Z., Guiot, Y., Beauvois, M. C., Henquin, J.-C., and Gilon, P. (2009) Glucose and Pharmacological Modulators of ATP-Sensitive $\mathrm{K}<$ sup $>+</$ sup $>$ Channels Control $[\mathrm{Ca}<\sup >2+</$ sup $>]<$ sub $>\mathrm{c}</$ sub $>$ by Different Mechanisms in Isolated Mouse $\alpha$-Cells. Diabetes 58, 412-421

188. Habegger, K. M., Heppner, K. M., Geary, N., Bartness, T. J., DiMarchi, R., and Tschop, M. H. (2010) The metabolic actions of glucagon revisited. Nat Rev Endocrinol 6, 689697

189. Longuet, C., Sinclair, E. M., Maida, A., Baggio, L. L., Maziarz, M., Charron, M. J., and Drucker, D. J. (2008) The Glucagon Receptor Is Required for the Adaptive Metabolic Response to Fasting. Cell Metabolism 8, 359-371

190. Berglund, E. D., Kang, L., Lee-Young, R. S., Hasenour, C. M., Lustig, D. G., Lynes, S. E., Donahue, E. P., Swift, L. L., Charron, M. J., and Wasserman, D. H. (2010) Glucagon and lipid interactions in the regulation of hepatic AMPK signaling and expression of PPAR $\alpha$ and FGF21 transcripts in vivo. American Journal of Physiology - Endocrinology and Metabolism 299, E607-E614 
191. Patel, V., Joharapurkar, A., Dhanesha, N., Kshirsagar, S., Patel, K., Bahekar, R., Shah, G., and Jain, M. (2013) Co-agonist of glucagon and GLP-1 reduces cholesterol and improves insulin sensitivity independent of its effect on appetite and body weight in dietinduced obese C57 mice. Can. J. Physiol. Pharmacol. 91, 1009-1015

192. Arafat, A. M., Kaczmarek, P., Skrzypski, M., Pruszyńska-Oszmalek, E., Kołodziejski, P., Szczepankiewicz, D., Sassek, M., Wojciechowicz, T., Wiedenmann, B., Pfeiffer, A. F.

H., Nowak, K. W., and Strowski, M. Z. (2012) Glucagon increases circulating fibroblast growth factor 21 independently of endogenous insulin levels: a novel mechanism of glucagon-stimulated lipolysis? Diabetologia 56, 588-597

193. Habegger, K. M., Stemmer, K., Cheng, C., Müller, T. D., Heppner, K. M., Ottaway, N., Holland, J., Hembree, J. L., Smiley, D., Gelfanov, V., Krishna, R., Arafat, A. M., Konkar, A., Belli, S., Kapps, M., Woods, S. C., Hofmann, S. M., D’Alessio, D., Pfluger, P. T., Perez-Tilve, D., Seeley, R. J., Konishi, M., Itoh, N., Kharitonenkov, A., Spranger, J., DiMarchi, R. D., and Tschöp, M. H. (2013) Fibroblast Growth Factor 21 Mediates Specific Glucagon Actions. Diabetes 62, 1453-1463

194. Cyphert, H. A., Alonge, K. M., Ippagunta, S. M., and Hillgartner, F. B. (2014) Glucagon Stimulates Hepatic FGF21 Secretion through a PKA- and EPAC-Dependent Posttranscriptional Mechanism. PLOS ONE 9, e94996

195. Barthel, A., and Schmoll, D. (2003) Novel concepts in insulin regulation of hepatic gluconeogenesis. Am J Physiol Endocrinol Metab 285, E685-692

196. Cherrington, A. D., Moore, M. C., Sindelar, D. K., and Edgerton, D. S. (2007) Insulin action on the liver in vivo. Biochem. Soc. Trans. 35, 1171-1174

197. Leavens, K. F., and Birnbaum, M. J. (2011) Insulin signaling to hepatic lipid metabolism in health and disease. Crit. Rev. Biochem. Mol. Biol. 46, 200-215

198. Czech, M. P., Tencerova, M., Pedersen, D. J., and Aouadi, M. (2013) Insulin signalling mechanisms for triacylglycerol storage. Diabetologia 56, 949-964

199. Dong, X. C., Copps, K. D., Guo, S., Li, Y., Kollipara, R., DePinho, R. A., and White, M. F. (2008) Inactivation of hepatic Foxol by insulin signaling is required for adaptive nutrient homeostasis and endocrine growth regulation. Cell metabolism 8, 65-76

200. Haeusler, R. A., Han, S., and Accili, D. (2010) Hepatic FoxO1 Ablation Exacerbates Lipid Abnormalities during Hyperglycemia. J. Biol. Chem. 285, 26861-26868

201. Vienberg, S. G., Brøns, C., Nilsson, E., Astrup, A., Vaag, A., and Andersen, B. (2012) Impact of short-term high-fat feeding and insulin-stimulated FGF21 levels in subjects with low birth weight and controls. Eur. J. Endocrinol. 167, 49-57

202. Hansen, J. S., Clemmesen, J. O., Secher, N. H., Hoene, M., Drescher, A., Weigert, C., Pedersen, B. K., and Plomgaard, P. (2015) Glucagon-to-insulin ratio is pivotal for splanchnic regulation of FGF-21 in humans. Mol Metab 4, 551-560

203. Bucher, M. L., and Swaffield, M. N. (1975) Regulation of hepatic regeneration in rats by synergistic action of insulin and glucagon. Proc Natl Acad Sci U S A 72, 1157-1160

204. Giacca, A., Fisher, S. J., McCall, R. H., Shi, Z. Q., and Vranic, M. (1997) Direct and indirect effects of insulin in suppressing glucose production in depancreatized dogs: role of glucagon. Endocrinology 138, 999-1007

205. Ito, Y., Uchijima, Y., Ariga, M., Seki, T., Takenaka, A., Hakuno, F., Takahashi, S. I., Ariga, T., and Noguchi, T. (1997) Interaction between cAMP-dependent and insulindependent signal pathways in tyrosine phosphorylation in primary cultures of rat hepatocytes. Biochem. J. 324 ( Pt 2), 379-388 
206. Kimura, M., and Ogihara, M. (1997) Proliferation of adult rat hepatocytes in primary culture induced by insulin is potentiated by cAMP-elevating agents. European Journal of Pharmacology 327, 87-95

207. Lewis, G. F., Vranic, M., and Giacca, A. (1997) Glucagon enhances the direct suppressive effect of insulin on hepatic glucose production in humans. Am. J. Physiol. 272, E371-378

208. Ito, Y., Takahashi, S.-I., Takenaka, A., Hidaka, T., and Noguchi, T. (1997) Starvationincreased Insulin-dependent Tyrosine Phosphorylation of the 195-kDa Protein in Intact Rat Liver. Bioscience, Biotechnology, and Biochemistry 61, 2122-2124 


\section{Chapter Two}

\section{Mechanisms Mediating Glucagon Plus Insulin and Chenodeoxycholic Acid Stimulation of FGF21 Gene Transcription in Primary Hepatocytes}

Alonge, K. M., Meares, G. P., and Hillgartner, F. B. (2017) Glucagon and Insulin Cooperatively Stimulate Fibroblast Growth Factor 21 Gene Transcription by Increasing the Expression of Activating Transcription Factor 4. J. Biol. Chem. DOI: 10.1074/jbc.M116.762922 


\begin{abstract}
Previous studies have shown that glucagon cooperatively interacts with insulin to stimulate hepatic fibroblast growth factor 21 (FGF21) gene expression. Here, we investigated the mechanisms by which glucagon plus insulin increases FGF21 gene transcription in primary hepatocyte cultures. Transfection analyses demonstrated that glucagon plus insulin induction of FGF21 gene transcription was conferred by two activating transcription factor 4 (ATF4) binding sites in the FGF21 gene. Glucagon plus insulin stimulated a 5-fold increase in ATF4 protein abundance, and treatment using glucagon plus insulin increased ATF4 binding activity to both ATF4 binding sites on the FGF21 promoter. Knockdown of ATF4 protein expression suppressed the ability of glucagon plus insulin to increase FGF21 expression. In primary rat hepatocytes, treatment with a glucagon analog and a protein kinase A (PKA)-selective agonist mimicked the ability of glucagon to stimulate ATF4 and FGF21 expression in the presence of insulin. Inhibition of PKA, PI3K, Akt, and mammalian target of rapamycin complex 1 (mTORC1) suppressed the ability of glucagon plus insulin to stimulate ATF4 and FGF21 expression. Additional analyses demonstrated that chenodeoxycholic acid (CDCA) induced a 6fold increase in ATF4 expression and primary hepatocytes treated with CDCA increased ATF4 binding activity to both ATF4 binding sites on the FGF21 promoter. Knockdown of ATF4 expression suppressed the ability of CDCA to increase FGF21 gene expression. CDCA increased the phosphorylation of eukaryotic initiation factor $2 \alpha$ (eIF2 $\alpha$ ), and inhibition of eIF2 $\alpha$ signaling activity suppressed CDCA regulation of ATF4 and FGF21 expression. These results demonstrate that glucagon plus insulin increases FGF21 transcription by stimulating ATF4 expression and that activation of the glucagon mediated cAMP/PKA pathway and the insulin mediated PI3K/Akt/mTORC1 pathway regulates the effect of glucagon plus insulin on ATF4 expression. These results also demonstrate that CDCA regulation of FGF21 transcription is mediated at least partially by an eIF $2 \alpha$-dependent increase in ATF4 expression.
\end{abstract}




\section{INTRODUCTION}

FGF21 is an atypical member of the fibroblast growth factor family that lacks the ability to bind to heparin sulfate proteoglycans allowing it to escape the extracellular matrix and function in an endocrine manner (1-3). Studies investigating the biological action of FGF21 have shown that starvation and other nutritional stresses (e.g. dietary protein restriction, consumption of a high-fat, low-carbohydrate ketogenic diet, and consumption of a high-fat obesogenic diet) stimulate an increase in the expression and secretion of FGF21 by the liver, the predominant site of FGF21 production in the body (4-10). FGF21 signals through FGF receptor 1c (FGFR1c) linked to the co-receptor, $\beta$-Klotho, to increase food intake, energy expenditure, gluconeogenesis, and insulin sensitivity and inhibit growth and female fertility in response to nutritional stress $(1-6,11)$

Several signaling pathways have been identified that mediate the effects of nutritional stress on FGF21 expression. One such pathway involves the activation of the nuclear receptor, peroxisome proliferator-activated receptor- $\alpha(\operatorname{PPAR} \alpha)$. Natural (i.e. non-esterified unsaturated fatty acids) and synthetic ligands of PPAR $\alpha$ induce hepatic FGF21 gene expression $(7,8,12,13)$. A PPAR $\alpha$ response element (PPRE) has been identified in the 5'-flanking region of the murine and human FGF21 genes $(8,13)$. Ablation of the PPAR $\alpha$ gene suppresses the ability of starvation and ketogenic diet consumption to increase hepatic FGF21 mRNA abundance and serum FGF21 concentrations $(7,8)$.

Another pathway mediating the nutritional regulation of FGF21 expression is activated by the glucagon receptor. This has been deduced from studies in mice showing that ablation of the glucagon receptor suppresses the ability of starvation to increase hepatic FGF21 mRNA abundance and serum FGF21 concentration (14). In examining the mechanism by which 
glucagon increases FGF21 production, we have shown that incubating rat and human hepatocyte cultures with glucagon causes a 3-fold increase in FGF21 secretion into the culture medium (15). Interestingly, the glucagon-induced increase in FGF21 secretion in hepatocytes is associated with a transient decrease in FGF21 mRNA abundance suggesting that glucagon acts at a translational/posttranslational step to increase hepatic FGF21 secretion.

The inability of glucagon to induce FGF21 mRNA abundance in hepatocyte cultures (15) contrasts with the results of glucagon receptor ablation studies (14) demonstrating that the starvation-induced increase in FGF21 mRNA abundance is mediated at least partially by glucagon receptor activation. One possible explanation for the discrepant findings is that glucagon stimulation of FGF21 mRNA abundance requires the presence of another hormone or signaling factor. Results of studies with intact mice containing defects in the insulin-signaling pathway suggest that insulin is one such factor that potentiates the ability of glucagon to increase FGF21 mRNA abundance. Dong et al. (16) have shown that liver-specific ablation of insulin receptor substrate-1 (IRS-1) and insulin receptor substrate-2 (IRS-2) causes a decrease in hepatic FGF21 mRNA abundance during both the fed state and the starved state. In addition, Haeusler et al. (17) have reported that streptozotocin-induced diabetes suppresses the stimulatory effect of starvation on hepatic FGF21 mRNA abundance. Although insulin is generally regarded as a hormone signaling the fed state, these observations suggest that basal insulin levels play a role in mediating the increase in FGF21 mRNA abundance during the starved state.

In support of this possibility, we have shown that insulin potentiates the ability of glucagon to stimulate FGF21 mRNA abundance in primary rat hepatocyte cultures (15). Treatment with insulin alone stimulates a 3.5-fold increase in FGF21 mRNA abundance and the addition of glucagon in the presence of insulin causes a further 2.5-fold elevation in FGF21 
mRNA abundance. This cooperative interaction between glucagon and insulin in the regulation of FGF21 mRNA abundance is associated with a substantially greater induction of FGF21 secretion (i.e. 28 -fold) relative to that by insulin or glucagon alone. The insulin concentration that is required to unmask glucagon regulation of FGF21 mRNA abundance is similar to that observed in the portal circulation during the starved state (15). We have postulated that insulin maintains a basal level of hepatic FGF21 mRNA abundance during the carbohydrate-fed state and synergistically interacts with elevated glucagon levels during the starved state to stimulate a further increase in FGF21 mRNA abundance. The mechanism by which glucagon and insulin increase FGF21 mRNA abundance is presently not known.

In addition to PPAR $\alpha$, glucagon, and insulin, the farnesoid $\mathrm{X}$ receptor (FXR) plays a role in the regulation of hepatic FGF21 production. We have shown that natural (i.e. bile acids) and synthetic activating ligands (i.e. GW4064) of FXR stimulate an increase in hepatic FGF21 mRNA abundance and secretion in rodent and human hepatocyte cultures (12). The effect of GW4064 on FGF21 gene transcription is mediated, at least in part, by a conserved FXR response element (FXRE) that binds heterodimers comprised of FXR and RXR. Ablation of the FXR gene suppresses the ability of ketogenic diet consumption to induce hepatic FGF21 mRNA abundance and serum FGF21 concentration.

In our studies analyzing the bile acid regulation of FGF21 expression, chenodeoxycholic acid (CDCA) was substantially more effective in inducing FGF21 gene expression in hepatocytes than a selective FXR activating ligand (i.e. GW4064) that bound to FXR with a $>100$-fold higher affinity than that of CDCA (12). Incubating rodent and human hepatocyte cultures with an optimal concentration of CDCA $(100 \mu \mathrm{M})$ stimulated a 25 -fold increase in FGF21 mRNA abundance, whereas incubating hepatocytes with an optimal concentration of 
GW4064 (3 $\mu \mathrm{M})$ stimulated a 3.2-fold increase in FGF21 mRNA abundance. These observations suggested that another mechanism(s) besides ligand activation of FXR is involved in mediating the stimulatory effect of bile acids on FGF21 gene transcription. This nature of this mechanism has not yet been defined.

The objective of the present study is to characterize the mechanisms by which glucagon plus insulin and CDCA increase hepatic FGF21 gene expression. We show that glucagon plus insulin and CDCA increase the expression of the stress-associated transcription factor, activating transcription factor 4 (ATF4), and that this protein plays a key role in mediating the stimulatory effect of these signaling factors on FGF21 gene transcription. We have also characterized the proximal signaling pathways mediating the effects of glucagon plus insulin and CDCA on ATF4 and FGF21 expression.

\section{EXPERIMENTAL PROCEDURES}

Cell Culture- Primary hepatocytes were isolated from $24 \mathrm{~h}$ starved male Sprague Dawley rats (approximately 175-200 g) as described by Stabile et al. (18). Cells were plated on 35-mm or 60-mm collagen-coated dishes $\left(1.4 \times 10^{5}\right.$ cells $\left./ \mathrm{cm}^{2}\right)$ containing Waymouth's medium MD752/1 supplemented with $20 \mathrm{mM}$ HEPES, $\mathrm{pH}$ 7.4, $0.5 \mathrm{mM}$ serine, $0.5 \mathrm{mM}$ alanine, $100 \mathrm{mg} / \mathrm{ml}$ penicillin, $100 \mathrm{mg} / \mathrm{ml}$ streptomycin, $50 \mathrm{mg} / \mathrm{ml}$ gentamicin, and 5\% newborn calf serum. At $4 \mathrm{~h}$ of incubation, the medium was replaced with one of the same composition lacking newborn calf serum. A Matrigel overlay $(0.3 \mathrm{mg} / \mathrm{ml})$ and insulin $(50 \mathrm{nM})$ were added at this time. At $24 \mathrm{~h}$ of incubation, the cells were washed in serum-free Medium 199 lacking insulin, and the incubation 
was continued in serum-free Medium 199. At $48 \mathrm{~h}$ of incubation, the medium was replaced with one of the same composition containing the treatments indicated in the figure legends. Hepatocyte cultures were maintained in a humidified chamber at $37^{\circ} \mathrm{C}$ in $5 \% \mathrm{CO}_{2}$ and $95 \%$ air. This study was carried out in strict accordance with the recommendations in the Guide for the Care and Use of Laboratory Animals of the National Institutes Health and was approved by the Institutional Animal Care and Use Committee of West Virginia University (Protocol Approval Number: 15-0904).

Chenodeoxycholic acid, dibutyryl cAMP, and Akti-1/2 were obtained from SigmaAldrich. Rapamycin and LY294002 were purchased from LC Laboratories. H89 and ISRIB were obtained from Cayman. Bovine insulin was a gift from Lilly. $\mathrm{N}^{6}$ - Benzoyladenosine- 3 ', 5'- cyclic monophosphate (Biolog) and 8-(4-chlorophenylthio)-2'-O-methyladenosine- 3', 5'cyclic monophosphate (R\&D Systems) were obtained from the indicated sources.

Transient Transfection- The construction of reporter plasmids containing fragments of the rat FGF21 promoter/regulatory region linked to the luciferase gene has been previously described (12). Site-directed mutations were introduced into the -1316 to +68 bp FGF21 reporter plasmid using the Agilent QuikChange II XL site-directed mutagenesis kit. Hepatocytes were plated on 35-mm dishes and transfected with $1 \mu \mathrm{g}$ of the -2940 to +68 FGF21 reporter plasmid or an equimolar amount of another reporter plasmid using Lipofectin reagent (Invitrogen). At $18 \mathrm{~h}$ of incubation, the transfection medium was replaced with fresh medium and a Matrigel overlay $(0.3$ $\mathrm{mg} / \mathrm{ml}$ ) was added. At $48 \mathrm{~h}$ of incubation, the medium was replaced with fresh medium with or without glucagon plus insulin. At $72 \mathrm{~h}$ incubation, cells were harvested and cell extracts were prepared in 1x Cell Culture Lysis Buffer (Promega). Cell extracts were centrifuged at 12,000 x $g$ 
for $2 \mathrm{~min}$ and the supernatants were assayed for protein concentration and luciferase activity. Luciferase assay reagent was obtained from Promega.

siRNA Knockdown Experiments- Primary hepatocytes were plated on 35-mm dishes and transfected with 30 pmols of siRNA targeting ATF4 (Silencer Select siRNA IDs: s135172 and s135173, Ambion), 30 pmols of siRNA targeting ChREBP (Silencer Select siRNA ID: s139670) or 30 pmols of negative control \#1 siRNA (Ambion) using Lipofectamine RNAiMAX reagent (Invitrogen). At $18 \mathrm{~h}$ of incubation, the transfection medium was replaced with Medium 199 and a Matrigel overlay $(0.3 \mathrm{mg} / \mathrm{ml})$ was added. The medium was replaced with fresh medium at $48 \mathrm{~h}$ and $66 \mathrm{~h}$ of incubation. After the medium change at $66 \mathrm{~h}$ of incubation, cells were treated with or without CDCA for $2 \mathrm{~h}$ or glucagon plus insulin for $12 \mathrm{~h}$. Cells were then harvested, cell extracts prepared, and total RNA isolated.

Western Analysis- Total cell extracts were prepared from hepatocytes as described by Hansmannel et al. (19) except that the lysis buffer contained $25 \mathrm{mM}$ Tris- $\mathrm{HCl}, \mathrm{pH} 7.6,150 \mathrm{mM}$ $\mathrm{NaCl}, 1 \% \mathrm{NP}-40,1 \%$ sodium deoxycholate, $0.1 \%$ SDS and a mixture of protease inhibitors and phosphatase inhibitors (Halt, Thermo Scientific). Equal amounts of denatured protein were subjected to electrophoresis in SDS-polyacrylamide gels and then transferred to polyvinylidene difluoride membranes (Immobilon-FL, Millipore) using an electroblotting apparatus (Bio-Rad). The blots were blocked in TBST (10 mM Tris- $\mathrm{HCl}, \mathrm{pH} 8.0,150 \mathrm{mM} \mathrm{NaCl}$, and $0.1 \%$ Tween) containing $5 \%$ nonfat dry milk for $1 \mathrm{~h}$ at room temperature and then incubated with primary antibody diluted 1:1000 in TBST containing 5\% bovine serum albumin. After incubation with primary antibody for $12 \mathrm{~h}$ at $4^{\circ} \mathrm{C}$, the blots were washed in TBST. Next, the blots were 
incubated with secondary antibody conjugated to horseradish peroxidase (Jackson ImmunoResearch) diluted 1:5000 in TBST, for $1 \mathrm{~h}$ at room temperature. After washing with TBST, antibody/protein complexes on blots were detected using enhanced chemiluminescence (Amersham Biosciences). Fluorescence on the blots was visualized using a Typhoon 9410 imager and signals were quantified using ImageQuant software. Antibodies against ATF4, phosphorylated Akt $\left(\mathrm{Ser}^{473}\right)$, phosphorylated eIF2 $\alpha\left(\mathrm{Ser}^{51}\right)$, phosphorylated ribosomal protein S6 $\left(\mathrm{Ser}^{235 / 236}\right)$, total Akt, total eIF2 $\alpha$, total ribosomal protein S6, and $\beta$-tubulin were obtained from Cell Signaling Technology.

Isolation of RNA and Quantitation of mRNA levels- Total RNA was extracted from cell cultures by the guanidinium thiocyanate/phenol/chloroform method (20). The abundance of mRNA encoding FGF21, ATF4, sterol regulatory element-binding protein-1c (SREBP-1c), and phosphoenolpyruvate carboxykinase (PEPCK) was measured by quantitative real-time PCR analysis using the QIAGEN Quantitect SYBR green RT-PCR system. Samples of DNase Itreated RNA (100 ng) were analyzed in triplicate according to the manufacturer's instructions. PCR was performed in ninety-six well plates using a Bio-Rad iCycler iQ. The relative amount of mRNA was calculated using the comparative $\mathrm{Ct}$ method. Rat cyclophilin and glucouronidase beta were used as reference genes. Amplification of specific transcripts was confirmed by analyzing the melting curve profile performed at the end of each run and by determining the size of the PCR products using agarose electrophoresis and ethidium bromide staining. The sequences of the primer sets can be obtained from the corresponding author upon request. 
Preparation of Nuclear Extracts- All of the procedures were carried out on ice. To prevent proteolysis, a mixture of protease inhibitors (Halt $\mathrm{TM}_{\mathrm{M}}$; ThermoFisher Scientific) was included in all of the buffers. The nuclear extracts were prepared from primary rat hepatocytes by a modification of the method described by Dignam et al. (21). Briefly, rat hepatocytes from eight $100-\mathrm{mm}$ plates were pooled and centrifuged and centrifuged at $250 \mathrm{xg}$ for $5 \mathrm{mins}$ at $4^{\circ} \mathrm{C}$. The resulting cell pellet was washed with PBS and centrifuged a second time at $1000 \mathrm{x} g$ for $5 \mathrm{~min}$. The resulting cell pellet was incubated in buffer 1 (10 mM Hepes, $\mathrm{pH} 7.9,10 \mathrm{mM} \mathrm{KCl}, 1.5 \mathrm{mM}$ $\mathrm{MgCl}_{2}, 1 \mathrm{mM}$ EDTA, $1 \mathrm{mM}$ dithiothreitol) for $10 \mathrm{~min}$ on ice then homogenized using 25 strokes in a type A Dounce homogenizer. The nuclear pellet was centrifuged at $1100 \times \mathrm{g}$ for $10 \mathrm{~min}$, supernatant aspirated, and centrifuged again at $1100 \mathrm{x} \mathrm{g}$ for $10 \mathrm{~min}$. The nuclear pellet was resuspended in Buffer 2 (20 mM Hepes, pH 7.9, $420 \mathrm{mM} \mathrm{NaCl}, 25 \%$ (v/v) glycerol, $1.5 \mathrm{mM}$ $\mathrm{MgCl}_{2}, 1 \mathrm{mM}$ EDTA, $1 \mathrm{mM}$ dithiothreitol). The resuspension was homogenized using 15 strokes in a type B Dounce homogenizer, rotated for $30 \mathrm{~min}$ at $4^{\circ} \mathrm{C}$, and centrifuged at $16000 \mathrm{xg}$ for $30 \mathrm{~min}$. The resulting supernatant was designated as the nuclear extract fraction.

Gel Mobility Shift Analysis- Double-stranded olgionucleotides were prepared by combining equal amounts of the complementary single-stranded DNA in a solution containing $10 \mathrm{mM}$ Tris, $\mathrm{pH} 8.0$ and $50 \mathrm{mM} \mathrm{NaCl}$ follow by heating to $95^{\circ} \mathrm{C}$ for $2 \mathrm{~min}$ and then cooling to room temperature. The annealed olgionucleotides were labeled by filling in overhanging 5 ' ends using the Klenow fragment of Escherichia coli DNA polymerase in the presence of $\left[\alpha-{ }^{32} \mathrm{P}\right]$ dGTP. The binding reactions were carried out in $30 \mu \mathrm{L}$ of $15 \mathrm{mM}$ Hepes, $\mathrm{pH} 7.9,150 \mathrm{mM} \mathrm{NaCl}, 0.5 \mathrm{mM}$ $\mathrm{MgCl}_{2}, 0.35 \mathrm{mM}$ EDTA, $0.35 \mathrm{mM}$ dithiothreitol, $15 \%$ glycerol (v/v), $0.2 \mathrm{mg} / \mathrm{mL}$ bovine serum albumin, $0.25 \%$ Triton X-100 (v/v), and $0.5 \mu \mathrm{g}$ poly d(I-C). $20 \mu \mathrm{g}$ of nuclear extract and reaction 
buffer were incubated on ice for 20 min prior to addition of 50,000 cpm of labeled DNA and incubation at room temperature for 20 min. DNA and DNA-protein complexes were resolved on $5 \%$ nondenaturing polyacrylamide gels at $4^{\circ} \mathrm{C}$ in $1 x$ Tris-Glycine $(0.5 \mathrm{M}$ Tris, $\mathrm{pH} 8.8,4 \mathrm{M}$ Glycine). Following electrophoresis, the gels were dried and subjected to phosphor autoradiography. The synthetic oligonucleotides that were used as probes in gel mobility shift assays are listed in Fig. 2A.

Statistical Methods- Data were subjected to analysis of variance, and statistical comparisons were made with the Student's $t$-test.

\section{RESULTS}

Identification of Cis-acting Sequences That Mediate the Stimulatory Effect of Glucagon Plus Insulin on FGF21 Gene Transcription.

To identify cis-acting sequences mediating the stimulatory effect of glucagon plus insulin on FGF21 gene expression, transient transfection experiments were performed in primary rat hepatocyte cultures using reporter constructs containing 5'-deletions of the rat FGF21 promoter linked to the luciferase gene. In cells transfected with the longest FGF21 fragment (-2940 to +68 bp), treatment with glucagon plus insulin stimulated a 10.8-fold increase in luciferase activity (Fig. 2.1). 5'-Deletion of FGF21 sequences to -1656 bp and -1316 bp had no effect on glucagon plus insulin responsiveness, whereas 5'-deletion of sequences to -1241 bp caused a 55\% decrease in glucagon plus insulin responsiveness. Further 5'-deletion of FGF21 sequences to -1164 bp 
had no effect on remaining glucagon plus insulin responsiveness, whereas deletion of sequences from -1164 to -103 caused a $46 \%$ decrease in glucagon plus insulin responsiveness. These results indicate that there are two regions (-1316 to -1241 bp and -1164 to -103 bp) that confer the stimulatory effect glucagon plus insulin on FGF21 gene transcription. Due to the small effect of insulin alone on FGF21 gene expression and the variability of the transient transfection assay, we were unable to identify FGF21 sequences that conferred regulation of transcription by insulin alone. Insulin treatment in the absence of glucagon did not stimulate a significant increase in the activity of any of the FGF21 reporter constructs (Fig. 2.2).

FGF21 sequences between -1316 to -1241 bp and between -1164 to -103 bp each contain a previously characterized sequence element that binds the stress-associated transcription factor, activating transcription factor 4 (ATF4) (22). Both of these elements play a role in mediating the stimulatory effect of essential amino acid deficiency on FGF21 gene transcription. They are designated as amino acid response element (AARE) 1 and AARE2 (Fig. 2.3A). To determine whether AARE1 and AARE2 mediate the stimulatory effect of glucagon plus insulin on FGF21 gene transcription, FGF21 reporter constructs were developed that contained site-specific mutations that abolished ATF4 binding to AARE1, AARE2 or both AARE1 and AARE2 in context of the -1316 to +68 bp FGF21 reporter construct. Mutation of the upstream AARE1 (1282 to $-1274 \mathrm{bp})$ or the downstream AARE2 (-140 to $-132 \mathrm{bp}$ ) caused a $54-56 \%$ decrease in glucagon plus insulin responsiveness (Fig. 2.3B). Mutation of both AARE1 and AARE2 caused an $87 \%$ decrease in glucagon plus insulin responsiveness. In contrast to the effect of mutation of AARE1 and AARE2 on glucagon plus insulin regulation of FGF21 promoter activity, mutations that abolished FXR and PPARa binding to the FGF21 FXRE/PPRE (-1222 to $-1203 \mathrm{bp}$ ) and carbohydrate response element binding protein binding to the FGF21 carbohydrate response 
element (ChoRE, -72 to $-56 \mathrm{bp}$ ) had no effect on the ability glucagon plus insulin to stimulate FGF21 promoter activity (Fig. 2.3B). These data indicate that glucagon and insulin act selectively through both of the AAREs in the FGF21 5-flanking DNA to induce FGF21 gene transcription.

Role of ATF4 in Mediating the Stimulatory Effect of Glucagon Plus Insulin on FGF21 Gene Transcription.

Previous studies have shown that ATF4 binds to AARE1 and AARE2 in hepatocytes and that expression of exogenous ATF4 in hepatocytes induces FGF21 gene transcription (22). These observations plus the results of the present study demonstrating that glucagon and insulin signal through AARE1 and AARE2 to induce FGF21 gene transcription led us to investigate whether glucagon and insulin modulated ATF4 expression in hepatocyte cultures. Incubating hepatocytes with insulin or glucagon alone for $12 \mathrm{~h}$ had no effect on ATF4 protein concentration or ATF4 mRNA abundance, whereas incubating hepatocytes with glucagon plus insulin stimulated a 5.3-fold increase in ATF4 protein concentration and 1.6-fold increase in ATF4 mRNA abundance (Fig. 2.4A). This cooperative interaction between glucagon and insulin in the regulation of ATF4 expression mirrored the regulation of FGF21 mRNA abundance by these hormones. In contrast, glucagon antagonized the ability of insulin to induce the expression of the lipogenic transcription factor, SREBP-1c (Fig. 2.4A). These findings demonstrate that glucagon and insulin cooperatively interact to increase ATF4 expression and that this effect is selective for ATF4 and its downstream targets.

Gel mobility shift assays were performed to determine whether the stimulatory effect of glucagon plus insulin on ATF4 expression was associated with an elevation in the binding of 
ATF4 to AARE1 and AARE2. Nuclear extracts were prepared from hepatocytes incubated with or without glucagon plus insulin for $12 \mathrm{~h}$. Incubation of nuclear extracts with ${ }^{32} \mathrm{P}$-labeled DNA probes containing the AARE1 or AARE2 resulted in the formation of multiple protein-DNA complexes (Fig. 2.4B). Competition analyses indicated that the binding of several of these DNA-protein complexes was specific. The abundance of these specific protein-DNA complexes was increased in nuclear extracts from hepatocytes treated with glucagon plus insulin. Preincubation of nuclear extracts with ATF4 antibody partially disrupted the formation of these protein-DNA complexes and caused the formation of new supershifted complexes. The abundance of these supershifted complexes was elevated in nuclear extracts from hepatocytes treated with glucagon plus insulin. These observations indicate that glucagon plus insulin increases the ATF4 binding to AARE1 and AARE2.

To further establish a role of ATF4 in mediating the stimulatory effect of glucagon plus insulin on FGF21 expression, we investigated whether knockdown of ATF4 expression modulated the ability of glucagon plus insulin to increase FGF21 expression. Primary rat hepatocytes were transfected with siRNAs targeting ATF4 (ATF4 siRNA 1 and ATF4 siRNA 2) or a non-targeting control siRNA and were treated with or without glucagon plus insulin. Transfection of hepatocytes with ATF4 siRNA 1 or ATF4 siRNA 2 inhibited both basal ATF4 protein expression and glucagon plus insulin induction of ATF4 protein expression relative to untransfected cells or cells transfected with control siRNA (Fig. 2.5). These effects on ATF4 expression were associated with a reduction in basal FGF21 mRNA abundance and the ability of glucagon plus insulin to increase FGF21 mRNA abundance. These results demonstrate that glucagon plus insulin regulation of FGF21 gene expression is dependent on ATF4. 
Role of ChREBP in Mediating the Stimulatory Effect of Glucagon Plus Insulin on FGF21 Gene Transcription.

Previous studies show the carbohydrate response element binding protein (ChREBP) increases FGF21 gene transcription by binding to and activating a downstream carbohydrate response element (ChoRE) on the FGF21 promoter in primary hepatocytes (23-25). These observations led us to ask whether ChREBP may play a passive role in enhancing glucagon plus insulin signaling through ATF4 binding at AARE1 and AARE2 to induce FGF21 gene transcription in hepatocytes cultures. Primary rat hepatocytes were transfected with siRNAs targeting ChREBP (ChREBP siRNA) or a non-targeting control siRNA and were treated with or without glucagon plus insulin. Transfection of hepatocytes with ChREBP siRNA inhibited the mRNA abundance for both ChREBP and downstream transcriptional target of ChREBP, liver pyruvate kinase (LPK), relative to cells transfected with control siRNA (Fig. 2.6). In contrast to ATF4 protein knockdown (Fig. 2.5), repression of ChREBP expression was not associated with a reduction in basal FGF21 mRNA abundance or did it hinder the ability of glucagon plus insulin to increase FGF21 mRNA abundance. In addition, glucagon plus insulin treatment did not induce LPK mRNA expression suggesting ChREBP activity is not enhanced during glucagon plus insulin treatment. These results demonstrate that glucagon plus insulin regulation of FGF21 gene expression does not require ChREBP and is dependent on ATF4. 
Downstream Insulin Mediators, PI3K, Akt, and mTORC1, Mediate the Stimulatory Effect of Insulin and Glucagon on FGF21 and ATF4 Expression.

We next investigated the proximal signaling pathways mediating the synergistic effect of glucagon and insulin on FGF21 and ATF4 expression. Insulin activation of the insulin receptor stimulates PI3K activity that in turn increases the conversion of phosphatidylinositol 4,5bisphosphate $\left(\mathrm{PIP}_{2}\right)$ to phosphatidylinositol 3,4,5-triphosphate $\left(\mathrm{PIP}_{3}\right)$ (26). Elevated $\mathrm{PIP}_{3}$ levels leads to an increase in the phosphorylation and activation of Akt (also known as protein kinase B). We performed studies with specific inhibitors of PI3K (i.e. LY294002) and Akt (i.e. Akti1/2) to investigate the role of the PI3K/Akt pathway in mediating the cooperative interaction of insulin with glucagon in inducing FGF21 gene expression. Incubating hepatocytes with LY294002 or Akti-1/2 suppressed the ability of glucagon plus insulin to stimulate FGF21 mRNA abundance and ATF4 protein concentration in a dose-dependent manner (Figs. 2.7A and 2.7B). In agreement with previous studies (27), Western analyses showed that insulin increased the abundance of the phosphorylated, active form of Akt $\left(\mathrm{Ser}^{473}\right)$ and that the presence of glucagon amplified this effect (Fig. 2.7A). The ability of LY294002 and Akti-1/2 to suppress the stimulatory effect of glucagon plus insulin on FGF21 and ATF4 expression was associated with a decrease in phosphorylated Akt (Figs. 2.7A and 2.7B). Surprisingly, treatment with LY294002 or Akti-1/2 did not suppress the ability of glucagon plus insulin to stimulate ATF4 mRNA abundance (Figs. 2.8A and 2.8B). These data demonstrate that insulin interacts with glucagon in a cooperative manner to stimulate Akt activity and that Akt is required for the stimulatory effect of glucagon plus insulin on FGF21 and ATF4 expression.

The hepatic insulin-signaling pathway bifurcates at a step distal to Akt. Akt phosphorylates FoxO1 leading to inactivation of gluconeogenic enzyme gene transcription 
$(28,29)$. Alternatively, Akt phosphorylates tuberous sclerosis complex 2 (TSC2) leading to an activation of mammalian target of rapamycin complex 1 (mTORC1) and an increase in lipogenic gene expression $(29,30)$. To evaluate the role mTORC1 in mediating the induction of FGF21 gene expression by glucagon plus insulin, we conducted experiments employing the specific mTORC1 inhibitor, rapamycin. Incubating hepatocytes with $1 \mathrm{nM}$ rapamycin suppressed the ability of glucagon plus insulin to increase FGF21 mRNA abundance and ATF4 protein concentration by $65 \%$ and $44 \%$, respectively (Fig. $2.7 \mathrm{C}$ ). The rapamycin-mediated reduction in glucagon plus insulin regulation of FGF21 mRNA abundance and ATF4 protein concentration was associated with a decrease in the phosphorylated active form of ribosomal protein S6, an effector protein downstream of mTORC1. In contrast, treatment with rapamycin had no effect on the abundance of the phosphorylated, active form of Akt. Unexpectedly, treatment with Rapamycin also did not suppress the ability of glucagon plus insulin to stimulate ATF4 mRNA abundance (Fig. 2.8C). These data suggest that insulin signals through the mTORC1 branch of the insulin pathway to potentiate the stimulatory effect of glucagon on FGF21 and ATF4 expression.

Downstream Glucagon Signaling Mediator PKA, but not EPAC, Mediate the Stimulatory Effect of Insulin and Glucagon on FGF21 and ATF4 Expression.

We next characterized the glucagon-signaling pathway mediating the induction of FGF21 and ATF4 expression by glucagon plus insulin. Glucagon regulates hepatic metabolic processes by binding to the glucagon receptor, stimulating an increase in adenylyl cyclase activity resulting in an elevation in cAMP production (31). Increased intracellular cAMP levels, in turn, activate protein kinase A (PKA) and exchange protein directly activated by cAMP (EPAC), a guanine 
nucleotide exchange factor that activates the small GTPase Rap1 $(31,32)$. To assess the role of the cAMP/PKA pathway and the cAMP/EPAC pathway in mediating the stimulatory effect of glucagon plus insulin on FGF21 gene expression, we tested the ability of a membrane permeable form of cAMP (i.e. dibutyryl cAMP), a PKA-selective agonist [i.e. N6'benzoyladenosine-3', $5^{\prime}$ cyclic monophosphate (6-Bnz-cAMP)] (33), and a EPAC-selective agonist [i.e. 8-(4chlorophenylthio)-2'-O-methyladenosine- 3', 5'-cyclic monophosphate (cpTOME)] (34) to mimic the glucagon induction of FGF21 mRNA abundance in the presence of insulin. In hepatocytes incubated in culture medium containing insulin, addition of dibutyryl cAMP or 6-Bnz-cAMP stimulated a 10 to 11 -fold increase in FGF21 mRNA abundance (Fig. 2.9A). This increase in FGF21 mRNA abundance was similar in magnitude to that observed when glucagon was added to the culture medium. Dibutyryl cAMP and 6-Bnz-cAMP also mimicked the ability of glucagon to stimulate ATF4 protein concentration, ATF4 mRNA abundance, Akt Ser ${ }^{473}$ phosphorylation, and ribosomal protein S6 $\operatorname{Ser}^{235 / 236}$ phosphorylation in the presence of insulin (Figs. 2.9A and 2.9B). In contrast, addition of cpTOME to the culture medium had no effect on FGF21 mRNA abundance, ATF4 protein concentration, ATF4 mRNA abundance, and Akt Ser ${ }^{473}$ phosphorylation in hepatocytes incubated with insulin. cpTOME treatment was effective in stimulating ribosomal protein $\mathrm{S} 6^{235 / 236}$ phosphorylation, suggesting the EPAC activation in the presence of insulin induces ribosomal protein S6 phosphorylation via a mechanism that is independent of changes in Akt activity. This observation is concordant with previous work showing that EPAC activation of Rap1 stimulates ribosomal protein S6 phosphorylation via a PI3K/Akt-independent mechanism (35). These data suggest that the glucagon signals through cAMP and PKA, but not through EPAC, to induce FGF21 and ATF4 expression in the presence of insulin. 
To obtain further evidence that PKA plays a role in mediating the stimulatory effect of glucagon and insulin on FGF21 gene expression, experiments were conducted using the PKAselective inhibitor, H89 (36). Incubating hepatocytes with H89 suppressed the ability of glucagon plus insulin to induce FGF21 mRNA abundance and ATF4 protein concentration (Fig. 2.10A). As a positive control for inhibition of PKA, H89 was effective in suppressing the stimulatory effect of glucagon on the abundance of mRNA encoding PEPCK, a PKA target (Fig. 2.10B) (37). These results provide support for a role of PKA in mediating the increase FGF21 gene expression caused by glucagon plus insulin.

\section{CDCA Stimulates FGF21 Gene Expression via an ATF4-dependent Mechanism.}

CDCA induces FGF21 gene expression not only by ligand activation of FXR but also by an undefined mechanism that is independent of ligand activation of FXR (12). Other work has shown that elevated levels of hepatic bile acids stimulate the accumulation of aberrant proteins in the endoplasmic reticulum (ER) and induce markers of ER stress (i.e. Grp78 and CHOP) (38). These observations, in combination with the current findings demonstrating that the stress associated protein ATF4 mediates the stimulatory effect of glucagon plus insulin on FGF21 expression, prompted us to investigate whether ATF4 plays a role in mediating the stimulatory effect of CDCA on FGF21 expression. We first examined whether CDCA modulated hepatic ATF4 expression. Incubating hepatocyte cultures with $100 \mathrm{mM}$ CDCA for $2 \mathrm{~h}$ stimulated a 6fold increase in ATF4 protein concentration and a 2.7-fold increase in ATF4 mRNA abundance (Fig. 2.11A). Results from gel mobility shift analyses demonstrated that this CDCA-induced increase in ATF4 expression was associated with an elevation in ATF4 binding to AARE1 and AARE2 (Fig. 2.11B). The specific binding of proteins to AARE1 and AARE2 was elevated in 
nuclear extracts from hepatocytes treated with CDCA. Preincubation of nuclear extracts with ATF4 antibody disrupted the formation of these DNA-protein complexes and caused the formation of new supershifted complexes. The abundance of these supershifted complexes were elevated in nuclear extracts from hepatocytes treated with CDCA.

We next investigated whether knockdown of ATF4 expression modulated the ability of CDCA to induce FGF21 expression. Transfection of hepatocytes with ATF4 siRNA 1 or ATF4 siRNA 2 suppressed the ability of CDCA to increase FGF21 mRNA abundance by 53 to $59 \%$ relative to cells transfected with control siRNA (Fig. 2.11C). Diminished CDCA regulation of FGF21 expression in cells transfected with ATF4 siRNA 1 and ATF4 siRNA 2 was associated with a marked reduction in ATF4 protein expression. These results indicate that CDCA increases ATF4 expression and ATF4 binding to the FGF21 gene and that ATF4 is required for CDCA induction of FGF21 gene expression.

Akt and Phosphorylated eIF2 $\alpha$ Mediate the Stimulatory Effect of CDCA on FGF21 Gene Expression.

Treatment of hepatocytes with CDCA stimulates Akt activity via mechanisms involving the increased production of mitochondrial reactive oxygen species (39) and the increased production of phosphatidic acid, a cellular metabolite that promotes Akt phosphorylation (40). These observations led us to investigate whether Akt plays a role in mediating the stimulatory effect of CDCA on FGF21 and ATF4 expression. Treatment of hepatocytes with Akti-1/2 suppressed the ability of CDCA to stimulate FGF21 mRNA abundance but had no effect on the ability of CDCA to increase ATF4 protein concentration (Fig. 2.12A). This finding suggests that Akt mediates the stimulatory effect of CDCA on FGF21 expression but not through a mechanism 
involving changes in ATF4 expression. The inability of Akt inhibition to suppress the stimulatory effect of CDCA on ATF4 expression raised the possibility that another signaling pathway besides Akt is involved in mediating CDCA regulation of FGF21 expression. ER stress increases the phosphorylation $\left(\operatorname{Ser}^{51}\right)$ of eukaryotic translation initiation factor $2 \alpha$ (eIF2 $\left.\alpha\right)(41)$. Phosphorylated eIF2 $\alpha$ (P-eIF2 $\alpha$ ) represses global protein translation while selectively increasing the translation of ATF4 mRNA (42). To investigate the role of P-eIF2 $\alpha$ in mediating the stimulatory effect of CDCA on FGF21 and ATF4 expression, experiments were performed using integrated stress response inhibitor B (ISRIB), a cell permeable small molecule that inhibits the downstream actions of P-eIF2 $\alpha$ without affecting eIF2 $\alpha$ phosphorylation state (43). Treatment of hepatocyte cultures with CDCA stimulated a 3.5-fold increase in the abundance of P-eIF2 $\alpha$ but had no effect on the abundance of total eIF2a (Fig. 2.12B). Incubating cells with ISRIB suppressed the ability of CDCA to increase FGF21 mRNA abundance and ATF4 protein concentration by $86 \%$ and $55 \%$, respectively. These results suggest that CDCA signals through P-eIF2 $\alpha$ to induce FGF21 and ATF4 expression.

\section{DISCUSSION}

The present study identifies two new signaling pathways controlling FGF21 gene transcription. In the first pathway, glucagon activation of PKA in the presence of insulin stimulates the activity of mTORC1, a signaling complex that promotes an increase in the expression of the transcription factor ATF4. Elevated ATF4 expression in turn stimulates FGF21 gene transcription (Fig. 2.13). In the second pathway, CDCA stimulates eIF2 $\alpha$ 
phosphorylation, causing an elevation in ATF4 expression and an increase in FGF21 gene transcription. To our knowledge, this is the first report demonstrating a role for ATF4 in mediating the effects of glucagon, insulin, and bile acids on hepatic gene expression. An elevation in ATF4 expression has been shown to mediate the stimulatory effect of essential amino acid deficiency on FGF21 gene transcription (22). This finding together with the results of the present study indicate that ATF4 is a distal regulatory factor that integrates a wide range of nutritional and hormonal signals controlling FGF21 gene transcription.

Previous studies have shown that ectopic activation of mTORC1 via knockdown of TSC1 causes an increase in FGF21 gene expression (44). Expression of exogenous ATF4 or a constitutively active form of Akt also induces FGF21 gene expression $(22,45)$. These findings provide support for our model that an elevation in mTORC1 signaling activity and ATF4 expression is involved in mediating that stimulatory effect of glucagon plus insulin on FGF21 gene transcription.

Our results show that inhibition of PI3K, Akt, and mTORC1 repressed glucagon plus insulin stimulation of FGF21 mRNA abundance and ATF4 protein expression, but did not repress the ability of glucagon plus insulin to increase ATF4 mRNA abundance (Figs. 2.7 and 2.8). These results suggest that the PI3K/Akt/mTORC insulin signaling axis plays a posttranscriptional role in mediating glucagon plus insulin induction of ATF4 expression. Previous studies have shown short term fasting in mice reduces mTORC1, S6K, and RPS6 activity in the liver (46). In contrast, long-term fasting paradoxically increases hepatic S6K, RPS6, and eIF4E activity while simultaneously decreasing eIF2G, phosphorylation of eIF2 $\alpha$, and global protein translation (47). The paradoxical increase in S6K, RPS6 and eIF4E translational machinery, but corresponding decrease in eIF2G protein and P-eIF2 $\alpha$ expression, during long- 
term fasting may allow for the translational shift from cap-dependent to cap-independent translation without requiring phosphorylation of eIF2 $\alpha$. In agreement to the above findings, long-term fasting increases ATF4 expression, but decreases eIF2 $\alpha$ expression, in the liver $(47,48)$. Furthermore, long-term thapsigargin treatment increases ATF4 mRNA association with heavy polysomes in an eIF $2 \alpha$ independent manner, although the nature of the translation has yet to be elucidated (49). Meanwhile, long-term thapsigargin treatment does not increase XBPs mRNA association with heavy polysomes suggesting the increase in ATF4 protein translation during extended stress conditions is a unique to ATF4 mRNA and does not encompass all UPR chaperones.

The internal ribosome entry site (IRES)-dependent translation is one type of translation mechanism that allows for cap-independent translation of mRNAs without requiring the phosphorylation of eIF2 $\alpha(50)$. IRESs are complex secondary and tertiary mRNA structures that recruit the 40S ribosomal subunit to select mRNAs independent of 5'-end recognition (51). Recruitment of the 40S ribosomal subunit independently of 5'cap recognition provides an advantage to IRES-containing mRNAs to compete for ribosomes during stress conditions (52). Tsai et al. (2014) demonstrated that the PI3K/Akt/mTORC1 axis is able to stimulate protein translation through both canonical cap-dependent and IRES-dependent translational mechanisms mediated by mTORC1 (53). It is tempting to suggest that prolonged stress in the liver produced during long-term starvation increases ATF4 protein expression through activation of the mTORC1/S6K/RPS6/eIF4E signaling axis and selective cap-independent translation of ATF4 through an identified internal ribosome entry site (IRES) (54).

Interactions between insulin and glucagon play an important role in regulating hepatic metabolic processes. For example, insulin acts in a dominant manner to suppress the stimulatory 
effect of glucagon on the transcription of the gluconeogenic genes, PEPCK and glucose-6phosphatase (37). This effect of insulin on gluconeogenic enzyme expression is mediated by the Akt/FoxO1 branch of the insulin-signaling pathway $(55,56)$. Other studies have shown that glucagon acts in a dominant manner to suppress the stimulatory effect of insulin on the expression of the lipogenic transcription factor, SREBP-1c, and its downstream target genes, acetyl-CoA carboxylase and fatty acid synthase $(57,58)$. This effect of glucagon on SREBP-1c expression is mediated at least partially through the mTORC1 branch of the insulin-signaling pathway $(29,58)$. In addition to these two types of antagonistic interactions, our studies investigating the regulation of FGF21 expression describe a third type of interaction in which glucagon cooperatively interacts with insulin to stimulate ATF4 and FGF21 expression. Glucagon also cooperatively interacts with insulin to stimulate hepatic DNA synthesis and cell proliferation $(59,60)$ and to increase the activity of Akt and mTORC1 (Figs. 2.7 and 2.9) (27), signaling proteins that are required for glucagon and insulin regulation of ATF4 and FGF21 expression. The observation that both antagonistic interactions (i.e. SREBP-1c) and cooperative interactions (i.e. FGF21) require the presence of mTORC1 suggests that a bifurcation of the insulin signaling pathway exists downstream of mTORC1.

Previous studies by our laboratory have shown that glucagon stimulates hepatic FGF21 secretion not only by a transcriptional mechanism but also by a posttranscriptional mechanism (15). In the absence of insulin, glucagon regulation of FGF21 expression is solely posttranscriptional, as glucagon treatment under this condition stimulates a 3 -fold increase in FGF21 secretion without a corresponding elevation in FGF21 mRNA abundance. Results of experiments employing selective agonists and/or inhibitors of PKA and EPAC indicate that glucagon regulation of FGF21 secretion in the absence of insulin is mediated by both the PKA 
and EPAC branch of the cAMP pathway. In contrast, the results of the present study demonstrate that glucagon regulation of FGF21 gene transcription in the presence of insulin is mediated solely by the PKA branch of the cAMP pathway (Figs. 2.9 and 2.10). Together, these findings indicate that the PKA branch of the cAMP pathway acts at both a transcriptional step and a posttranscriptional step to control FGF21 secretion, whereas the EPAC branch of the cAMP pathway acts only at a posttranscriptional step to control FGF21 secretion. These findings also indicate that cooperative interactions with insulin are restricted to the PKA branch of the cAMP pathway.

Interestingly, only the cAMP analog (db cAMP) and PKA activator (Bnz-6-cAMP), but not the EPAC activator (cpTOME), was able to increase ATF4 mRNA abundance in the presence of insulin (Fig. 2.9). These results suggest the PKA branch, but not the EPAC branch, of glucagon signaling increases ATF4 mRNA abundance in the presence of insulin. Inhibition of PI3K, Akt, and mTORC did not repress the ability of glucagon plus insulin treatment to induce ATF4 mRNA abundance (Fig. 2.8). Together, these results suggest insulin and PKA signal upstream of PI3K to cooperatively stimulate ATF4 gene transcription (Fig. 2.14) but signal downstream of PI3K to mediate ATF4 protein expression (Fig. 2.10). Dey, et al. (2012) showed UV treatment suppressed the induction of thapsigargin/P-eIF2 $\alpha$ mediated ATF4 protein translation by decreasing the ATF4 mRNA pool available for translation, concluding ATF4 protein translation does occur unless ATF4 mRNA abundance is elevated above basal expression (61). In our study, we propose H89 inhibits ATF4 protein expression by repressing the cooperative effects of glucagon plus insulin on ATF4 mRNA abundance. PKA also phosphorylates ATF4 and increases its transactivation to target gene sequences, and that this activation is repressed in the presence of H89 $(62,63)$. Future studies aim to further characterize 
the transcriptional, translational, and posttranslational role of glucagon plus insulin on ATF4 expression and activity.

In contrast to the mechanisms mediating the regulation of FGF21 transcription by glucagon plus insulin, CDCA and other bile acids induce FGF21 transcription in part through ligand activation of FXR (12). The results of the present study indicate that two additional pathways also contribute to the CDCA induction of FGF21 gene transcription. One pathway involves CDCA stimulation of ATF4 expression via a P-eIF2 $\alpha$-dependent mechanism (Fig. 2.12B). The other pathway requires Akt activity and is independent of changes in ATF4 expression (Fig. 2.12B). We postulate that that the latter pathway involves the transcription factor, nuclear factor E2-related factor 2 (Nrf2), as previous studies have shown that bile acids stimulate Nrf2 activity via a PI3K/Akt-dependent mechanism and that Nrf2 induction stimulates hepatic FGF21 expression in diabetic mice $(64,65)$. The ability of CDCA to act through multiple signaling pathways to induce FGF21 gene expression provides a means through which CDCA can finely control FGF21 production during different conditions.

Nutritional stress (e.g. starvation) and diseases associated with metabolic syndrome (e.g. obesity, type 2 diabetes, nonalcoholic fatty liver disease) stimulate an increase in hepatic FGF21 expression and serum FGF21 levels (5,7-10). Elevated FGF21 production in turn mediates adaptive changes in insulin sensitivity, growth, circadian behavior, and energy metabolism during these conditions $(1-7,11)$. What is the role of the CDCA/eIF2a/ATF4 pathway and the glucagon/insulin/PKA/mTORC1/ATF4 pathway in mediating changes in FGF21 expression caused by nutritional stress and metabolic syndrome? Previous studies have shown that hepatic levels of bile acids and serum levels of bile acids, glucagon, and insulin are elevated in obesity, type 2 diabetes, and nonalcoholic fatty liver disease (66-68). Hepatic ATF4 expression, eIF $\alpha$ 
phosphorylation, PKA activity, and mTORC1 activity are also elevated in obesity, type 2 diabetes, and nonalcoholic fatty liver disease (69-72). Recent studies have shown that insulin induction of mTORC1 activity during conditions of insulin resistance requires signaling through Akt1/2 (73). These observations provide support for a role of both the CDCA/eIF2a/ATF4 pathway and the glucagon/insulin/PKA/mTORC1/ATF4 pathway in mediating changes in FGF21 expression caused by metabolic syndrome.

There is evidence that the glucagon/insulin/PKA/mTORC1/ATF4 pathway also plays a role in mediating the increase in FGF21 expression caused by starvation. First, results of experiments employing mice lacking hepatic insulin signaling activity (i.e. liver-specific deletion of IRS-1 and IRS-2) or glucagon signaling activity (i.e. deletion of the glucagon receptor) have shown that both of these pathways are required for the starvation-induced increase in hepatic FGF21 expression $(14,16,17)$. Second, fasting for $48 \mathrm{~h}$ causes an increase in hepatic PKA and mTORC1 signaling activity and ATF4 protein expression $(37,47,48)$. Previous studies have shown that mTORC1 signaling activity induces both cap-dependent and cap-independent translation of selective IRES-containing mRNAs (53). We hypothesize glucagon plus insulin stimulates ATF4 protein expression by enhancing mTORC1-dependent IRES translation of ATF4 mRNA (54).

In conclusion, the results of the present study demonstrate that glucagon and insulin act through PKA and mTORC1 to induce the expression of ATF4, a transcription factor that binds the FGF21 gene and activates transcription. This finding in combination with the observation that PKA activity, mTORC1 activity, and ATF4 expression are elevated after $48 \mathrm{~h}$ of starvation supports previous studies demonstrating that both insulin signaling activity and glucagon signaling activity are required for the stimulatory effect of starvation on hepatic FGF21 gene 
expression $(14,16,17)$. The results of the present study also demonstrate that alterations in ATF4 expression play a role in mediating the stimulatory effect of CDCA on FGF21 gene expression and that eIF $2 \alpha$ mediates the increase in ATF4 expression caused by CDCA. Previous studies have shown that the eIF2 $\alpha /$ ATF4 pathway mediates the induction of hepatic FGF21 expression caused by essential amino acid deficiency $(5,22)$. Knockout studies performed in mice suggest that the eIF2 $\alpha$ kinase, general control nonderepressible 2 (GCN2), plays a role a mediating the induction in ATF4 and FGF21 expression caused by acute dietary protein restriction (74). The role of GCN2 and other eIF2 $\alpha$ kinases in mediating the stimulatory effect of bile acids on FGF21 expression is the subject of future investigations. 
Figure 2.1: Effects of deletions of the 5'-flanking region of the rat FGF21 gene on transcriptional activity in the absence and presence of glucagon plus insulin. Primary rat hepatocytes were transiently transfected with a series of plasmids containing fragments of the rat FGF21 gene linked to the luciferase (Luc) gene as described under "Experimental Procedures." After transfection, cells were treated with or without $25 \mathrm{nM}$ glucagon (gln) and $50 \mathrm{nM}$ insulin (ins) for $24 \mathrm{~h}$. Cells were harvested, extracts were prepared, and luciferase assays were performed. Left, the constructs used in these experiments. The number at the left of each construct is the 5'-end of FGF21 DNA in nucleotides relative to the transcription initiation site. The 3'-end of each construct is $+68 \mathrm{bp}$. The location of a previously identified FXRE (-1222 to $1210 \mathrm{bp})$, PPRE (-1215 to $-1203 \mathrm{bp})$, ChoRE (-72 to $-56 \mathrm{bp})$, and AAREs (-1282 to -1274 bp and -140 to $-132 \mathrm{bp}$ ) are indicated by boxes with different fills or patterns. Right, luciferase activity of cells transfected with the -2940 to +68 bp FGF21 construct and treated with vehicle was set at 1, and all other activities were adjusted proportionately. The -fold stimulation by glucagon plus insulin was calculated by dividing the luciferase activity for cells treated with glucagon plus insulin by that for cells treated with vehicle. The -fold responses were calculated for individual experiments and then averaged. The results are the means \pm S.E. of six experiments. Different superscript letters indicate that the means are significantly $(p \leq 0.05)$ different. 
Figure 2.2: Effects of deletions of the 5'-flanking region of the rat FGF21 gene on transcriptional activity in the absence and presence of insulin. Primary rat hepatocytes were transiently transfected with a series of plasmids containing fragments of the rat FGF21 gene linked to the luciferase (Luc) gene as described under "Experimental Procedures." After transfection, cells were treated with $50 \mathrm{nM}$ insulin for $24 \mathrm{~h}$. Cells were harvested, extracts were prepared, and luciferase assays were performed. Left, the constructs used in these experiments. The number at the left of each construct is the 5'-end of FGF21 DNA in nucleotides relative to the transcription initiation site. The 3 '-end of each construct is $+68 \mathrm{bp}$. The location of a previously identified FXRE (-1222 to -1210 bp), PPRE (-1215 to -1203 bp), ChoRE (-72 to -56 bp), and AAREs (-1282 to $-1274 \mathrm{bp}$ and -140 to $-132 \mathrm{bp}$ ) are indicated by boxes with different fills or patterns. Right, luciferase activity of cells transfected with the -2949 to +68 bp FGF21 construct and treated with vehicle was set at 1 , and all other activities were adjusted proportionately. The -fold stimulation by insulin was calculated by dividing the luciferase activity for cells treated with insulin by that for cells treated with vehicle. The -fold responses were calculated for individual experiments and then averaged. The results are the means \pm S.E. of five experiments. 
Figure 2.3: Two AAREs in the FGF21 gene confer the stimulatory effect of glucagon plus insulin on FGF21 transcription. Reporter plasmids containing mutations of the AARE1, AARE2, AARE1/AARE2, FXRE/PPRE, and/or ChoRE in the context of the -1316 to $+68 \mathrm{bp}$ FGF21 promoter fragment were transiently transfected into hepatocytes as described in the legend of Fig. 1 and under "Experimental Procedures." $A$, native and mutant sequences of the AARE1, AARE2, FXRE/PPRE, and ChoRE in the rat FGF21 gene. The native sequence of each regulatory element is indicated in bold letters and the mutated sequence is shown underneath. The hexameric half-sites comprising the FXRE and PPRE are indicated by arrows. $B$, luciferase activity of hepatocytes transfected with wild type and mutant reporter plasmids. Mutation of the AARE1, AARE2, FXRE/PPRE, and ChoRE is indicated by an X through the box designated for that element. The results are the means \pm S.E. of six experiments. Different superscript letters indicate that the means are significantly $(p \leq 0.05)$ different. 
Figure 2.4: Glucagon and insulin cooperatively induce ATF4 expression and ATF4 binding

to AARE1 and AARE2. $A$, primary rat hepatocytes were incubated with or without glucagon, insulin or glucagon plus insulin. The abundance of ATF4 mRNA, FGF21 mRNA, and SREBP1c mRNA in total RNA was measured after $6 \mathrm{~h}$ of treatment. The abundance of ATF4 protein in cell extracts was measured after $12 \mathrm{~h}$ of treatment. The level of ATF4 protein, ATF4 mRNA, FGF21 mRNA, and SREBP-1c mRNA in cells incubated with vehicle was set at 1, and the other values were adjusted proportionately. Values are means \pm S.E. of seven experiments. An asterisk indicates that the mean is significantly $(p \leq 0.05)$ higher than any other mean. $B$, gel mobility shift analyses were performed using nuclear extracts (N.E.) prepared from hepatocytes treated with or without glucagon plus insulin for $12 \mathrm{~h}$. The sequences of ${ }^{32} \mathrm{P}$-labeled probes containing AARE1 or AARE2 are shown in Fig. 2A. The binding reactions were performed as described in "Experimental Procedures." Nuclear extracts were incubated with antibodies against ATF4 prior to addition of the probe. Competition analyses were performed by mixing the labeled probe with a 5- and 50-fold molar excess of unlabeled probe (self comp.) or a competitor DNA containing a mutation of AARE1 or AARE2 (AARE mut comp.). Positions of specific DNA-protein complexes (brackets) and supershifted complexes (SS) are indicated. 
Figure 2.5: Knockdown of ATF4 expression suppresses the ability of glucagon plus insulin to increase FGF21 mRNA abundance. Primary rat hepatocytes were transfected with control siRNA or siRNA targeting ATF4 as described in "Experimental Procedures." After transfection, cells were incubated with glucagon and insulin for $12 \mathrm{~h}$. Cells were then harvested, total RNA was isolated, and cellular extracts were prepared. Top panel, FGF21 mRNA abundance was measured in total RNA. The level of FGF21 mRNA in non-transfected cells incubated with vehicle was set at 1 , and all other values were adjusted proportionately. The -fold stimulation by glucagon plus insulin was calculated by dividing the FGF21 mRNA abundance of cells treated with glucagon plus insulin by that of cells treated with vehicle. The -fold responses were calculated for individual experiments and then averaged. Values are the means \pm S.E. of five experiments. Different superscript letters indicate that the means are significantly $(p \leq 0.05)$ different. Bottom panel, the abundance ATF4 protein and $\beta$-tubulin in cell lysates was measured by Western analysis. These data are representative of five experiments. 
Figure 2.6: Knockdown of ChREBP expression does not suppress the ability of glucagon plus insulin to increase FGF21 mRNA abundance. Primary rat hepatocytes were transfected with control siRNA or siRNA targeting ChREBP as described in "Experimental Procedures." After transfection, cells were incubated with glucagon and insulin for $12 \mathrm{~h}$. Cells were then harvested, total RNA was isolated, and cellular extracts were prepared. Top panel, FGF21 mRNA abundance was measured in total RNA. Middle panel, ChREBP mRNA abundance was measured in total RNA. Bottom panel, LPK mRNA abundance was measured in total RNA. The level of mRNA in non-transfected cells incubated with vehicle was set at 1 , and all other values were adjusted proportionately. The -fold stimulation by glucagon plus insulin was calculated by dividing the FGF21, ChREBP, or LPK mRNA abundance of cells treated with glucagon plus insulin by that of cells treated with vehicle. The -fold responses were calculated for individual experiments and then averaged. Values are the means \pm S.E. of three-five experiments. Different superscript letters indicate that the means are significantly $(p \leq 0.05)$ different. 
Figure 2.7: Inhibition of PI3K, Akt or mTORC1 suppresses the ability of glucagon plus insulin to induce FGF21 mRNA abundance and ATF4 protein expression. Primary rat hepatocytes were isolated and incubated in serum-free Medium 199. At $47 \mathrm{~h}$ of incubation, the medium was replaced with one of the same composition containing vehicle or the indicated concentrations of LY294002 (A), Akti-1/2 (B) or Rapamycin $(C)$. At $48 \mathrm{~h}$ of incubation, glucagon and/or insulin was added to the medium and the incubation was continued for $12 \mathrm{~h}$. Cells were harvested, total RNA was isolated, and cellular extracts were prepared. Left panels, the abundance of FGF21 mRNA in total RNA and the level of ATF4 protein in total cell lysates were measured as described in "Experimental Procedures." Values for cells incubated in the absence of inhibitor and hormones were set at 1, and the other values were adjusted proportionately. Values are means \pm S.E. of four experiments. Significant differences $(p \leq 0.05)$ between means are indicated by asterisks. Right panels, the abundance of phosphorylated Akt $\left(\mathrm{Ser}^{473}\right)(\mathrm{P}-\mathrm{Akt})$, phosphorylated ribosomal protein S6 ( $\left.\mathrm{Ser}^{235 / 236}\right)$ (P-RPS6), total Akt, and total RPS6 in total cell lysates was measured by Western analysis. These data are representative of four experiments. 
Figure 2.8: Inhibition of PI3K, Akt or mTORC1 does not suppress the ability of glucagon plus insulin to induce ATF4 mRNA abundance. Primary rat hepatocytes were isolated and incubated in serum-free Medium 199. At $47 \mathrm{~h}$ of incubation, the medium was replaced with one of the same composition containing vehicle or the indicated concentrations of LY294002 $(A)$, Akti-1/2 $(B)$ or Rapamycin $(C)$. At $48 \mathrm{~h}$ of incubation, glucagon and/or insulin was added to the medium and the incubation was continued for $12 \mathrm{~h}$. Cells were harvested, total RNA was isolated, and cellular extracts were prepared. The abundance of FGF21 mRNA in total RNA was measured as described in "Experimental Procedures." Values for cells incubated in the absence of inhibitor and hormones were set at 1 , and the other values were adjusted proportionately. Values are means \pm S.E. of three experiments. Significant differences $(p \leq 0.05)$ between means are indicated by asterisks. 
Figure 2.9: Dibutyryl cAMP and 6-Bnz-cAMP mimic the ability of glucagon to stimulate FGF21 and ATF4 expression in the presence of insulin. Primary rat hepatocytes were isolated and incubated in serum-free Medium 199. At $48 \mathrm{~h}$ of incubation, the medium was replaced with one of the same composition containing glucagon (25 nM), dibutyryl cAMP (100 $\mu \mathrm{M}), 6$-Bnz-cAMP $(100 \mu \mathrm{M})$, cpTOME $(5 \mu \mathrm{M})$ or vehicle in the absence or presence of insulin $(50 \mathrm{nM})$. After $12 \mathrm{~h}$ of incubation, cells were harvested, total RNA was isolated, and cellular extracts were prepared. $A$, the abundance of FGF21 mRNA and ATF4 mRNA in total RNA and the level of ATF4 protein in total cell lysates were measured as described in "Experimental Procedures." Values for cells incubated with vehicle alone were set at 1, and the other values were adjusted proportionately. Values are means \pm S.E. of three experiments. An asterisk indicates that the mean is significantly $(p \leq 0.05)$ higher compared to that of cells incubated with insulin alone. $B$, the abundance of ATF4, b-tubulin, phosphorylated Akt $\left(\operatorname{Ser}^{473}\right)$, phosphorylated RPS6 $\left(\mathrm{Ser}^{235 / 236}\right)$, total Akt, and total RPS6 in total cell lysates was measured by Western analysis. These data are representative of three experiments. Quantitation of the signals for ATF4 protein is shown in $A$. $C$, signaling diagram showing the proteins that are activated by dibutyryl cAMP, 6-Bnz-cAMP, and cpTOME. 
Figure 2.10: Inhibition of PKA suppresses the ability of glucagon plus insulin to induce FGF21 mRNA abundance and ATF4 protein expression. Primary rat hepatocytes were isolated and incubated in serum-free Medium 199. At $47 \mathrm{~h}$ of incubation, the medium was replaced with one of the same composition containing H89 $(20 \mu \mathrm{M})$ or vehicle. At $48 \mathrm{~h}$ of incubation, glucagon plus insulin $(A)$ or glucagon alone $(B)$ was added to the medium and the incubation was continued for $12 \mathrm{~h}$. Cells were harvested, total RNA was isolated, and cellular extracts were prepared. The abundance of FGF21 mRNA and PEPCK mRNA in total RNA and the level of ATF4 protein in total cell lysates were measured as described in "Experimental Procedures." Values for cells incubated in the absence of H89 and hormones were set at 1, and the other values were adjusted proportionately. Values are means \pm S.E. of three experiments. Significant differences $(p \leq 0.05)$ between means are indicated by the asterisks. 
Figure 2.11: CDCA induces ATF4 expression and ATF4 binding to AARE1 and AARE2, and knockdown of ATF4 expression suppresses the ability of CDCA to increase FGF21 mRNA abundance. $A$, effect of CDCA on ATF4 expression in primary rat hepatocytes. The abundance of ATF4 protein in total cell lysates and levels of ATF4 mRNA and FGF21 mRNA in total RNA were measured after $2 \mathrm{~h}$ of treatment with CDCA $(100 \mu \mathrm{M})$ or vehicle. The level of ATF4 protein, ATF4 mRNA, and FGF21 mRNA, in cells incubated with vehicle was set at 1, and the other values were adjusted proportionately. Values are means \pm S.E. of seven experiments. An asterisk indicates that the mean is significantly $(p \leq 0.05)$ higher compared to that of cells treated with vehicle. $B$, gel mobility shift analyses were performed as described under "Experimental Procedures" using nuclear extracts (N.E.) prepared from hepatocytes treated with or without CDCA for $2 \mathrm{~h}$. Positions of specific DNA-protein complexes (brackets) and supershifted complexes (SS) are indicated. C, effect of knockdown of ATF4 expression on CDCA regulation of FGF21 gene expression. Hepatocytes were transfected with control siRNA or siRNA targeting ATF4 as described in "Experimental Procedures." After transfection, cells were incubated with CDCA for $2 \mathrm{~h}$. Cells were then harvested, total RNA was isolated, and cellular extracts were prepared. Top panel, FGF21 mRNA abundance was measured in total RNA. The level of FGF21 mRNA in non-transfected cells incubated with vehicle was set at 1 , and all other values were adjusted proportionately. The -fold stimulation by CDCA was calculated by dividing the FGF21 mRNA abundance of cells treated with CDCA by that of cells treated with vehicle. The -fold responses were calculated for individual experiments and then averaged. The results are the means \pm S.E. of five experiments. Different superscript letters indicate that the means are significantly $(p \leq 0.05)$ different. Bottom panel, the abundance ATF4 protein and $\beta$-tubulin in cell lysates was measured by Western analysis. These data are 
representative of five experiments.

Figure 2.12: Inhibition of Akt and eIF2 $\alpha$ signaling activity suppresses the ability of CDCA to induce FGF21 mRNA abundance. Primary rat hepatocytes were isolated and incubated in serum-free Medium 199. At $47 \mathrm{~h}$ of incubation, the medium was replaced with one of the same composition containing 0.3 or $1 \mu \mathrm{M}$ Akti-1/2 $(A), 10 \mathrm{nM}$ ISRIB $(B)$ or vehicle. At $48 \mathrm{~h}$ of incubation, CDCA was added to the medium and the incubation was continued for $2 \mathrm{~h}$. Cells were then harvested, total RNA was isolated, and cellular extracts were prepared. The abundance of FGF21 mRNA and ATF4 mRNA in total RNA and the level of ATF4 protein, $\beta$ tubulin, phosphorylated Akt $\left(\operatorname{Ser}^{473}\right)$, phosphorylated eIF2 $\alpha\left(\operatorname{Ser}^{51}\right)$, total Akt, and total eIF2 $\alpha$ in total cell lysates were measured as described in "Experimental Procedures." Values for cells incubated in the absence of inhibitor and hormones were set at 1 , and the other values were adjusted proportionately. Values are means \pm S.E. of four experiments. Significant differences $(p \leq 0.05)$ between means are indicated by asterisks. 
Figure 2.13: Proposed model for how glucagon, insulin, and CDCA increase hepatic FGF21 gene expression and secretion. Glucagon binding to the glucagon receptor stimulates cAMP production resulting in an activation of PKA and EPAC. Activation of PKA enhances the ability of insulin to stimulate the activity of mTORC1, a signaling complex that promotes an increase in the ATF4 expression. ATF4 binds to the FGF21 gene triggering an increase in FGF21 transcription and FGF21 secretion. In combination with EPAC, PKA also stimulates FGF21 secretion via a translational and/or posttranslational mechanism that remains to be defined. In addition to glucagon and insulin, CDCA induces FGF21 transcription by increasing ATF4 expression. Here, the elevation in ATF4 expression is mediated by phosphorylated eIF2 $\alpha$. CDCA also induces FGF21 transcription by ligand activation of FXR and by an undefined mechanism requiring Akt activity. Results from genetic ablation studies and correlative analyses suggest that glucagon, insulin, and bile acid signaling activity plays a role in mediating the induction of hepatic FGF21 expression during starvation and conditions related to metabolic syndrome $(14,16,17,66-68)$. Dose-response studies performed in hepatocyte cultures have shown that insulin is effective in stimulating FGF21 mRNA abundance at a concentration observed in the portal vein during fasted conditions (i.e. $1 \mathrm{nM})(15)$. 


\section{Figure 2.14: Proposed model for how glucagon plus insulin increase hepatic ATF4}

expression. Glucagon binding to the glucagon receptor stimulates cAMP production resulting in the activation of PKA and EPAC. PKA and insulin signal cooperatively to increase ATF4 mRNA abundance. Inhibition of P13K, Akt, and mTORC did not suppress the ability of glucagon plus insulin to stimulate ATF4 mRNA suggesting insulin and PKA interact upstream of PI3K to modulate ATF4 gene transcription. In contrast, inhibition of PI3K, Akt, and mTORC did suppress the ability of glucagon plus insulin to stimulate ATF4 protein expression suggesting mTORC is the downstream mediator of ATF4 protein translation. One hypothesis for mTORC mediated ATF4 protein translation is by enhancing IRES-dependent translation of ATF4 mRNA. PKA phosphorylates ATF4 and increases its transactivation to target promoters $(62,63)$, suggesting PKA posttranslational modification of ATF4 may also contribute to its enhanced binding to AAREs on the FGF21 promoter. 


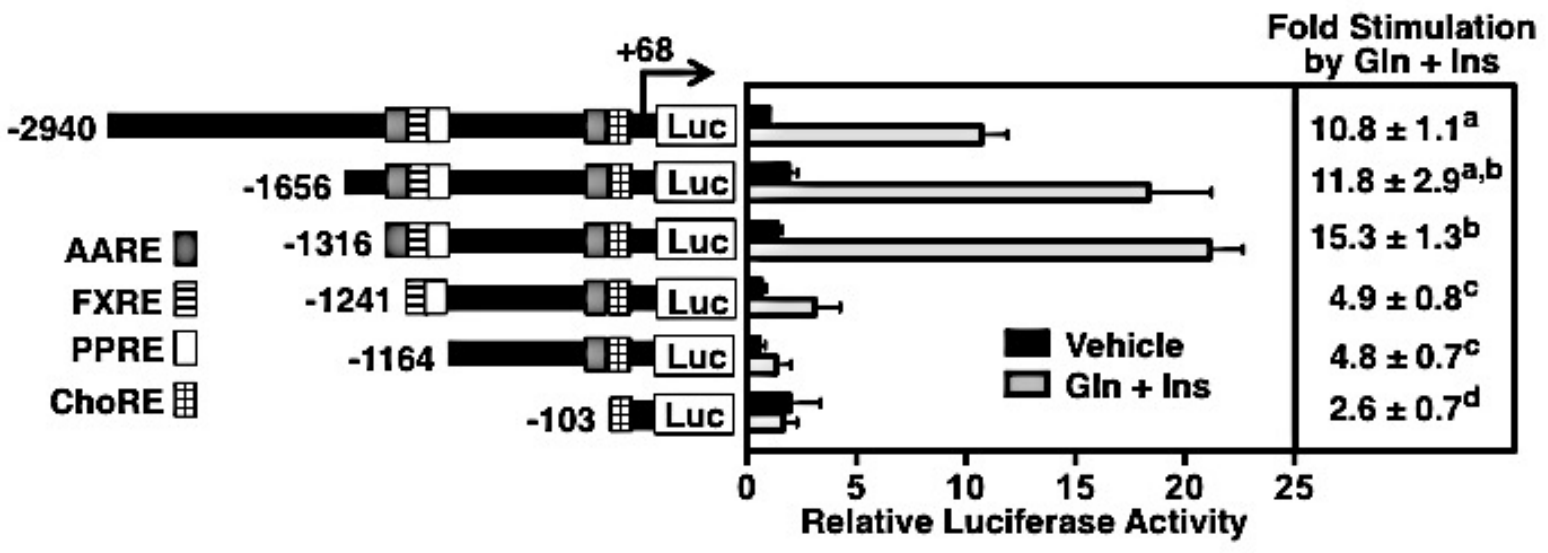

Figure 2.1: Effects of deletions of the 5'-flanking region of the rat FGF21 gene on transcriptional activity in the absence and presence of glucagon plus insulin. 


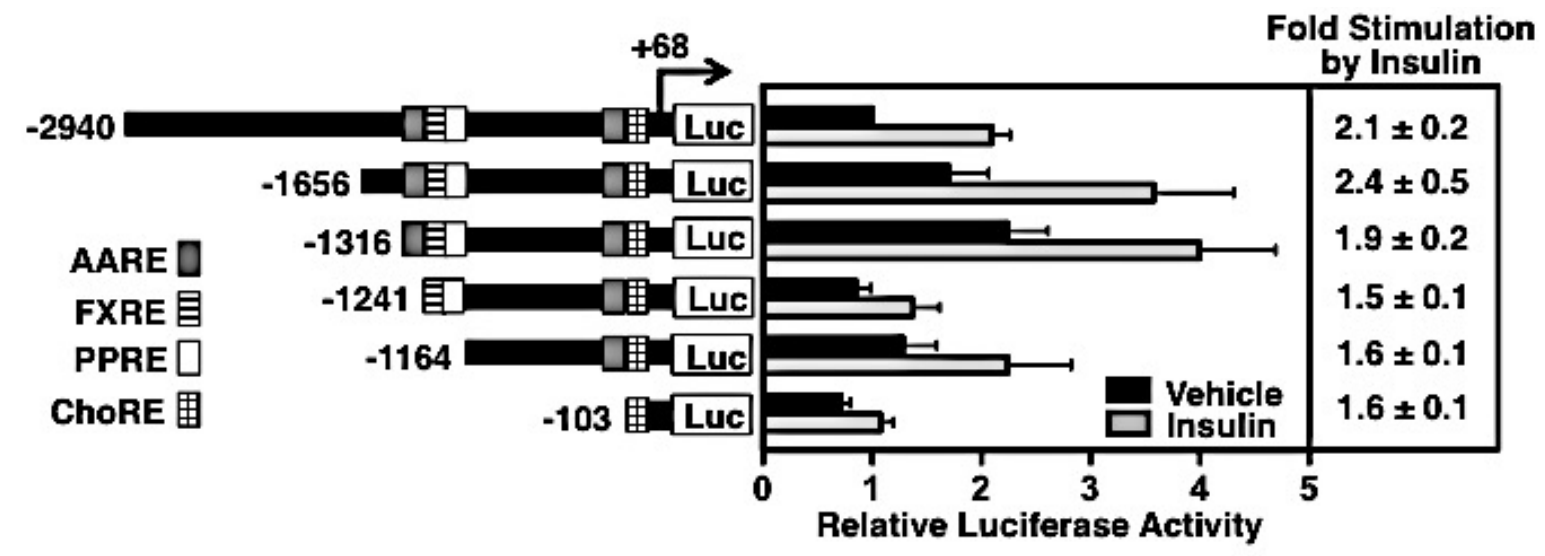

Figure 2.2: Effects of deletions of the 5'-flanking region of the rat FGF21 gene on transcriptional activity in the absence and presence of insulin. 

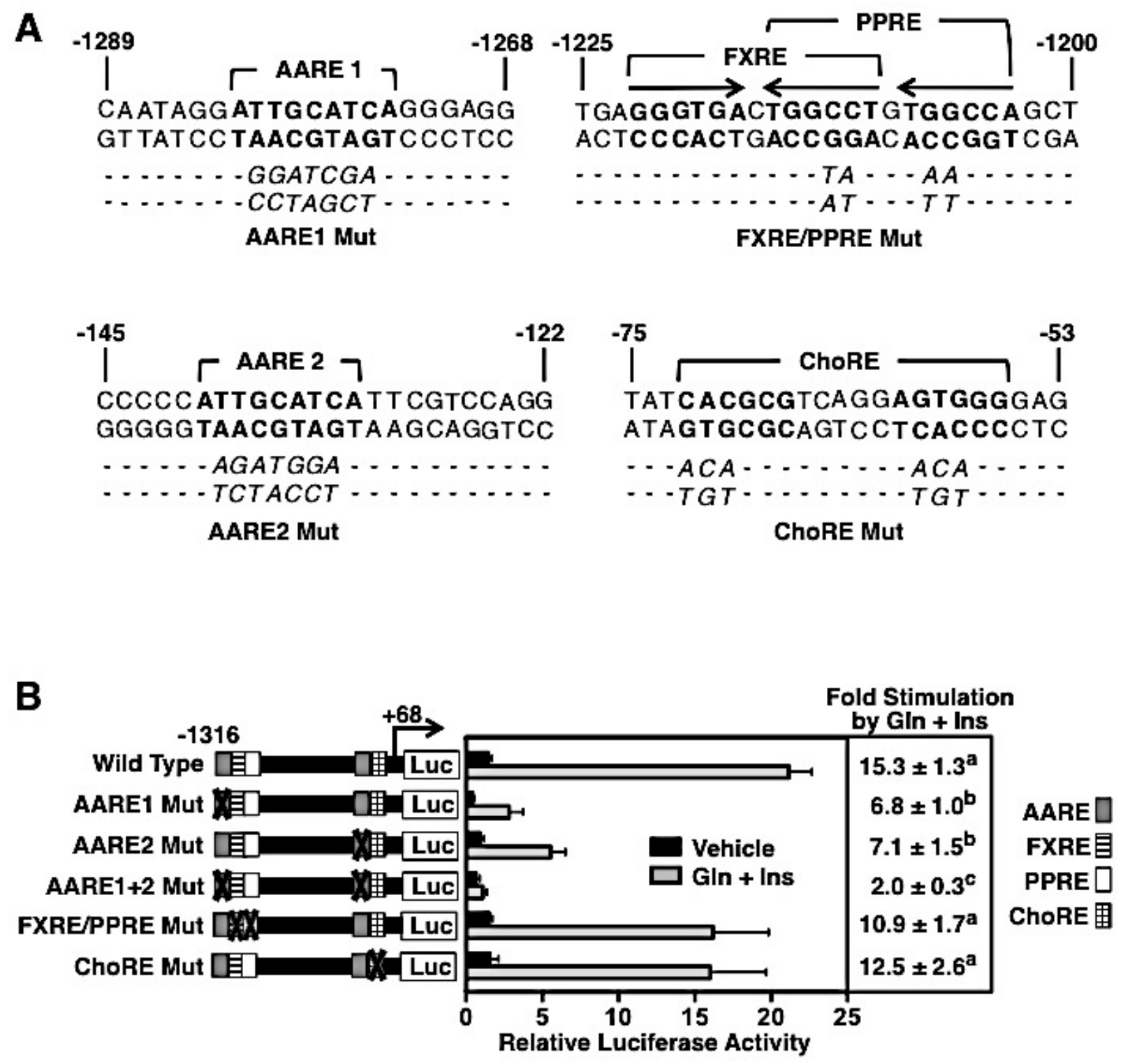

Figure 2.3: Two AAREs in the FGF21 gene confer the stimulatory effect of glucagon plus insulin on FGF21 transcription. 
A
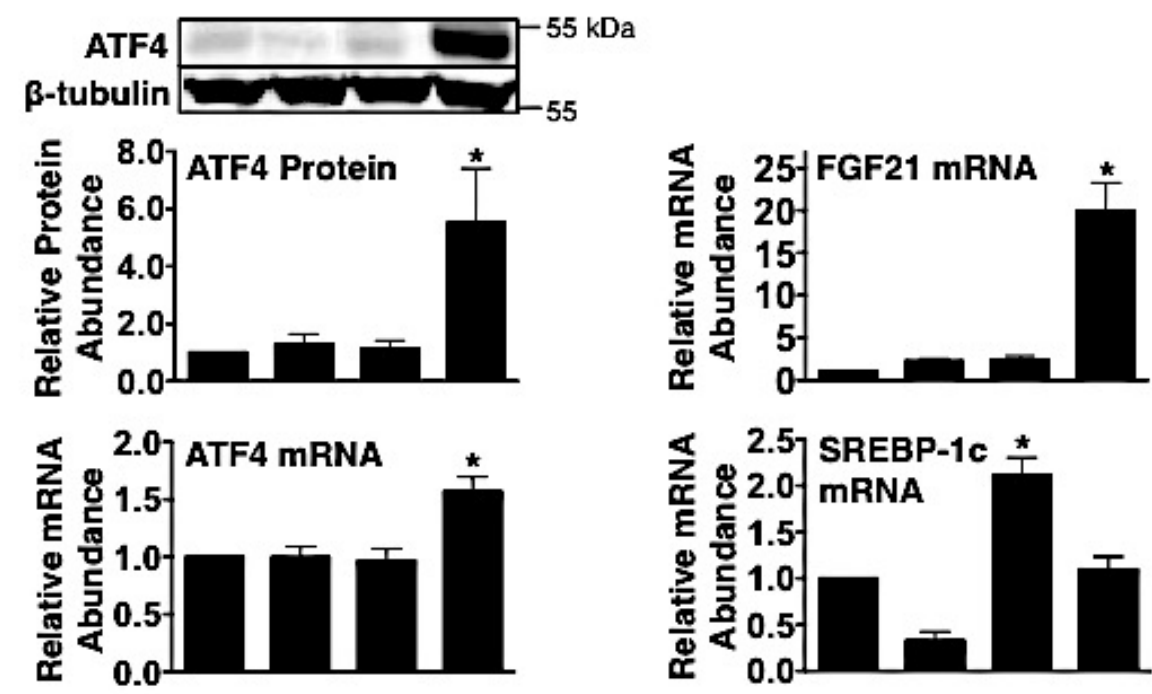

Glucagon
Insulin

Glucagon -
Insulin

B

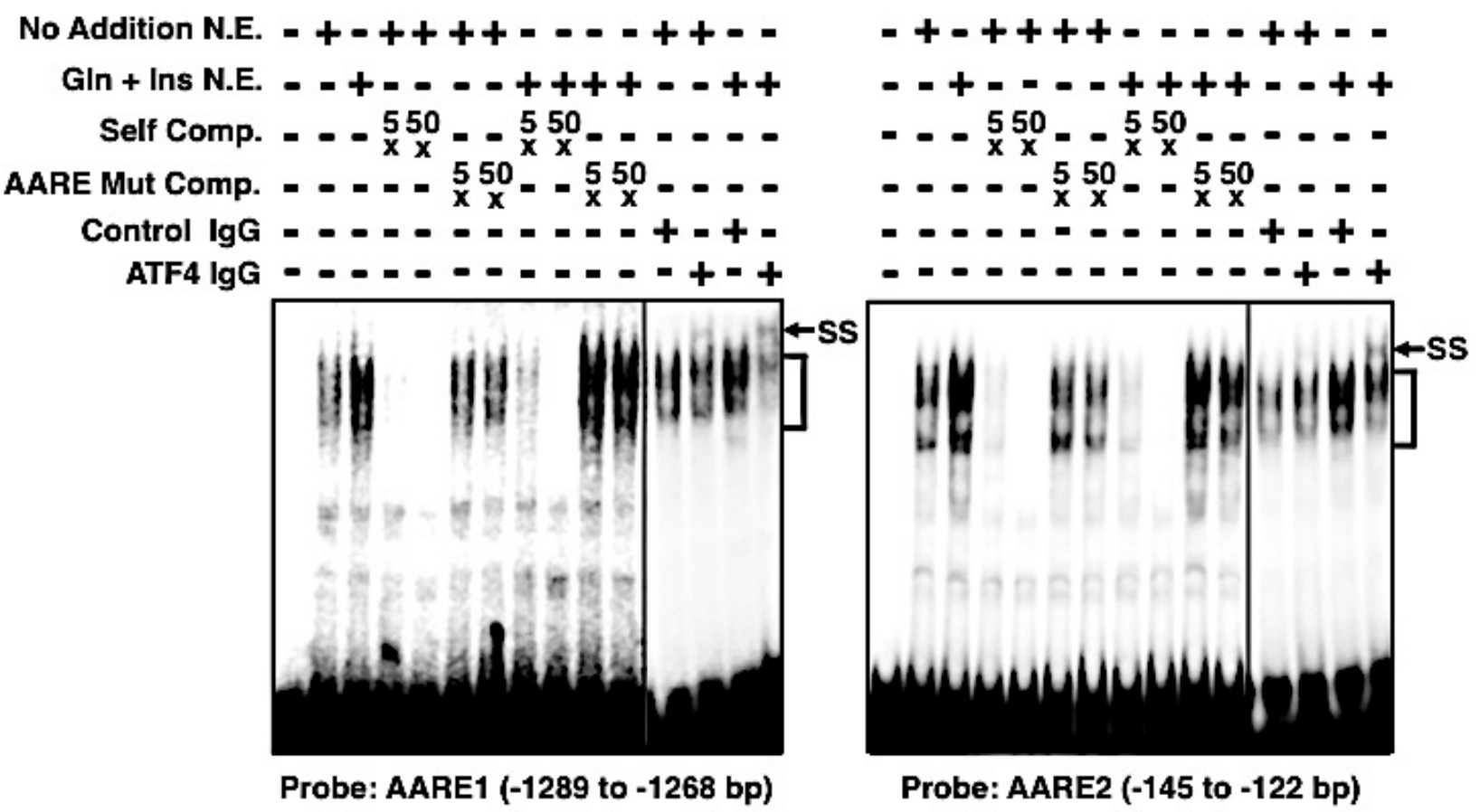

Figure 2.4: Glucagon and insulin cooperatively induce ATF4 expression and ATF4 binding to AARE1 and AARE2. 

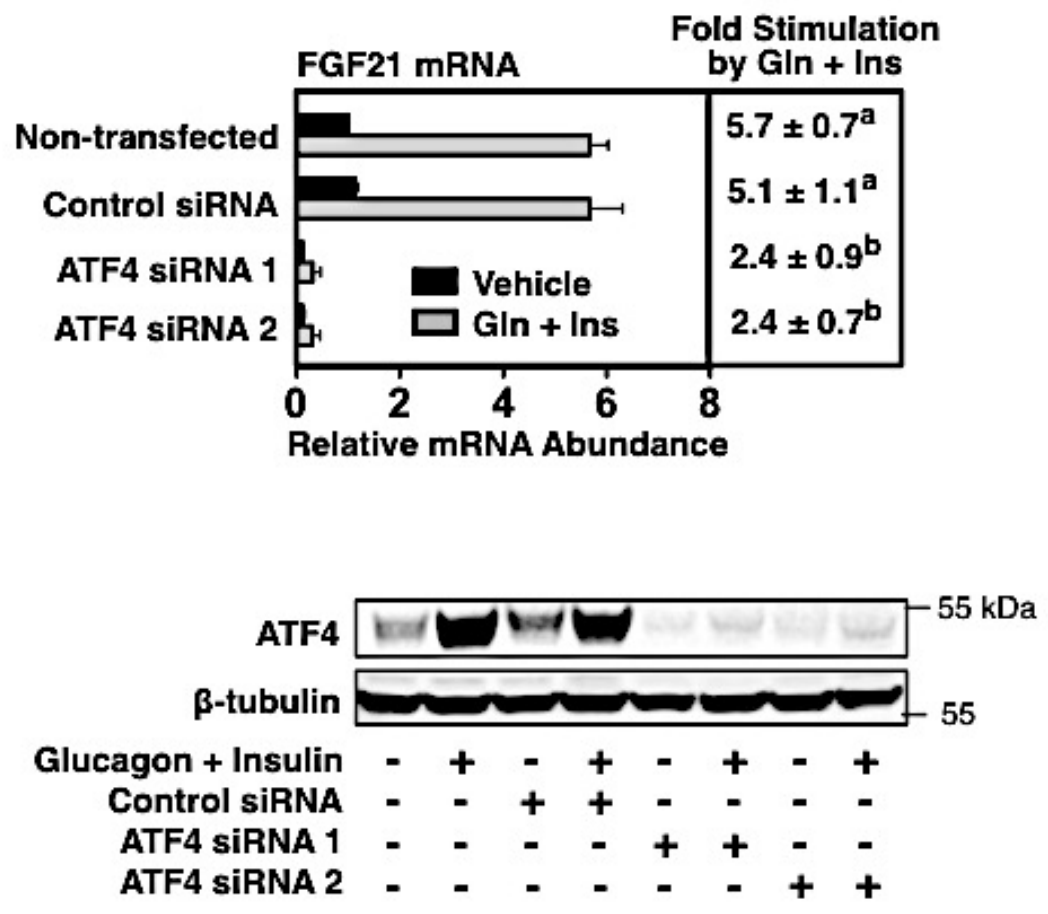

Figure 2.5: Knockdown of ATF4 expression suppresses the ability of glucagon plus insulin to increase FGF21 mRNA abundance. 
A
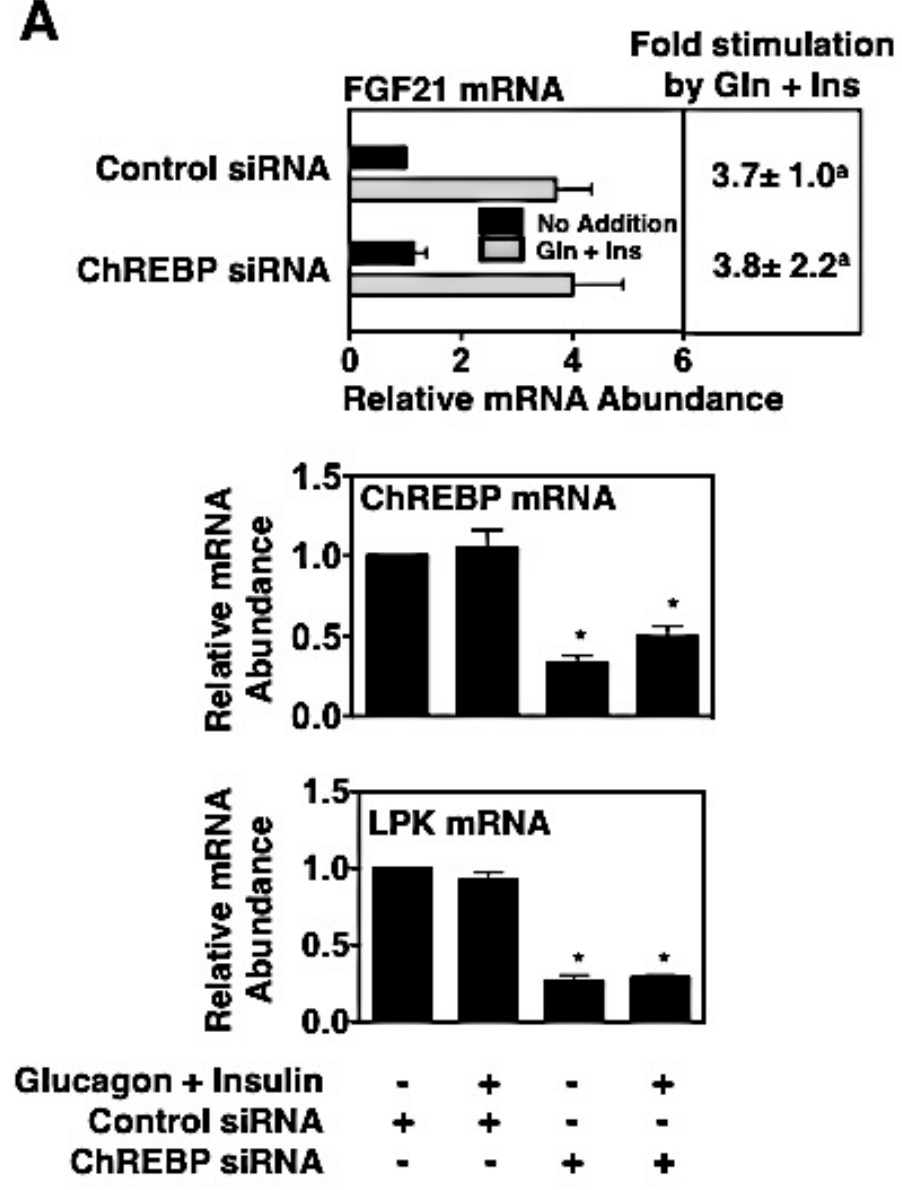

Figure 2.6: Knockdown of ChREBP expression does not suppress the ability of glucagon plus insulin to increase FGF21 mRNA abundance. 
A
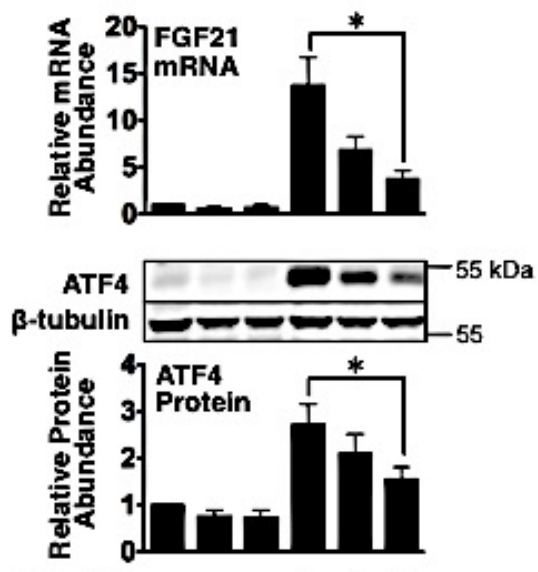

Gin + Ins - - - + + + LY294002 ( $\mu \mathrm{M})-1020-1020$

B

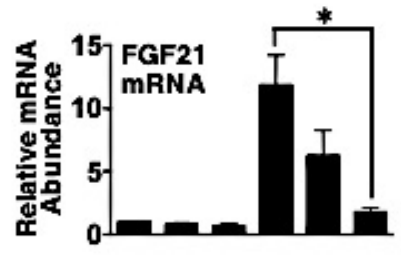

ATF4 $=\square=0-55 \mathrm{kDa}$

B-tubulin $-(-2-\ldots-55$

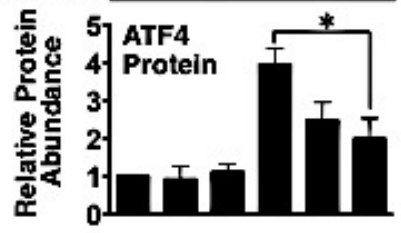

$\mathrm{Gin}+\operatorname{lns}--+++$ Aktt-1/2 ( $(\mu \mathrm{M})-310-310$

C
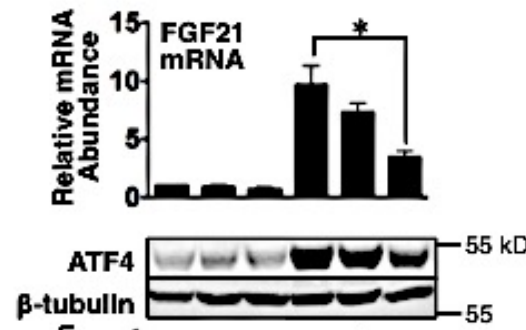

B-tubulin

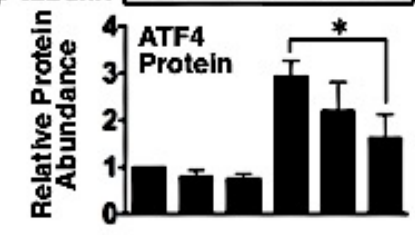

Gln $+\operatorname{lns}--2++$

$\underset{(\mathrm{nM})}{\operatorname{Rapamycin}}-0.11-0.11$

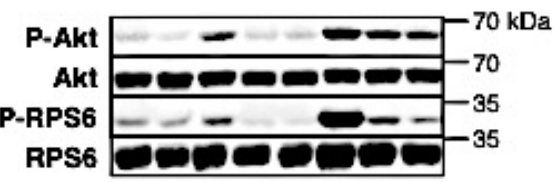

Glucagon - + - - - + + +

Insulln - - + - +++ LY294002 ( $\mu$ M) - - $1020-1020$
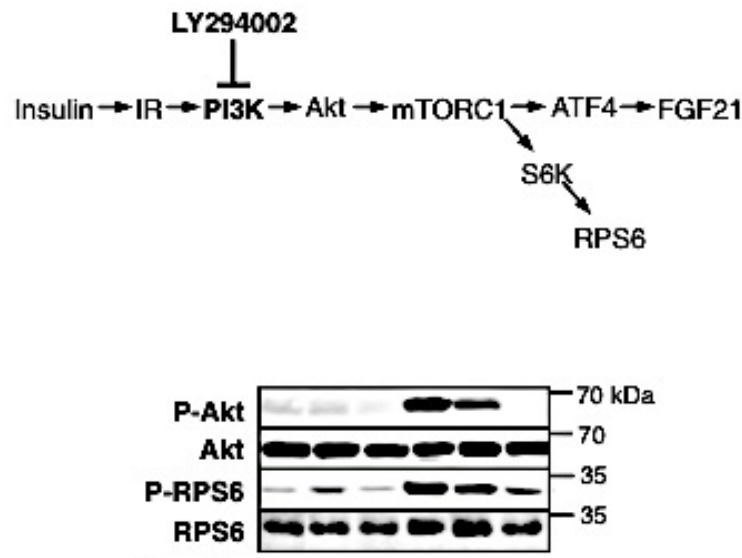

Gin + Ins - - - + + +

Akti-1/2 ( $\mu M)=310-310$

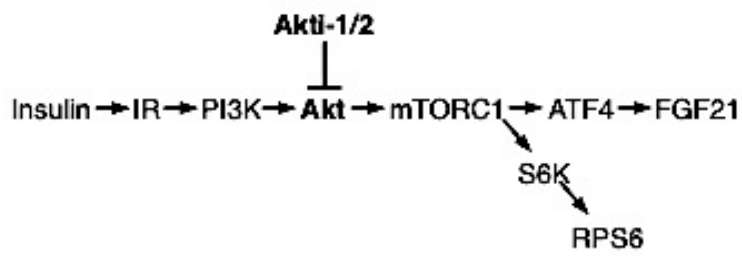

Figure 2.7: Inhibition of PI3K, Akt and mTORC1 suppresses the ability of glucagon plus insulin to induce FGF21 mRNA abundance and ATF4 protein expression. 

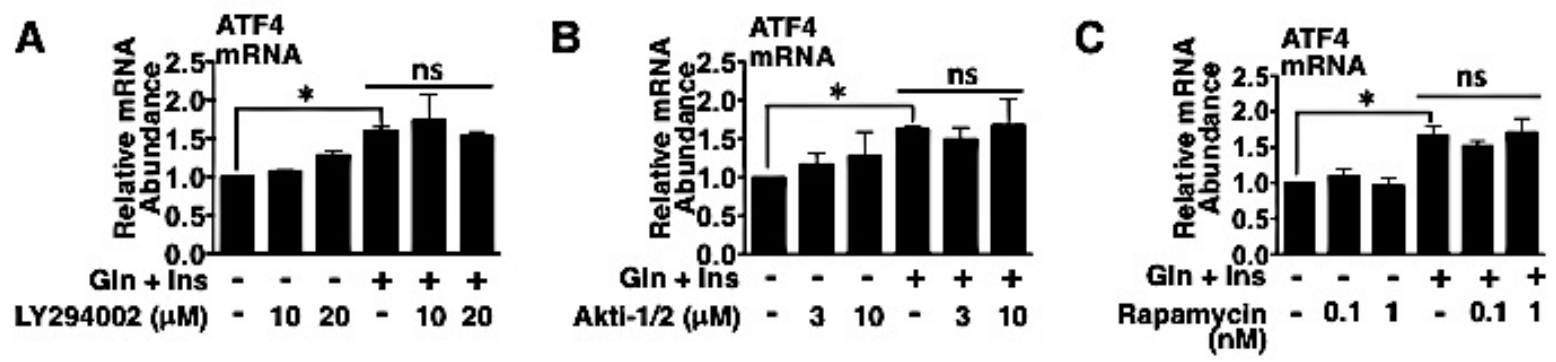

Figure 2.8: Inhibition of PI3K, Akt, and mTORC1 does not suppress the ability of glucagon plus insulin to induce ATF4 mRNA abundance. 
A
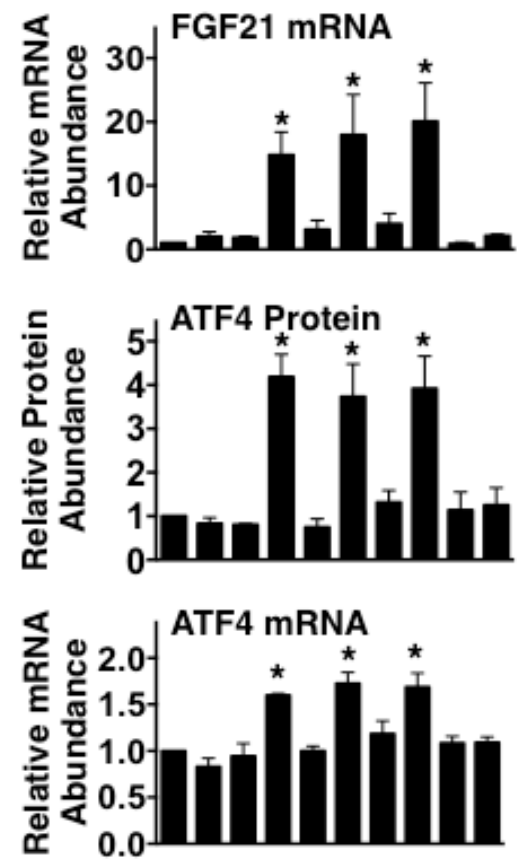

Glucagon - + + - - - - Insulin --++-++-+ Dibutyryl cAMP - . - + + + - 6-Bnz-cAMP - - - - - + + срTOME - - - - - - ++
B

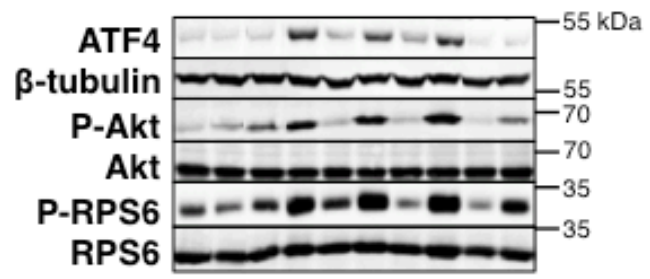

Glucagon - + - + - - - -

Insulin -++++-++

Dibutyryl cAMP - - - + + - - -

6-Bnz-cAMP - - - - - + + -

срTOME - - - - - - + +

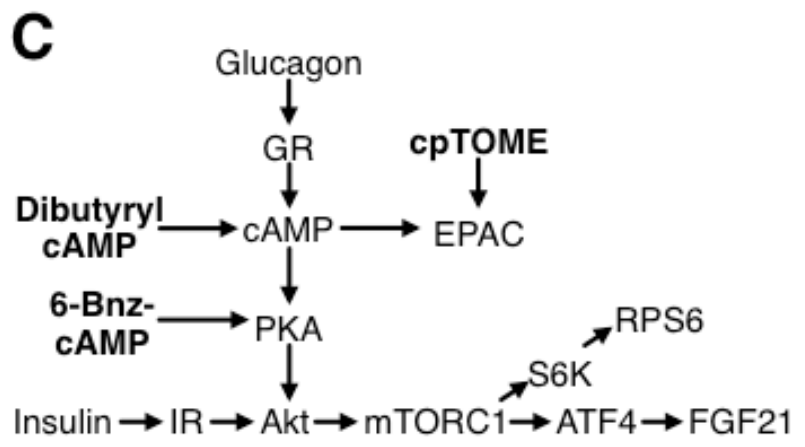

Figure 2.9: Dibutyryl cAMP and 6-Bnz-cAMP mimic the ability of glucagon to stimulate FGF21 and ATF4 expression in the presence of insulin. 
A

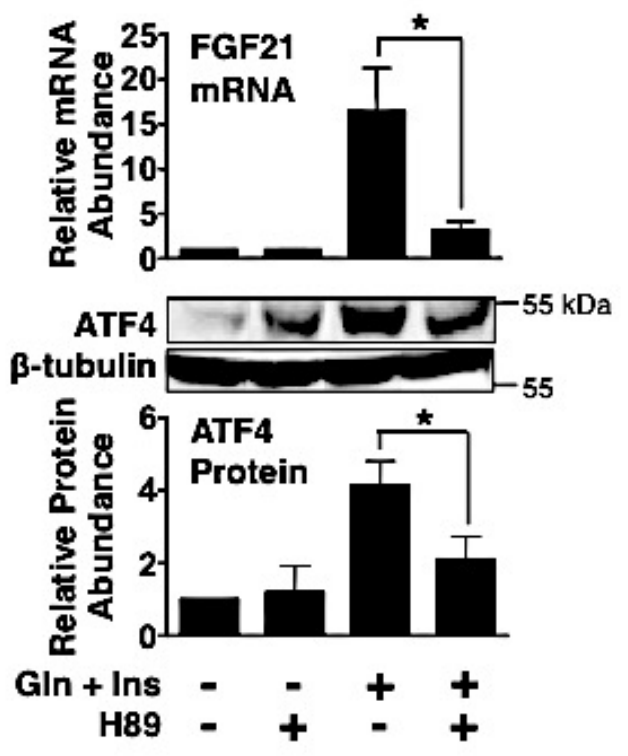

B

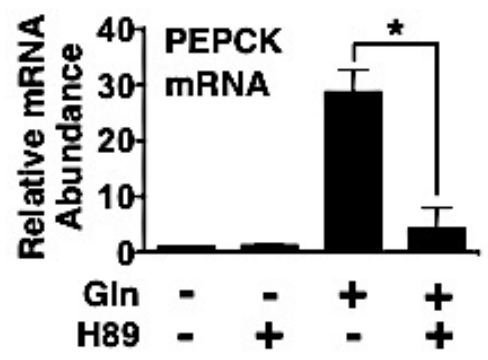

Figure 2.10: Inhibition of PKA suppresses the ability of glucagon plus insulin to induce FGF21 mRNA abundance and ATF4 protein expression. 
A
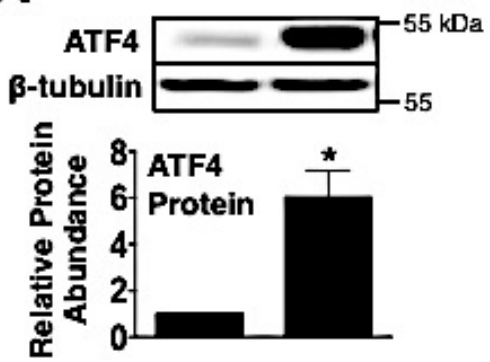

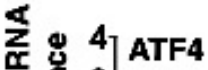

E 空 3 mRNA

巳 2

壳豆 1

व

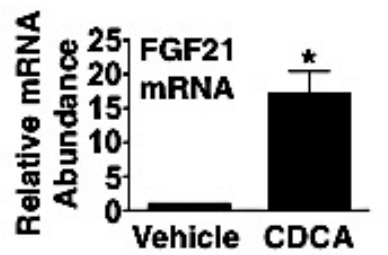

B

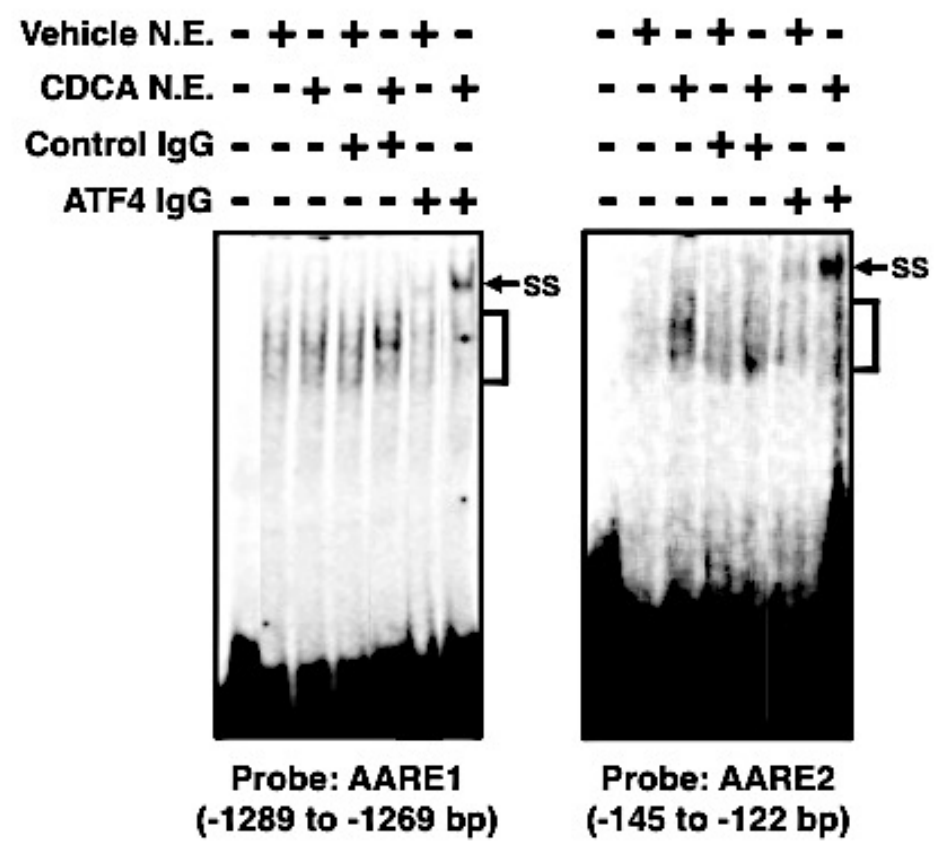

C

Fold Stimulation
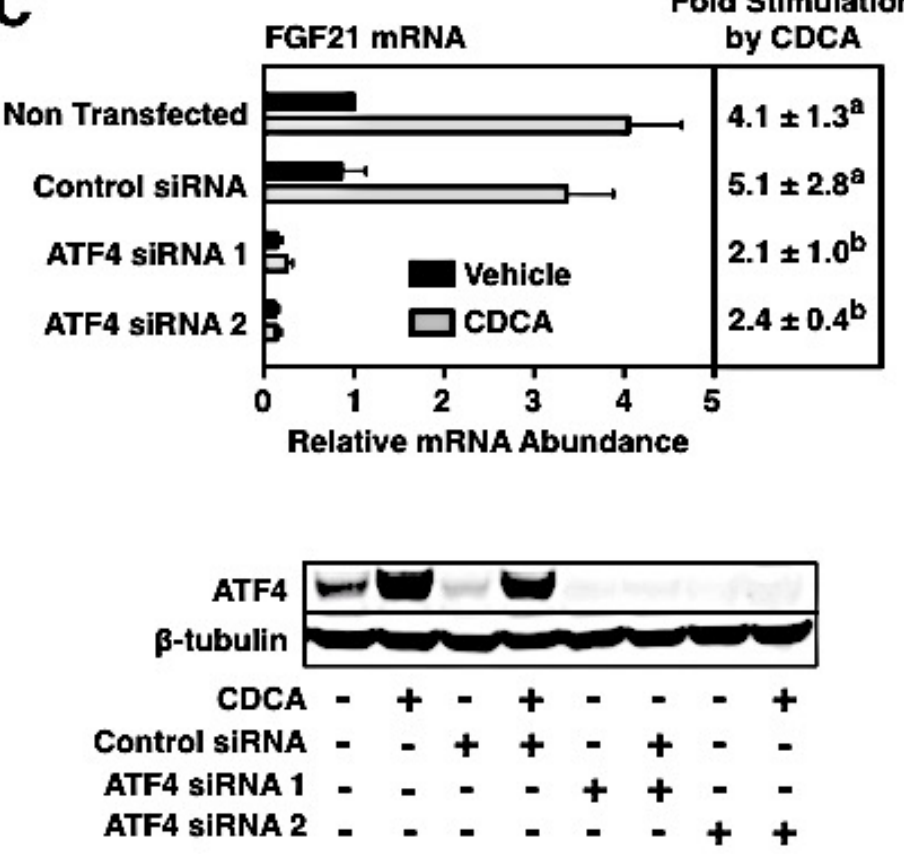

Figure 2.11: CDCA induces ATF4 expression and ATF4 binding to AARE1 and AARE2, and knockdown of ATF4 expression suppresses the ability of CDCA to increase FGF21 mRNA abundance. 
A
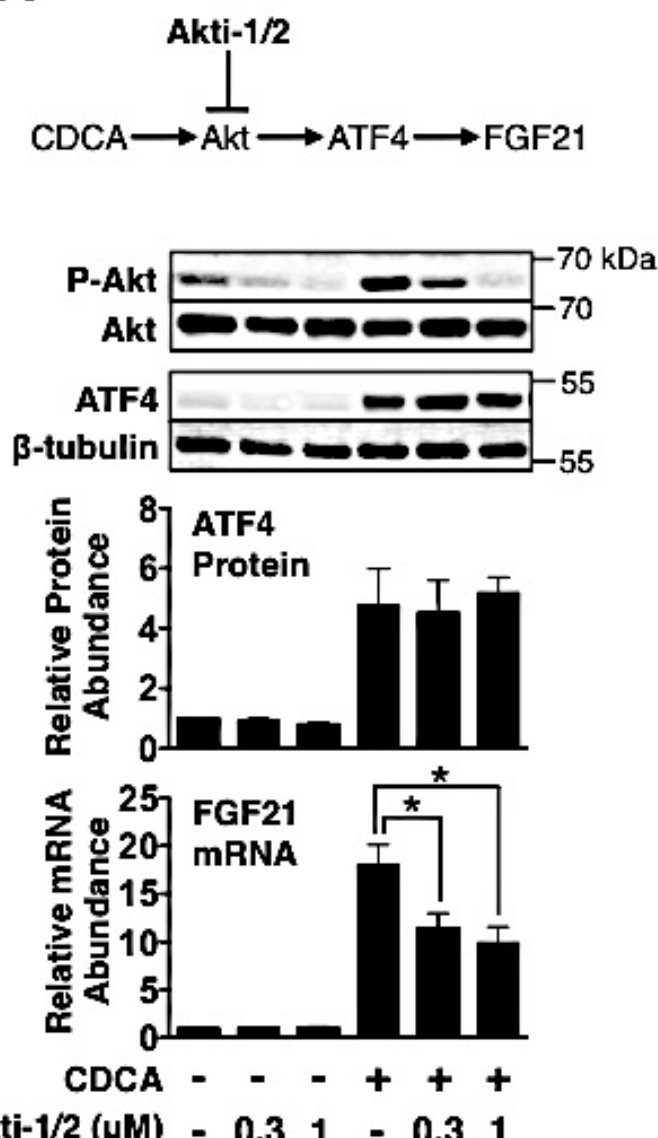

B
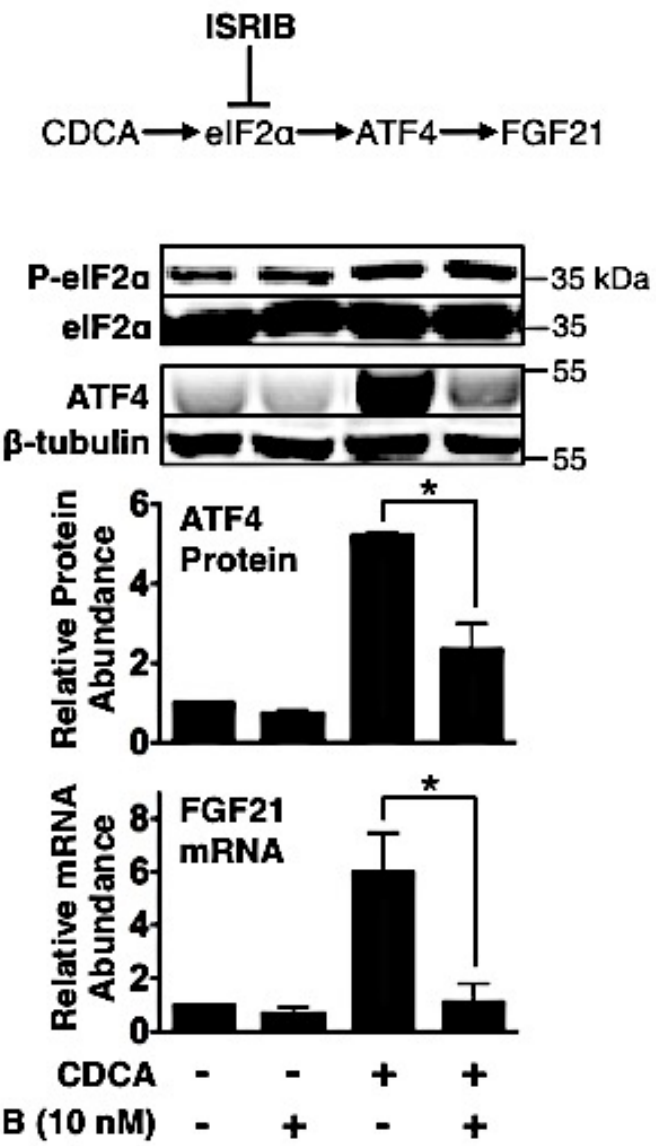

Figure 2.12: Inhibition of Akt and eIF2 $\alpha$ signaling activity suppresses the ability of CDCA to induce FGF21 mRNA abundance. 


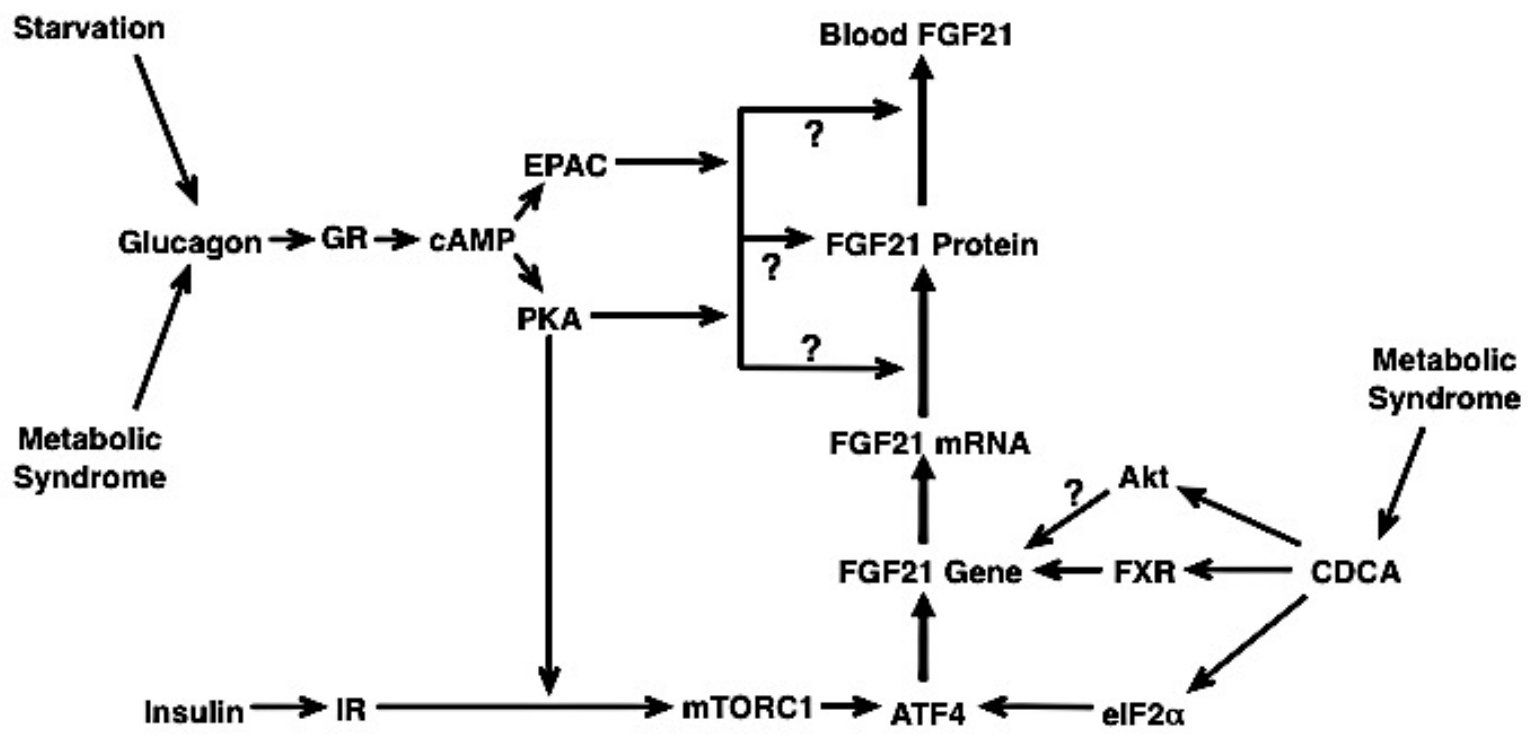

Figure 2.13: Proposed model for how glucagon, insulin, and CDCA increase hepatic FGF21 gene expression and secretion. 


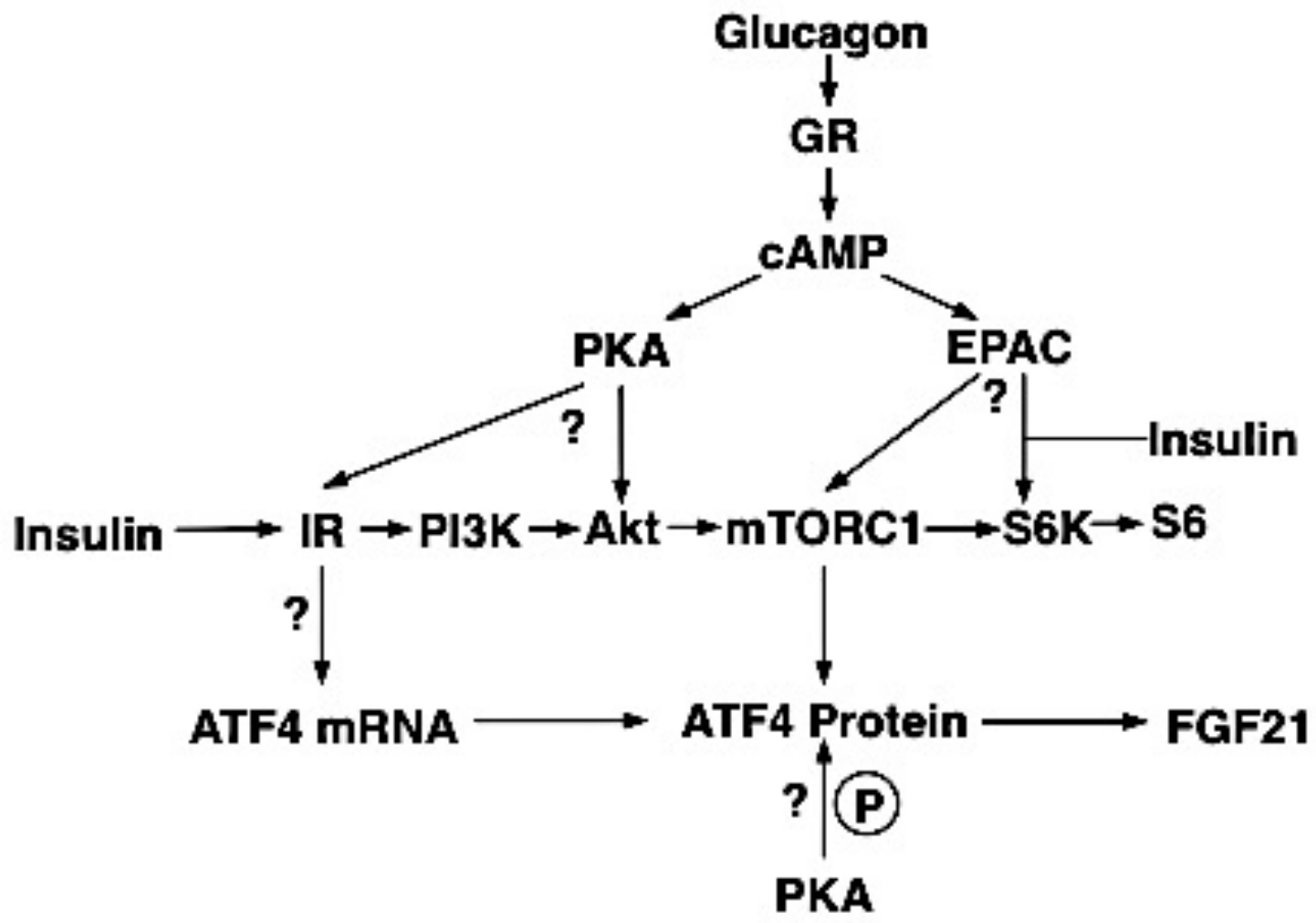

Figure 2.14: Proposed model for how glucagon plus insulin increase hepatic ATF4 expression. 


\section{REFERENCES}

1. Potthoff, M. J., Kliewer, S. A., and Mangelsdorf, D. J. (2012) Endocrine fibroblast growth factors 15/19 and 21: from feast to famine. Genes Dev. 26, 312-324

2. Kharitonenkov, A., and DiMarchi, R. (2015) FGF21 Revolutions: Recent Advances Illuminating FGF21 Biology and Medicinal Properties. Trends Endocrinol Metab 26, 608-617

3. Fisher, F. M., and Maratos-Flier, E. (2016) Understanding the Physiology of FGF21. Annu Rev Physiol 78, 223-241

4. De Sousa-Coelho, A. L., Relat, J., Hondares, E., Perez-Marti, A., Ribas, F., Villarroya, F., Marrero, P. F., and Haro, D. (2013) FGF21 mediates the lipid metabolism response to amino acid starvation. J Lipid Res 54, 1786-1797

5. Laeger, T., Henagan, T. M., Albarado, D. C., Redman, L. M., Bray, G. A., Noland, R. C., Munzberg, H., Hutson, S. M., Gettys, T. W., Schwartz, M. W., and Morrison, C. D. (2014) FGF21 is an endocrine signal of protein restriction. J Clin Invest 124, 3913-3922

6. Markan, K. R., Naber, M. C., Ameka, M. K., Anderegg, M. D., Mangelsdorf, D. J., Kliewer, S. A., Mohammadi, M., and Potthoff, M. J. (2014) Circulating FGF21 Is Liver Derived and Enhances Glucose Uptake During Refeeding and Overfeeding. Diabetes 63, 4057-4063

7. Badman, M. K., Pissios, P., Kennedy, A. R., Koukos, G., Flier, J. S., and Maratos-Flier, E. (2007) Hepatic fibroblast growth factor 21 is regulated by PPARalpha and is a key mediator of hepatic lipid metabolism in ketotic states. Cell metabolism 5, 426-437

8. Inagaki, T., Dutchak, P., Zhao, G., Ding, X., Gautron, L., Parameswara, V., Li, Y., Goetz, R., Mohammadi, M., Esser, V., Elmquist, J. K., Gerard, R. D., Burgess, S. C., Hammer, R. E., Mangelsdorf, D. J., and Kliewer, S. A. (2007) Endocrine regulation of the fasting response by PPARalpha-mediated induction of fibroblast growth factor 21. Cell metabolism 5, 415-425

9. Dushay, J., Chui, P. C., Gopalakrishnan, G. S., Varela-Rey, M., Crawley, M., Fisher, F. M., Badman, M. K., Martinez-Chantar, M. L., and Maratos-Flier, E. (2010) Increased fibroblast growth factor 21 in obesity and nonalcoholic fatty liver disease. Gastroenterology 139, 456-463

10. Zhang, X., Yeung, D. C., Karpisek, M., Stejskal, D., Zhou, Z. G., Liu, F., Wong, R. L., Chow, W. S., Tso, A. W., Lam, K. S., and Xu, A. (2008) Serum FGF21 levels are increased in obesity and are independently associated with the metabolic syndrome in humans. Diabetes 57, 1246-1253

11. Owen, B. M., Mangelsdorf, D. J., and Kliewer, S. A. (2015) Tissue-specific actions of the metabolic hormones FGF15/19 and FGF21. Trends in Endocrinology \& Metabolism 26, 22-29

12. Cyphert, H. A., Ge, X., Kohan, A. B., Salati, L. M., Zhang, Y., and Hillgartner, F. B. (2012) Activation of the Farnesoid X Receptor Induces Hepatic Expression and Secretion of Fibroblast Growth Factor 21. J Biol Chem 287, 25123-25138

13. Lundasen, T., Hunt, M. C., Nilsson, L. M., Sanyal, S., Angelin, B., Alexson, S. E., and Rudling, M. (2007) PPARalpha is a key regulator of hepatic FGF21. Biochem Biophys Res Commun 360, 437-440 
14. Berglund, E. D., Kang, L., Lee-Young, R. S., Hasenour, C. M., Lustig, D. G., Lynes, S. E., Donahue, E. P., Swift, L. L., Charron, M. J., and Wasserman, D. H. (2010) Glucagon and lipid interactions in the regulation of hepatic AMPK signaling and expression of PPAR $\alpha$ and FGF21 transcripts in vivo. American Journal of Physiology - Endocrinology and Metabolism 299, E607-E614

15. Cyphert, H. A., Alonge, K. M., Ippagunta, S. M., and Hillgartner, F. B. (2014) Glucagon Stimulates Hepatic FGF21 Secretion through a PKA- and EPAC-Dependent Posttranscriptional Mechanism. PLOS ONE 9, e94996

16. Dong, X. C., Copps, K. D., Guo, S., Li, Y., Kollipara, R., DePinho, R. A., and White, M. F. (2008) Inactivation of hepatic Foxol by insulin signaling is required for adaptive nutrient homeostasis and endocrine growth regulation. Cell metabolism 8, 65-76

17. Haeusler, R. A., Han, S., and Accili, D. (2010) Hepatic FoxO1 Ablation Exacerbates Lipid Abnormalities during Hyperglycemia. J. Biol. Chem. 285, 26861-26868

18. Stabile, L. P., Klautky, S. A., Minor, S. M., and Salati, L. M. (1998) Polyunsaturated fatty acids inhibit the expression of the glucose-6-phosphate dehydrogenase gene in primary rat hepatocytes by a nuclear posttranscriptional mechanism. J Lipid Res 39, 1951-1963

19. Hansmannel, F., Mordier, S., and Iynedjian, P. B. (2006) Insulin induction of glucokinase and fatty acid synthase in hepatocytes: analysis of the roles of sterol-regulatory-elementbinding protein-1c and liver X receptor. Biochem J 399, 275-283

20. Chomczynski, P., and Sacchi, N. (1987) Single-step method of RNA isolation by acid guanidinium thiocyanate-phenol-chloroform extraction. Analytical Biochemistry 162, $156-159$

21. Dignam, J. D., Lebovitz, R. M., and Roeder, R. G. (1983) Accurate transcription initiation by RNA polymerase II in a soluble extract from isolated mammalian nuclei. Nucleic Acids Res 11, 1475-1489

22. De Sousa-Coelho, Ana L., Marrero, Pedro F., and Haro, D. (2012) Activating transcription factor 4-dependent induction of FGF21 during amino acid deprivation. Biochemical Journal 443, 165-171

23. Iizuka, K., Takeda, J., and Horikawa, Y. (2009) Glucose induces FGF21 mRNA expression through ChREBP activation in rat hepatocytes. FEBS Letters 583, 2882-2886

24. Uebanso, T., Taketani, Y., Yamamoto, H., Amo, K., Ominami, H., Arai, H., Takei, Y., Masuda, M., Tanimura, A., Harada, N., Yamanaka-Okumura, H., and Takeda, E. (2011) Paradoxical regulation of human FGF21 by both fasting and feeding signals: is FGF21 a nutritional adaptation factor? PLOS ONE 6, e22976

25. Iizuka, K. (2013) Recent progress on the role of ChREBP in glucose and lipid metabolism. Endocr. J. 60, 543-555

26. Taniguchi, C. M., Emanuelli, B., and Kahn, C. R. (2006) Critical nodes in signalling pathways: insights into insulin action. Nat Rev Mol Cell Biol 7, 85-96

27. Zhao, A. Z., Shinohara, M. M., Huang, D., Shimizu, M., Eldar-Finkelman, H., Krebs, E. G., Beavo, J. A., and Bornfeldt, K. E. (2000) Leptin induces insulin-like signaling that antagonizes cAMP elevation by glucagon in hepatocytes. J Biol Chem 275, 11348-11354

28. Gross, D. N., Wan, M., and Birnbaum, M. J. (2009) The role of FOXO in the regulation of metabolism. Curr Diab Rep 9, 208-214 
29. Li, S., Brown, M. S., and Goldstein, J. L. (2010) Bifurcation of insulin signaling pathway in rat liver: mTORC1 required for stimulation of lipogenesis, but not inhibition of gluconeogenesis. Proc Natl Acad Sci U S A 107, 3441-3446

30. Yecies, J. L., Zhang, H. H., Menon, S., Liu, S., Yecies, D., Lipovsky, A. I., Gorgun, C., Kwiatkowski, D. J., Hotamisligil, G. S., Lee, C. H., and Manning, B. D. (2011) Akt stimulates hepatic SREBP1c and lipogenesis through parallel mTORC1-dependent and independent pathways. Cell Metab 14, 21-32

31. Habegger, K. M., Heppner, K. M., Geary, N., Bartness, T. J., DiMarchi, R., and Tschop, M. H. (2010) The metabolic actions of glucagon revisited. Nat Rev Endocrinol 6, 689697

32. Almahariq, M., Mei, F. C., and Cheng, X. (2014) Cyclic AMP sensor EPAC proteins and energy homeostasis. Trends Endocrinol Metab 25, 60-71

33. Beebe, S. J., Blackmore, P. F., Chrisman, T. D., and Corbin, J. D. (1988) Use of synergistic pairs of site-selective cAMP analogs in intact cells. Methods Enzymol 159, $118-139$

34. Enserink, J. M., Christensen, A. E., de Rooij, J., van Triest, M., Schwede, F., Genieser, H. G., Doskeland, S. O., Blank, J. L., and Bos, J. L. (2002) A novel Epac-specific cAMP analogue demonstrates independent regulation of Rap1 and ERK. Nat Cell Biol 4, 901906

35. Kelly, P., Bailey, C. L., Fueger, P. T., Newgard, C. B., Casey, P. J., and Kimple, M. E. (2010) Rap1 promotes multiple pancreatic islet cell functions and signals through mammalian target of rapamycin complex 1 to enhance proliferation. J Biol Chem $\mathbf{2 8 5}$, $15777-15785$

36. Hidaka, H., Watanabe, M., and Kobayashi, R. (1991) Properties and use of H-series compounds as protein kinase inhibitors. Methods Enzymol 201, 328-339

37. Pilkis, S. J., and Granner, D. K. (1992) Molecular physiology of the regulation of hepatic gluconeogenesis and glycolysis. Annu Rev Physiol 54, 885-909

38. Bochkis, I. M., Rubins, N. E., White, P., Furth, E. E., Friedman, J. R., and Kaestner, K. H. (2008) Hepatocyte-specific ablation of Foxa2 alters bile acid homeostasis and results in endoplasmic reticulum stress. Nat Med 14, 828-836

39. Dent, P., Fang, Y., Gupta, S., Studer, E., Mitchell, C., Spiegel, S., and Hylemon, P. B. (2005) Conjugated bile acids promote ERK1/2 and AKT activation via a pertussis toxinsensitive mechanism in murine and human hepatocytes. Hepatology 42, 1291-1299

40. Cai, K., and Sewer, M. B. (2013) Diacylglycerol kinase theta couples farnesoid X receptor-dependent bile acid signalling to Akt activation and glucose homoeostasis in hepatocytes. Biochem J 454, 267-274

41. Wek, R. C., Jiang, H. Y., and Anthony, T. G. (2006) Coping with stress: eIF2 kinases and translational control. Biochem. Soc. Trans. 34, 7-11

42. Vattem, K. M., and Wek, R. C. (2004) Reinitiation involving upstream ORFs regulates ATF4 mRNA translation in mammalian cells. Proc Natl Acad Sci U S A 101, 1126911274

43. Sidrauski, C., McGeachy, A. M., Ingolia, N. T., and Walter, P. (2015) The small molecule ISRIB reverses the effects of eIF2alpha phosphorylation on translation and stress granule assembly. eLife $\mathbf{4}$

44. Cornu, M., Oppliger, W., Albert, V., Robitaille, A. M., Trapani, F., Quagliata, L., Fuhrer, T., Sauer, U., Terracciano, L., and Hall, M. N. (2014) Hepatic mTORC1 controls 
locomotor activity, body temperature, and lipid metabolism through FGF21. Proc Natl Acad Sci U S A 111, 11592-11599

45. Izumiya, Y., Bina, H. A., Ouchi, N., Akasaki, Y., Kharitonenkov, A., and Walsh, K. (2008) FGF21 is an Akt-regulated myokine. FEBS Letters 582, 3805-3810

46. Matsushima, R., Harada, N., Webster, N. J., Tsutsumi, Y. M., and Nakaya, Y. (2006) Effect of TRB3 on insulin and nutrient-stimulated hepatic p70 S6 kinase activity. $J$ Biol Chem 281, 29719-29729

47. Anand, P., and Gruppuso, P. A. (2005) The Regulation of Hepatic Protein Synthesis during Fasting in the Rat. J. Biol. Chem. 280, 16427-16436

48. Sokolović, M., Sokolović, A., Wehkamp, D., van Themaat, E. V. L., de Waart, D. R., Gilhuijs-Pederson, L. A., Nikolsky, Y., van Kampen, A. H. C., Hakvoort, T. B. M., and Lamers, W. H. (2008) The transcriptomic signature of fasting murine liver. BMC Genomics 9, 528

49. Guan, B.-J., Krokowski, D., Majumder, M., Schmotzer, C. L., Kimball, S. R., Merrick, W. C., Koromilas, A. E., and Hatzoglou, M. (2014) Translational Control during Endoplasmic Reticulum Stress beyond Phosphorylation of the Translation Initiation Factor eIF2 $\alpha$. J. Biol. Chem. 289, 12593-12611

50. Spriggs, K. A., Stoneley, M., Bushell, M., and Willis, A. E. (2008) Re-programming of translation following cell stress allows IRES-mediated translation to predominate. Biology of the cell 100, 27-38

51. Hellen, C. U., and Sarnow, P. (2001) Internal ribosome entry sites in eukaryotic mRNA molecules. Genes Dev 15, 1593-1612

52. Komar, A. A., and Hatzoglou, M. (2011) Cellular IRES-mediated translation: The war of ITAFs in pathophysiological states. Cell Cycle 10, 229-240

53. Tsai, B. P., Jimenez, J., Lim, S., Fitzgerald, K. D., Zhang, M., Chuah, C. T., Axelrod, H., Wilson, L., Ong, S. T., Semler, B. L., and Waterman, M. L. (2014) A novel Bcr-AblmTOR-eIF4A axis regulates IRES-mediated translation of LEF-1. Open Biol 4, 140180

54. Chan, C. P., Kok, K. H., Tang, H. M., Wong, C. M., and Jin, D. Y. (2013) Internal ribosome entry site-mediated translational regulation of ATF4 splice variant in mammalian unfolded protein response. Biochim Biophys Acta 1833, 2165-2175

55. Puigserver, P., Rhee, J., Donovan, J., Walkey, C. J., Yoon, J. C., Oriente, F., Kitamura, Y., Altomonte, J., Dong, H., Accili, D., and Spiegelman, B. M. (2003) Insulin-regulated hepatic gluconeogenesis through FOXO1-PGC-1alpha interaction. Nature 423, 550-555

56. Liao, J., Barthel, A., Nakatani, K., and Roth, R. A. (1998) Activation of protein kinase $\mathrm{B} /$ Akt is sufficient to repress the glucocorticoid and cAMP induction of phosphoenolpyruvate carboxykinase gene. J Biol Chem 273, 27320-27324

57. Foretz, M., Pacot, C., Dugail, I., Lemarchand, P., Guichard, C., Le Liepvre, X., Berthelier-Lubrano, C., Spiegelman, B., Kim, J. B., Ferre, P., and Foufelle, F. (1999) $\mathrm{ADD} 1 / \mathrm{SREBP}-1 \mathrm{c}$ is required in the activation of hepatic lipogenic gene expression by glucose. Mol Cell Biol 19, 3760-3768

58. Owen, J. L., Zhang, Y., Bae, S.-H., Farooqi, M. S., Liang, G., Hammer, R. E., Goldstein, J. L., and Brown, M. S. (2012) Insulin stimulation of SREBP-1c processing in transgenic rat hepatocytes requires p70 S6-kinase. Proc Natl Acad Sci U S A 109, 16184-16189

59. Kimura, M., and Ogihara, M. (1997) Proliferation of adult rat hepatocytes in primary culture induced by insulin is potentiated by cAMP-elevating agents. Eur J Pharmacol 327, 87-95 
60. Bucher, M. L., and Swaffield, M. N. (1975) Regulation of hepatic regeneration in rats by synergistic action of insulin and glucagon. Proc Natl Acad Sci U S A 72, 1157-1160

61. Dey, S., Savant, S., Teske, B. F., Hatzoglou, M., Calkhoven, C. F., and Wek, R. C. (2012) Transcriptional repression of ATF4 gene by CCAAT/enhancer-binding protein $\beta$ $(\mathrm{C} / \mathrm{EBP} \beta)$ differentially regulates integrated stress response. J Biol Chem 287, 2193621949

62. Elefteriou, F., Benson, M. D., Sowa, H., Starbuck, M., Liu, X., Ron, D., Parada, Luis F., and Karsenty, G. (2006) ATF4 mediation of NF1 functions in osteoblast reveals a nutritional basis for congenital skeletal dysplasiae. Cell Metabolism 4, 441-451

63. Elefteriou, F., Ahn, J. D., Takeda, S., Starbuck, M., Yang, X., Liu, X., Kondo, H., Richards, W. G., Bannon, T. W., Noda, M., Clement, K., Vaisse, C., and Karsenty, G. (2005) Leptin regulation of bone resorption by the sympathetic nervous system and CART. Nature 434, 514-520

64. Arisawa, S., Ishida, K., Kameyama, N., Ueyama, J., Hattori, A., Tatsumi, Y., Hayashi, H., Yano, M., Hayashi, K., Katano, Y., Goto, H., Takagi, K., and Wakusawa, S. (2009) Ursodeoxycholic acid induces glutathione synthesis through activation of PI3K/Akt pathway in HepG2 cells. Biochem Pharmacol 77, 858-866

65. Furusawa, Y., Uruno, A., Yagishita, Y., Higashi, C., and Yamamoto, M. (2014) Nrf2 induces fibroblast growth factor 21 in diabetic mice. Genes Cells 19, 864-878

66. Li, T., Francl, J. M., Boehme, S., Ochoa, A., Zhang, Y., Klaassen, C. D., Erickson, S. K., and Chiang, J. Y. (2012) Glucose and insulin induction of bile acid synthesis: mechanisms and implication in diabetes and obesity. J Biol Chem 287, 1861-1873

67. Reaven, G. M. (2005) The insulin resistance syndrome: definition and dietary approaches to treatment. Annu Rev Nutr 25, 391-406

68. Haeusler, R. A., Astiarraga, B., Camastra, S., Accili, D., and Ferrannini, E. (2013) Human insulin resistance is associated with increased plasma levels of 12alphahydroxylated bile acids. Diabetes 62, 4184-4191

69. Jiang, S., Yan, C., Fang, Q.-c., Shao, M.-1., Zhang, Y.-1., Liu, Y., Deng, Y.-p., Shan, B., Liu, J.-q., Li, H.-t., Yang, L., Zhou, J., Dai, Z., Liu, Y., and Jia, W.-p. (2014) Fibroblast Growth Factor 21 Is Regulated by the IRE1 $\alpha$-XBP1 Branch of the Unfolded Protein Response and Counteracts Endoplasmic Reticulum Stress-induced Hepatic Steatosis. $J$. Biol. Chem. 289, 29751-29765

70. Khamzina, L., Veilleux, A., Bergeron, S., and Marette, A. (2005) Increased Activation of the Mammalian Target of Rapamycin Pathway in Liver and Skeletal Muscle of Obese Rats: Possible Involvement in Obesity-Linked Insulin Resistance. Endocrinology 146, 1473-1481

71. Ozcan, U., Cao, Q., Yilmaz, E., Lee, A.-H., Iwakoshi, N. N., Ozdelen, E., Tuncman, G., Görgün, C., Glimcher, L. H., and Hotamisligil, G. S. (2004) Endoplasmic reticulum stress links obesity, insulin action, and type 2 diabetes. Science 306, 457-461

72. Yang, H., and Yang, L. (2016) Targeting cAMP/PKA pathway for glycemic control and type 2 diabetes therapy. J Mol Endocrinol 57, R93-R108

73. Cook, J. R., Langlet, F., Kido, Y., and Accili, D. (2015) Pathogenesis of selective insulin resistance in isolated hepatocytes. J Biol Chem 290, 13972-13980

74. Laeger, T., Albarado, D. C., Burke, S. J., Trosclair, L., Hedgepeth, J. W., Berthoud, H.R., Gettys, T. W., Collier, J. J., Münzberg, H., and Morrison, C. D. (2016) Metabolic 
Responses to Dietary Protein Restriction Require an Increase in FGF21 that Is Delayed by the Absence of GCN2. Cell Reports 16, 707-716 
Chapter Three

\section{GENERAL DISCUSSION}




\section{SUMMARY}

Obesity rates have increased at an unchecked rate throughout the years leading to the development of metabolic syndrome and adverse health outcomes in a significant portion of the population. Current therapies for the treatment and prevention of obesity and metabolic syndrome are ineffective and/or produce undesirable side effects. FGF21 is a hormone that induced striking reversals of obesity and T2D in both animal and human models. The use of FGF21 as treatment to combat obesity, T2D, and metabolic syndrome offers a fresh alternative to current therapies.

The objective of this study was to determine novel mechanisms mediating the endogenous expression of FGF21 in the liver. We focused on characterizing the molecular pathways regulating the ability of glucagon plus insulin and chenodeoxycholic acid to stimulate FGF21 gene transcription in primary hepatocytes. Here we identified ATF4 as a common transcriptional mediator that facilitates glucagon plus insulin and CDCA induction of FGF21 gene expression. We first employed a reverse genetics approach to discover cis-acting sequences on the FGF21 promoter that confer gene regulation under glucagon plus insulin treatment. Next, we identified ATF4 as the primary transcription factor that binds to, and activates, the FGF21 promoter after glucagon plus insulin and CDCA treatment. We then used loss-of function and gain-of-function techniques to identify the PI3K/Akt/mTORC1 insulin-signaling pathway and the cAMP/PKA glucagon-signaling pathway as regulatory mediators for both ATF4 and FGF21 expression during glucagon plus insulin treatment. Furthermore, we uncovered Akt and eIF2 $\alpha$ as the key mediators of ATF4 and FGF21 expression during CDCA treatment. 
One important finding of this study is the discovery that ATF4 facilitates the positive cooperatively between glucagon and insulin on target gene transcription. To date, ATF4 represents the only known transcription factor shown to mediate the positive interaction between glucagon and insulin in the liver. Glucagon and insulin have been shown to signal synergistically to mediate selective cellular processes in the liver (1-3). Zhao, et al. (2000) showed that glucagon and insulin work cooperatively to increase the phosphorylation of the downstream metabolic mediator, Akt, and this induction might be due to PKA inhibition of phosphatases that dephosphorylate the Akt kinase (4). Meanwhile, additional studies suggest the glucagon and insulin synergism occurs upstream of PI3K. For example, glucagon potentiates insulin induction of the insulin tyrosine receptor kinase's ability to uniquely increase phosphorylation of downstream targets (5). This selectivity suggests glucagon may potentiate the ability of insulin to active unique pathways downstream of the insulin tyrosine kinase while simultaneously repressing others. My data suggests glucagon plus insulin signal both upstream and downstream of PI3K (Figs. 2.13 and 2.14). Glucagon plus insulin treatment cooperatively increased phosphorylation of Akt and P-S6 ribosomal subunit, and that PI3K, Akt, and mTORC1 inhibition repressed this effect (Fig. 2.7). These results suggest glucagon and insulin signal cooperatively downstream of PI3K. Surprisingly, inhibition of the PI3K/Akt/mTORC1 axis did not repress the ability of glucagon plus insulin to increase ATF4 mRNA, suggesting the cooperatively observed between the two hormones also lies upstream of PI3K at the insulin receptor (Fig. 2.8). Additional studies need to be performed to elucidate the role of the insulin receptor tyrosine kinase in mediating the effects of glucagon plus insulin on ATF4 and FGF21 expression. 


\section{FUTURE DIRECTIONS}

A second important finding of this study is the discovery that nutritional signals mediate mTORC1 driven cap-dependent translational of target mRNAs during non-stress cellular conditions, but also that nutritional signals may also mediate mTORC1 translational activity to cap-independent translation of IRES-containing metabolic mRNAs during prolonged stress induced states. The high glucagon to insulin concentrations present during the portal vein during starvation may represent one type of metabolic stimuli that may induce the switch of mTORC1mediated cap-dependent to cap-independent translation of mRNAs. Starvation paradoxically increases the activities of hepatic S6K, RPS6, and eIF4E translational machineries, but decreases eIF2G, phosphorylation of eIF2 $\alpha$, and general protein translation (6). In addition to starvation, protein free diets are a second type of dietary condition that increases $\mathrm{PI} 3 \mathrm{~K} / \mathrm{mTORC} 1$ activity in primary livers during low nutrient availability (7). These findings suggest that, similar to mode of action for eIF $2 \alpha$ phosphorylation, the switch from mTORC1 mediated cap-dependent to cap-independent translation allows for a decrease in global protein translation while simultaneously allowing for the translation of selective mRNAs during stress conditions. Starvation and prolonged ER stress increase ATF4 expression in an unknown eIF2 $\alpha$ independent mechanism $(6,8,9)$. We hypothesize the increase in ATF4 protein translation observed during starvation may be mediated through cap-independent mTORC1 mediated translation.

Additional nutritional factors have been shown to follow the cap-dependent to capindependent translational switch depending on dietary conditions. For example, insulin receptor biosynthesis in pancreatic $\beta$-cells is cap-dependently translated during high glucose conditions but switches to cap-independent, IRES-dependent translation during starvation $(10,11)$. The 
selective upregulation of insulin receptor mRNA translation during starvation is believed to increase cellular insulin sensitivity during low nutrient availability. These results suggest low nutrient availability may switch mTORC1 translation from cap-dependent to cap-independent translation of IRES containing mRNAs. IRES-dependent translation effectively out-competes the cap-dependent mRNA translation for access to translational machinery during stress, allowing for the select increase in critical nutrient adaptation factors over global protein translation. ATF4 mRNA contains an IRES that can be translated during cap-independent conditions (12). The potential role for mTORC1 to mediate IRES-dependent translation of mRNAs during different dietary conditions is currently an unexplored area in the biomedical sciences. 


\section{REFERENCES}

1. Bucher, M. L., and Swaffield, M. N. (1975) Regulation of hepatic regeneration in rats by synergistic action of insulin and glucagon. Proc Natl Acad Sci U S A 72, 1157-1160

2. Giacca, A., Fisher, S. J., McCall, R. H., Shi, Z. Q., and Vranic, M. (1997) Direct and indirect effects of insulin in suppressing glucose production in depancreatized dogs: role of glucagon. Endocrinology 138, 999-1007

3. Kimura, M., and Ogihara, M. (1997) Proliferation of adult rat hepatocytes in primary culture induced by insulin is potentiated by cAMP-elevating agents. European Journal of Pharmacology 327, 87-95

4. Zhao, A. Z., Shinohara, M. M., Huang, D., Shimizu, M., Eldar-Finkelman, H., Krebs, E. G., Beavo, J. A., and Bornfeldt, K. E. (2000) Leptin induces insulin-like signaling that antagonizes cAMP elevation by glucagon in hepatocytes. J Biol Chem 275, 11348-11354

5. Ito, Y., Uchijima, Y., Ariga, M., Seki, T., Takenaka, A., Hakuno, F., Takahashi, S. I., Ariga, T., and Noguchi, T. (1997) Interaction between cAMP-dependent and insulindependent signal pathways in tyrosine phosphorylation in primary cultures of rat hepatocytes. Biochem. J. 324 ( Pt 2), 379-388

6. Anand, P., and Gruppuso, P. A. (2005) The Regulation of Hepatic Protein Synthesis during Fasting in the Rat. J. Biol. Chem. 280, 16427-16436

7. Toyoshima, Y., Tokita, R., Ohne, Y., Hakuno, F., Noguchi, T., Minami, S., Kato, H., and Takahashi, S. (2010) Dietary protein deprivation upregulates insulin signaling and inhibits gluconeogenesis in rat liver. Journal of molecular endocrinology 45, 329-340

8. Sokolović, M., Sokolović, A., Wehkamp, D., van Themaat, E. V. L., de Waart, D. R., Gilhuijs-Pederson, L. A., Nikolsky, Y., van Kampen, A. H. C., Hakvoort, T. B. M., and Lamers, W. H. (2008) The transcriptomic signature of fasting murine liver. $B M C$ Genomics 9, 528

9. Guan, B.-J., Krokowski, D., Majumder, M., Schmotzer, C. L., Kimball, S. R., Merrick, W. C., Koromilas, A. E., and Hatzoglou, M. (2014) Translational Control during Endoplasmic Reticulum Stress beyond Phosphorylation of the Translation Initiation Factor eIF2 $\alpha$. J. Biol. Chem. 289, 12593-12611

10. Fred, R. G., Sandberg, M., Pelletier, J., and Welsh, N. (2011) The human insulin mRNA is partly translated via a cap- and eIF4A-independent mechanism. Biochemical and Biophysical Research Communications 412, 693-698

11. Spriggs, K. A., Cobbold, L. C., Ridley, S. H., Coldwell, M., Bottley, A., Bushell, M., Willis, A. E., and Siddle, K. (2009) The human insulin receptor mRNA contains a functional internal ribosome entry segment. Nucleic Acids Res 37, 5881-5893

12. Chan, C. P., Kok, K. H., Tang, H. M., Wong, C. M., and Jin, D. Y. (2013) Internal ribosome entry site-mediated translational regulation of ATF4 splice variant in mammalian unfolded protein response. Biochim Biophys Acta 1833, 2165-2175 